\title{
Predictors of Adherence to Mammography Screening Guidelines and Preferences for Intervention Strategies in a Mobile Mammography Program
}

Ami Vyas

West Virginia University

Follow this and additional works at: https://researchrepository.wvu.edu/etd

\section{Recommended Citation}

Vyas, Ami, "Predictors of Adherence to Mammography Screening Guidelines and Preferences for Intervention Strategies in a Mobile Mammography Program" (2012). Graduate Theses, Dissertations, and Problem Reports. 4934.

https://researchrepository.wvu.edu/etd/4934

This Thesis is protected by copyright and/or related rights. It has been brought to you by the The Research Repository @ WVU with permission from the rights-holder(s). You are free to use this Thesis in any way that is permitted by the copyright and related rights legislation that applies to your use. For other uses you must obtain permission from the rights-holder(s) directly, unless additional rights are indicated by a Creative Commons license in the record and/ or on the work itself. This Thesis has been accepted for inclusion in WVU Graduate Theses, Dissertations, and Problem Reports collection by an authorized administrator of The Research Repository @ WVU. For more information, please contact researchrepository@mail.wvu.edu. 
"Predictors of Adherence to Mammography Screening Guidelines and Preferences for Intervention Strategies in a Mobile Mammography Program”

\author{
Ami Vyas ${ }^{1}$ \\ Thesis submitted to the School of Pharmacy \\ at West Virginia University \\ in partial fulfillment of the requirements \\ for the degree of
}

Master of Science

in

Pharmaceutical Sciences

Suresh Madhavan, Ph.D. Chair ${ }^{1}$

Kimberly M Kelly, Ph.D. ${ }^{1,2}$

Aaron Metzger, Ph.D. ${ }^{3}$

${ }^{1}$ Department of Pharmaceutical Systems and Policy, School of Pharmacy, West Virginia University

${ }^{2}$ Mary Babb Randolph Cancer Center, West Virginia University

${ }^{3}$ Department of Psychology, West Virginia University

Morgantown, West Virginia

2012

Keywords: Breast Cancer; Mobile Mammography; Stationary Mammography Facility; Mammography Screening; Adherence, Intervention; Information Seeking; Preference 


\title{
ABSTRACT \\ "Predictors of Adherence to Mammography Screening Guidelines and Preferences for Intervention Strategies in a Mobile Mammography Program"
}

\begin{abstract}
Ami Vyas
Early detection of breast cancer (BC) in women can lead to long-term survival and better quality of life. Mammography screening is considered to be the 'gold standard' for women at an average risk to detect $\mathrm{BC}$ early and hence reduce $\mathrm{BC}$-related mortality. West Virginia (WV) has a lower incidence of $\mathrm{BC}$ but higher rates of advanced and unstaged $\mathrm{BC}$ which has been attributed to lower mammography screening rates in women in WV. Mobile mammography programs have been in use for more than two decades to overcome barriers and increase mammography screening rates in rural and hard-to-reach populations. WV has one such mobile mammography program named Bonnie Wells Wilson Mobile Mammography Program (called Bonnie's Bus hereafter). There are no reported studies on the profiles of women who utilize mobile mammography services and those who utilize stationary mammography facility and predictors of adherence to mammography screening guidelines in these two populations. Not much has been reported about what types of intervention strategies linked with mobile mammography are likely to improve screening rates thereby the effectiveness of a mobile mammography program.

Though, many interventions effective in increasing screening rates have been reported in the literature, no studies have assessed the perspective of women at whom these interventions are targeted, such as their receptiveness towards these interventions and their perception of whether they would be successful with their peers and in their communities. Therefore, the objectives of this research study were: (1) to describe the profiles of women who utilize mobile mammography services, at the Bonnie's Bus and those who utilize a stationary mammography facility, Betty Puskar Breast Care Center(BPBCC) in Morgantown, WV, and to identify the predictors of adherence to mammography screening guidelines in these populations, and (2) to determine what types of targeted educational interventions coupled with mobile mammography are perceived as likely to be acceptable and effective by women who had their first mammogram at the Bonnie's Bus. A cross-sectional study was conducted with the primary data collected from 1,161 women age 40 years and above who utilized Bonnie's Bus and 1,104 women age 40 years and above who utilized BPBCC using the 'Mammography Screening and Preventive Care Survey'. The 'expanded' version of Andersen Behavioral Model for Health Services Utilization was utilized as the conceptual model. Structured telephone interviews of 16 women age 40 years and above residing in WV who reported never having had a mammogram prior to getting one through the Bonnie's Bus were conducted. Descriptive statistics were used to separately describe the characteristics of women who utilized Bonnie's Bus and the BPBCC. Chi-square statistics for categorical variables and t-tests for continuous variables were used separately in both the study samples to determine significant differences between self-reported adherent and non-adherent groups. Logistic regressions were also performed to analyze the relationship between self-reported adherence with all the constructs of Andersen model, after controlling for all the independent variables, separately for both the study samples. To determine whether or not women who did not participate in the study were different from women who participated, non-response bias was assessed in both the study samples. Thematic analysis of audio-recorded data from the telephone interviews was conducted to identify women's receptiveness and
\end{abstract}


preferences for various interventions. Among women who utilized mobile mammography unit, only $48.15 \%$ were adherent to mammography screening guidelines and among women who utilized stationary mammography facility, an overwhelming $92.3 \%$ were adherent to mammography screening guidelines. The predictors of self-reported adherence to mammography screening guidelines in women who utilized mobile mammography services were older age (adjusted odds ratio $(A O R)=2.025,95 \%$ confidence interval $(\mathrm{CI})=1.489-2.754$ for age group 50-64 years; $\mathrm{AOR}=3.181,95 \% \mathrm{CI}=1.904-5.314$ for age 65 and above), unemployed status, extreme obesity ( $\mathrm{AOR}=1.880,95 \% \mathrm{CI}=1.161-3.046)$ and morbid obesity ( $\mathrm{AOR}=$ $1.918,95 \% \mathrm{CI}=1.128-3.261$ ), no reported delay in care due to transportation problem, family history of BC, breast biopsy in the past, and adherence to Pap test and routine screenings such as blood glucose, blood cholesterol, blood pressure and bone mineral density test. While the predictors of adherence to mammography screening guidelines in women who utilized stationary mammography facility were health insurance coverage, no reported delay in care due transportation problem, adherence to clinical breast exam (CBE), Pap test and other routine screenings, and having strong agreement with the positive views about mammography screening. The sources of information about health and mammography screening used by rural women who had their first mammogram at the Bonnie's Bus mostly included doctors or obstetrician / gynecologist $(\mathrm{OB} / \mathrm{GYN})$, materials from library, health fairs, and internet. Among communitybased interventions, community-based health educational programs that could be held at public places such as library or church or work-sites and among individual-level interventions, mailed educational materials were perceived to be the most helpful interventions. BC-related events such as family history of BC and having had biopsy, and adherence to screening tests were associated with adherence to mammography screening guidelines in older women who utilized mobile mammography services. While access factors, adherence to other screening tests such as $\mathrm{CBE}$, Pap test and having strong positive views about mammography screening were associated with adherence to mammography screening guidelines in women who utilized stationary mammography facility. Intervention strategies such as community-based educational programs and mailed educational materials could be developed along with the mobile mammography unit that may be effective in attracting rural and underserved women in WV. Incorporating various information sources such doctor and/or OB/GYN, and internet in the intervention strategies may help gain synergistic effect on the mammography screening rates in women in WV. 


\section{ACKNOWLEDGEMENTS}

I would like to genuinely thank my major advisor and committee chair, Dr. Suresh Madhavan for guidance and support during the completion of this thesis. Special thanks to Dr. Kimberly Kelly and Dr. Aaron Metzger for their time, participation and valuable feedback on my project as members on my committee. I would also like to acknowledge all the faculties of my department for their continued support, my friends from the department, and Angie Frame, who helped me in the ordering the stationaries for my project. I would like to express my sincere appreciation to all the women who participated in my research studies.

I would like to thank my mom, my dad, my two sisters, Pinky and Bansary, and my husband, Maulik, for supporting me and motivating me to and make me who I am today. 


\section{TABLE OF CONTENTS}

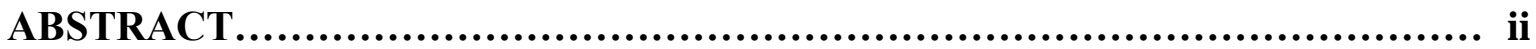

ACKOWLEDGEMENTS........................................................... iv

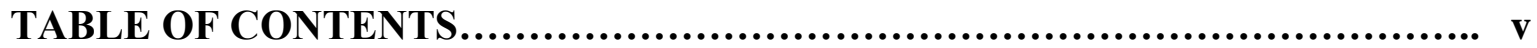

CHAPTER 1: INTRODUCTION........................................................ 1

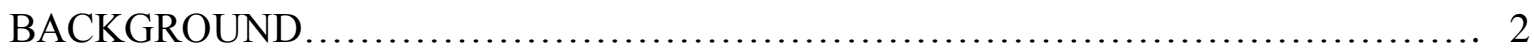

Breast Cancer and Mammography Screening ................................. 2

Factors Influencing Adherence to Mammography Screening................... 2

Mammography Screening in West Virginia.................................. 3

Interventions to Overcome Barriers to Mammography Screening ............... 5

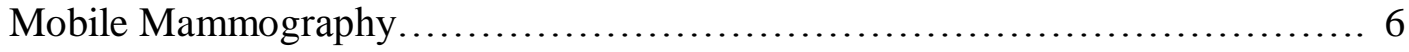

Bonnie Wells Wilson Mobile Mammography Program........................... 6

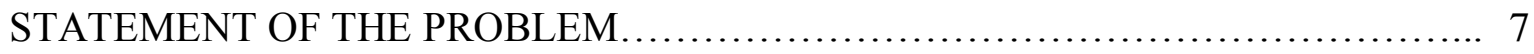

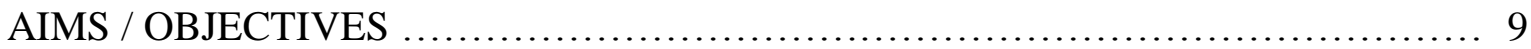

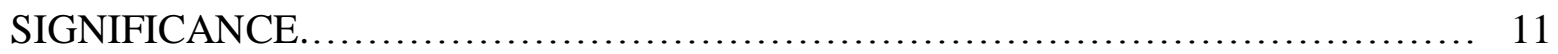

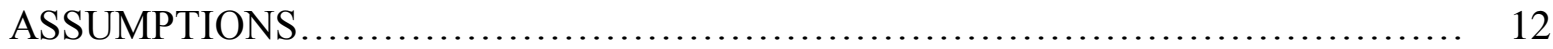

LIMITATIONS ............................................................. 12

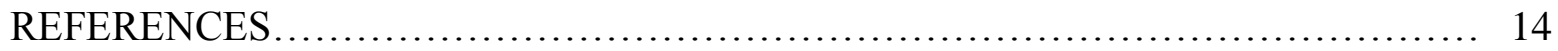

CHAPTER 2: MANUSCRIPT 1 "Predictors of Adherence to Mammography"..... 20

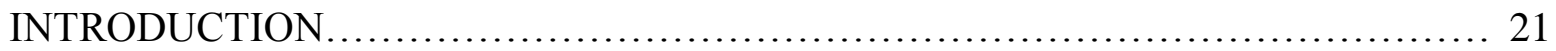

Mammography Screening in West Virginia................................. 21

Factors Influencing Adherence to Mammography Screening................... 22

Interventions to Overcome Barriers to Mammography Screening ................ 23 
Bonnie Wells Wilson Mobile Mammography Program....................... 24

CONCEPTUAL FRAMEWORK........................................... 26

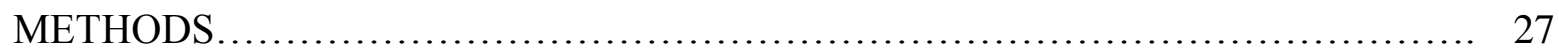

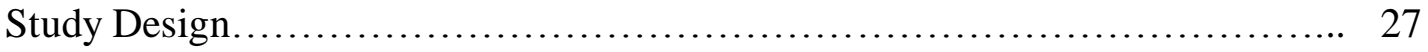

Participants.................................................... 27

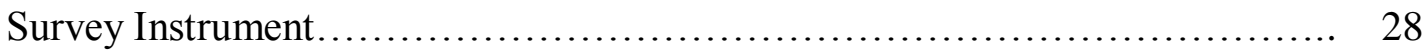

Survey Administration and Data Collection.............................. 28

Dependent Variable-Self-Reported Adherence............................ 29

Independent Variables................................................ 30

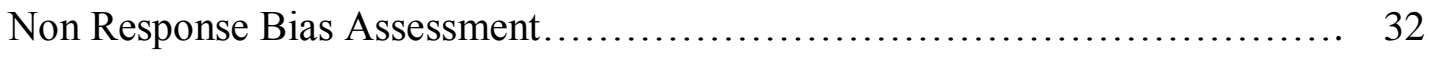

Statistical Analyses................................................... 33

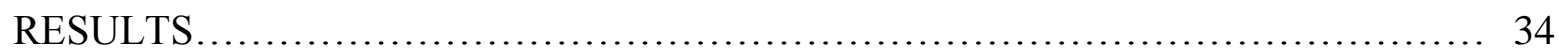

Characteristics of the Mobile Mammography Study Sample.................. 33

Characteristics of the Stationary Facility Study Sample...................... 35

Results of the Bivariate Analyses.................................... 36

Results of Multivariate Analyses for the Mobile Mammography Study Sample.... 38

Results of Multivariate Analyses for the Stationary Facility Study Sample........... 40

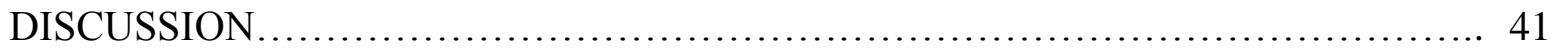

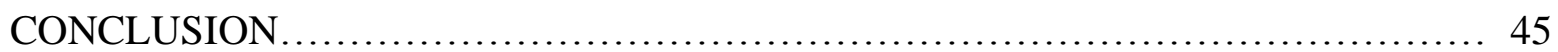

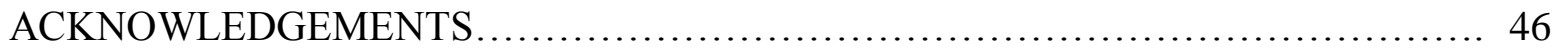

REFERENCES....................................................... 47

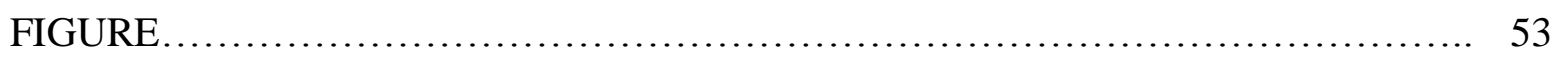

Figure 1: Expanded Version of Andersen Behavioral Model.................. 53 
Table 1: Description of the Study Samples of WV Women................... 54

Table 2: Description of the BBMMP Study Sample by Adherence............. 57

Table 3: Description of the BPBCC Study Sample by Adherence................ 60

Table 4: Logistic Regressions of Adherence in both the Samples............... 63

CHAPTER 3: MANUSCRIPT 2 "Preferences for Intervention Strategies"............ 66

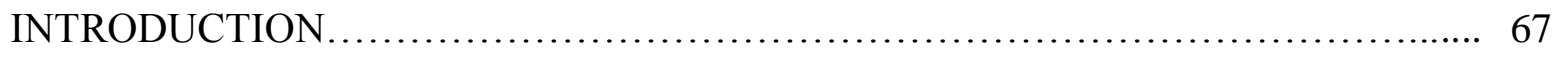

METHODS.......................................................... 70

Study Design .................................................... 70

Setting ......................................................... 70

Study Population................................................. 71

Participant Recruitment.............................................. 71

Interview Guide................................................. 72

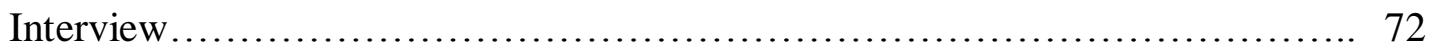

Analysis....................................................... 72

Non-Response Bias Assessment..................................... 73

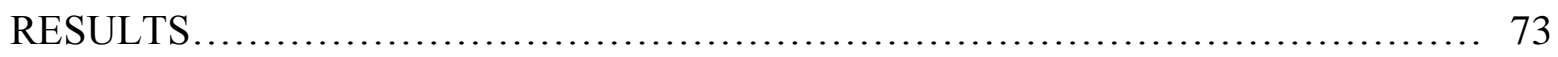

Characteristics of the Participants.................................... 74

Barriers and Facilitators to Mammography Screening ...................... 74

Sources and Channels of Information............................... 77

Acceptance of Social Media and Cell-Phones to Receive Information........... 77

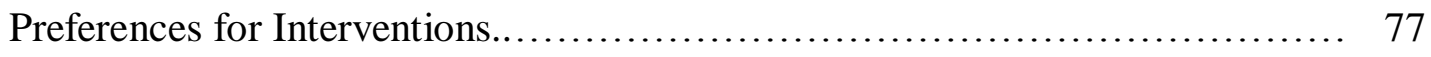

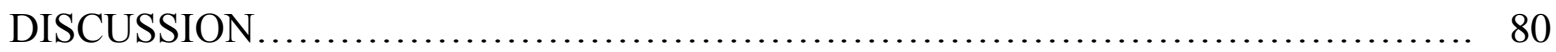


CONCLUSION.

ACKNOWLEDGEMENTS ................................................... 83

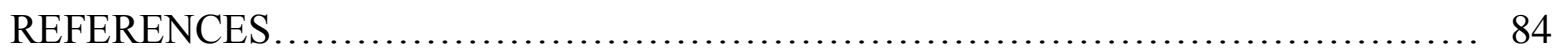

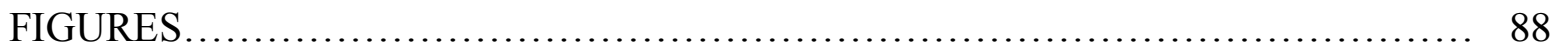

Figure 1: Sources and Channels of Information for Mammography Screening.... 88

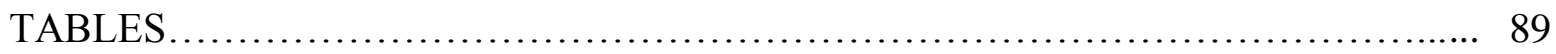

Table 1: Characteristics of the Study Participants............................. 89

Table 2: Barriers and Facilitators to Mammography Screening................. 90

Table 3: Preferences for Interventions................................... 91

Table 4: Reasons for the Preferences of the Interventions....................... 92

CHAPTER 4: GENERAL DISCUSSION..................................... 93

RATIONALE AND OBJECTIVES........................................ 94

SUMMARY OF THE FINDINGS...................................... 96

SIGNIFICANCE OF THE STUDIES ..................................... 97

FUTURE RESEARCH.................................................. 97

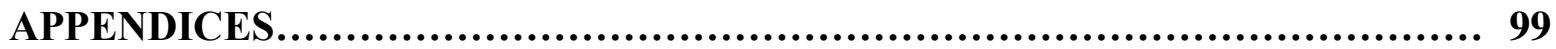

APPENDIX A: Mammography Screening and Preventive Care Survey........ 100

APPENDIX B: Cover Letter for the First Mailing ............................ 107

APPENDIX C: Cover Letter for the Second Mailing........................... 108

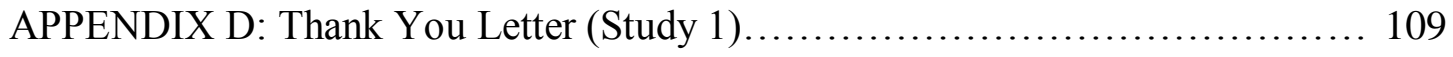

APPENDIX E: Cover Letter for Non-Response Bias Assessment............... 110

APPENDIX F: Non-Response Bias Assessment Survey....................... 111

APPENDIX G: Cover Letter for Telephone Interviews....................... 112 
APPENDIX H: Telephone Interview Schedule.......................... 113

APPENDIX I: Script for Telephone Interview.............................. 114

APPENDIX J: Thank You Letter (Study 2) ............................. 119 
CHAPTER 1 


\section{CHAPTER 1 \\ INTRODUCTION}

\section{BACKGROUND}

\section{Breast Cancer and Mammography Screening}

Breast cancer $(\mathrm{BC})$ is the most common cancer among women and is the second leading cause of cancer deaths among women in the United States ${ }^{1}$. In 2012, it is estimated that 226,870 new cases of BC and 39,510 deaths due to BC will occur in women ${ }^{1,2}$. Early BC detection can lead to long-term survival and better quality of life in women. Mammography screening is considered to be the 'gold standard' for women at an average risk to detect BC early and hence reduce mortality ${ }^{3,4}$. Several clinical trials have shown that mammography screening decreases mortality by $20-35 \%$ in women age $40-69$ years of age ${ }^{5-9}$. Also, a recent Cochrane Review has demonstrated that mammography screening reduces the relative risk in mortality by $15 \%$ with $0.05 \%$ reduction in absolute risk ${ }^{10}$. Thus, adherence to mammography screening guidelines should be fostered in women age 40 years and above to reduce morbidity and mortality due to BC.

\section{Factors Influencing Adherence to Mammography Screening}

Overall, mammography screening rates have declined or have stagnated nationally since 2000 after seeing remarkable increases since $1987^{11}$. This poses a fundamental challenge in regards to breast health ${ }^{11}$. Mammography screening rates for women age 40 years and above vary by demographic, socio-economic, cultural, geographical, access, and psychosocial factors.

Demographic factors: $:$ Several studies have recognized demographic characteristics such as older age $^{12-17}$, being married or partnered ${ }^{15,16,18}$, being employed ${ }^{15}$, and having higher education $^{12,14,15,19,20}$ as predictors of women's adherence to mammography screening 
guidelines.

Socio-economic and access factors: Socio-economic and access factors such as higher income ${ }^{12}$, $14,15,17,18,21$, having health insurance ${ }^{12,17,21}$, visit to a primary care provider in past one year ${ }^{14,15}$, ${ }^{17}$, and visit to an obstetrician/gynecologist $(\mathrm{OB} / \mathrm{GYN})$ in past one year ${ }^{22,23}$ are also associated with women's adherence to mammography screening guidelines.

Health-related behavioral factors: Various health-related behavioral factors such as not smoking $^{12,16,19,21}$, not consuming alcohol ${ }^{15}$, having good to excellent self-reported health ${ }^{13,15,20}$, participating in other screening tests such as CBE, Pap test, cholesterol or blood pressure check $^{15}$, and not being overweight or morbidly obese ${ }^{15}$ have been associated with adherence to mammography screening guidelines in women.

Personal and family medical history related factors: Having family history of $\mathrm{BC}^{12,14,16,17}$, having had breast problems ${ }^{17,20}$, and having had breast biopsy ${ }^{24,25}$ are also significantly associated with adherence to mammography screening guidelines in women.

Psychosocial factors: Studies have shown that psychosocial factors such as having higher perceived risk of developing $\mathrm{BC}^{26,27}$, having knowledge of $\mathrm{BC}$ and mammography screening ${ }^{27}$, ${ }^{28}$, and having positive views and beliefs about mammography screening ${ }^{27}$ as being associated with women's adherence to mammography screening guidelines.

\section{Mammography Screening in West Virginia}

West Virginia (WV) is the only state that lies entirely within Appalachia and 39 out of its 55 counties are categorized as rural ${ }^{29}$. Appalachia is a predominantly rural, medically underserved region in the United States characterized by higher median age, poverty, low levels of education, high rates of chronic disease, and poor health behaviors ${ }^{30-33}$. WV has a lower incidence but higher rates of advanced and unstaged $\mathrm{BC}$ in spite of higher rates than national 
averages of all-cancer incidence and mortality ${ }^{29,34-37}$. The lower incidence but higher rates of late and unstaged $\mathrm{BC}$ has been attributed to lower mammography screening rates in women in $\mathrm{WV}^{29,39}$. In 2010, WV was ranked $48^{\text {th }}$ among other states of the United States for women having mammography screening within the past two years ${ }^{40}$. A study on screening, incidence, and mortality associated with BC in WV using different data sources such as the 2006 Centers for Disease Control and Prevention (CDC) Behavioral Risk Factor and Surveillance System Survey (BRFSS), WV Cancer Registry (WVCR), and the CDC Wide-ranging Online Data for Epidemiologic Research (WONDER) indicated that $74.5 \%$ of WV women had a mammogram in the past two years compared to $76.6 \%$ women nationally ${ }^{39}$. The significant predictors of adherence to mammography screening guidelines reported in this study were older age, higher income, having health insurance, and visit to a primary care provider in the past one year ${ }^{39}$. A recent study in WV Medicaid fee-for-service women indicated that less than $40 \%$ women had a mammogram related billing in 2007-2008 within the previous two years ${ }^{41}$ although mammography screening services are covered under Medicaid programs. The authors of this study suggested that there may be factors other than insurance coverage and financial constraints, such as lack of knowledge about mammography, cultural influences, views and attitudes about mammography, lack of physician's recommendations, lack of transportation, which may influence screening rates in the Medicaid population. This coincides with the findings of other studies that have reported that women enrolled in state Medicaid programs have lower mammography screening rates ${ }^{42-43}$ and are more likely to be diagnosed with advanced stage $\mathrm{BC}^{44-46}$. Moreover, studies have also reported that women residing in rural and underserved areas are less likely to ever have had a mammogram ${ }^{47-48}$.

It is essential for rural and underserved women to have accessible health and BC 
prevention information sources from which they can learn about the benefits of mammography screening. A recent study has reported various interpersonal sources such as doctors, nurses, friends and channel sources such as television, magazines and internet among the most preferred sources of information for women residing in rural areas ${ }^{49}$. In addition, the authors of this study suggested that multiple channels including internet and text messages may become regular BC prevention sources and health educators may use these when developing educational interventions to increase mammography screening in women in rural areas.

\section{Interventions to Overcome Barriers to Mammography Screening}

Several effective interventions to reduce disparities related to mammography screening and $\mathrm{BC}$ have been reported. A meta-analysis ${ }^{50}$ reported that women exposed to tailored interventions were significantly more likely to get a mammogram. It also indicated that a tailored physician's letter and/or booklets along with telephone counseling, use of printed educational materials, tailored telephone counseling, and educational programs coupled with onsite mammography screening increased adherence to mammography screening guidelines. Some programs which utilized qualitative study designs indicated that lay health advisors influenced the attitudes and behavior of women in their social networks and hence favorably influenced their screening behaviors ${ }^{51,52}$. A review of intervention studies ${ }^{53}$, which included 151 published and unpublished trials listed letter of invitation, a mailed educational material, a letter of invitation plus a telephone call, and training activities plus direct reminders to women as effective strategies likely to increase participation of women in community mammography

screening. Another review article ${ }^{54}$, which summarized seven studies indicated that peer support telephone calls increased mammography screening by $49 \%$. One intervention that has been in 
use for more than two decades to overcome barriers and increase mammography screening rates in rural and hard-to-reach populations is the use of mobile mammography ${ }^{55}$.

\section{Mobile Mammography}

Mobile mammography programs offer low cost or free mammography screening services to rural and hard-to-reach women populations and hence help to overcome barriers related to mammography screening. A review of literature mentioned that rural women who have to travel long distances to get a mammogram, who lack insurance and who have an inconsistent history of previous screenings are more likely to get screened if they have access to mobile mammography services $^{56}$. Hence, mobile mammography screening programs increase accessibility for women by providing services closer to home, at work sites, health clinics, health fairs, churches and community centers.

\section{Bonnie Wells Wilson Mobile Mammography Program}

The ‘Bonnie Wells Wilson Mobile Mammography Program' (called Bonnie’s Bus hereafter) was established in 2009 with the long term goal of increasing persistence of mammography screening in underserved women in rural WV. It is a program of the Mary Babb Randolph Cancer Center (MBRCC) in partnership with West Virginia University Healthcare. Bonnie's Bus was put into practice in honor of Bonnie Wells Wilson who succumbed to BC in a remote area of the state with no access to screening mammography. The goal of the Bonnie's Bus is to provide BC screening services to women in $\mathrm{WV}$, especially those in rural parts of the state with limited or no access to screening mammography. It is a statewide partnership of women's groups, clinicians, public health professionals and other community leaders all working toward reducing mortality from $\mathrm{BC}$ in WV. The self-contained mobile unit has a digital mammography instrument, patient-education area and waiting area, and a restroom. The bus has 
been in service since September 2009 and travels across the state from early spring to late fall. However, it goes off-road during winter due to extreme climate and snow. Although the program does require a physician referral, walk-ins are also accepted for which the provider on staff can write the referral. Mammograms are billed to third-party payers, and the program works closely with the West Virginia Breast and Cervical Screening Program (CDC) to provide service to women who are uninsured. Funding from grants and donations also help in providing mammograms to the uninsured women and those whose income is at or below $200 \%$ of the federal poverty level.

Before Bonnie's Bus was established, women in WV typically utilized mammography screening services from the stationary facilities such as the Betty Puskar Breast Care Center (BPBCC), Montgomery General Hospital, Advanced Women's Imaging by Saint Francis Hospital and few others located throughout WV. The BPBCC is the largest mammogram and $\mathrm{BC}$ treatment facility in WV and is housed at the MBRCC that launched and operates Bonnie's Bus. The BPBCC provides a comprehensive program for breast care, offering the best available expertise, educational tools, and technology aimed at the early detection of BC in Morgantown, WV. The center sees approximately 10,000 women every year.

\section{STATEMENT OF THE PROBLEM}

As mammography screening rates have stagnated or declined overall and in WV and large segments of rural WV women remain hard-to-reach, the number of advanced and unstaged $\mathrm{BC}$ cases detected and mortality related to $\mathrm{BC}$ will only increase in the future. Hence, there is a pressing need to increase mammography screening among these rural women in WV. Bonnie's Bus is a major effort towards reaching the underserved and rural women and increase mammography screening rates. 
Mobile mammography programs have been in service for more than twenty years, however there have been very few studies about their effectiveness. Several studies have demonstrated that mobile mammography increased mammography utilization in vulnerable populations by reducing access barriers ${ }^{57-59}$. A randomized clinical trial that assessed the benefit of on-site mobile mammography coupled with health education for older women reported that offering on-site mammography at community-based sites where older women gather is an effective method for increasing breast cancer screening rates ${ }^{57}$. Another study which evaluated interventions to promote screening mammography among women in rural communities through community education and low-cost mobile mammography van services found that utilization of mammography screening increased when access and cost barriers were reduced ${ }^{58}$. Yet another study documented that partnering with churches to provide mobile mammography screening increased the potential to improve adherence to mammography screening in under-screened women $^{59}$. However, no studies have described women who are utilizing mobile mammography screening services or explored the factors that may influence their adherence to mammography screening guidelines. Such information can be useful to develop effective intervention strategies aimed at increasing mammography screening rates in these women. To date, only one study has reported the characteristics of women utilizing mobile mammography unit (Bonnie's Bus) and predictors of adherence to mammography screening guidelines ${ }^{60}$. However, this study did not compare the characteristics and predictors of adherence to mammography screening guidelines in women who utilize stationary mammography facilities, and how they are different from those who utilize mobile mammography unit. Understanding the characteristics and hence predictors of adherence in women who utilize Bonnie's Bus to get a mammogram and compare those to women who utilize BPBCC to get a mammogram can help to identify the determinant 
characteristics of these women to help guide the development of targeted educational programs and interventions to increase mammography screening rates. Also, there are no reported studies that have looked at the views and attitudes towards mammography screening of women who never had a mammogram before. As suggested by a recent study ${ }^{41}$, it is vital to understand the barriers and facilitators to mammography screening in women who never had a mammogram before getting it at Bonnie's Bus. Also, little research has examined the types of intervention strategies linked with mobile mammography that are likely to improve screening rates and the effectiveness of such a program. Although many interventions effective in increasing screening rates have been reported in the literature, no studies have assessed the perspectives of women at whom these interventions are targeted, such as their receptiveness towards these interventions and their perception of whether or not they would be effective with their peers and in their communities. Besides determining the information sources used by women for mammography screening and their advice seeking behavior, it is important to target these rural and underserved women through appropriate sources and channels to increase mammography screening rates. Hence, understanding women's' barriers and facilitators for mammography screening, their perception and receptiveness about intervention strategies, and the sources and channels of health-related information they rely on, can be used in developing targeted educational programs and interventions that linked to Bonnie's Bus can increase mammography screening rates in women in WV.

\section{AIMS / OBJECTIVES}

The aims of this research study are: (1) to describe the profiles of women and determine predictors of adherence to mammography screening guidelines in women who utilize Bonnie's Bus in WV and those who utilize a stationary mammography facility, BPBCC, and (2) to 
determine what types of targeted educational interventions coupled with mobile mammography are perceived as likely to be acceptable and effective by non-adherent women. The specific study aims and objectives are:

Aim 1: Identify the differences in the profiles of women age 40 years and above who utilize Bonnie's Bus mobile mammography service with those women age 40 years and above who obtain mammography screening at the BPBCC.

Objective 1.1: Describe the characteristics (demographic, socio-economic, access, healthrelated behavioral, personal and family history, and psychosocial factors) of women age 40 years and above who utilize Bonnie’s Bus mobile mammography service.

Objective 1.2: Describe the characteristics (demographic, socio-economic, access, healthrelated behavioral, personal and family history, and psychosocial factors) of women age 40 years and above who utilize a typical mammography stationary facility such as the BPBCC. Objective 1.3: Determine how the two study populations of women age 40 years and above differ in terms of their demographic, socio-economic, access, health-related behavioral, personal and family history and psychosocial factors.

Aim 2: Identify the differences in the predictors of self-reported adherence in women age 40 years and above who utilize Bonnie's Bus mobile mammography services with those women age 40 years and above who obtain mammography screening at the BPBCC.

Objective 2.1: Determine the predictors of self-reported adherence in women who utilize Bonnie's Bus mobile mammography services by comparing the women who are adherent to mammography screening guidelines with those who are not. 
Objective 2.2: Determine the predictors of self-reported adherence in women who obtain mammography screening at a stationary facility such as the BPBCC, by comparing women who are adherent to mammography screening guidelines with those who are not.

Objective 2.3: Determine how the predictors of self-reported adherence in these two study populations of women age 40 years and above who utilize Bonnie's Bus mobile mammography service and mammography service at a stationary facility (BPBCC) are different.

Aim 3: Determine which of the personal and community tailored intervention programs reported as effective in the literature could be developed around Bonnie's Bus that are perceived as most likely to be effective in increasing mammography screening rates among the hard-to-reach and non-adherent women population.

Objective 3.1: Conduct telephone interviews among a sample of women age 40 years and above who were identified as having received their first mammogram during a Bonnie's Bus visit to their community.

Objective 3.2: To examine women's barriers and facilitators for mammography screening, their sources of health-related information, and to identify from their perspective the receptiveness for intervention strategies that are most likely to be effective in increasing screening rates when linked to mobile mammography.

\section{SIGNIFICANCE}

This project will determine the differences in the characteristics of women of WV who utilize mobile units and stationary facilities to obtain mammography screening. It will also determine the differences in the predictors of self-reported adherence to mammography screening guidelines in these two study populations. These findings along with the findings from 
the telephone interviews will assist in developing intervention strategies that are likely to be most effective for Bonnie's Bus to attract women age 40 years and above who have had mammograms at irregular time intervals or who have never had a mammogram before. This project will also guide the development of interventions such as breast health education programs, and public communication campaigns that could be easily implemented in the community. These interventions and programs may be coupled with other screening and healthcare services in rural, medically underserved areas thus leading to increased mammography screening rates and adherence to mammography screening guidelines.

\section{ASSUMPTIONS}

- Women who utilize Bonnie's Bus are representative of the age eligible rural Appalachian women population for whom mammography screening is recommended.

- Women who obtain mammography screening at BPBCC are representative of women who get mammogram at stationary facilities and they will be able to provide the required survey information with limited recall bias. Minimal recall bias is being assumed in the answers to survey questionnaire to be reported by both the sample populations.

\section{LIMITATIONS}

- Since a self-administered mail survey was used to collect the required information from a sample of BPBCC women, limitations associated with mail surveys respondent misinterpretation of survey instructions, and difference between respondents and nonrespondents may affect the study results.

- Self-reported information about mammography screening may differ from the information obtained from the records of healthcare providers. An individual tends to 
over-report his or her use of screening and to underreport the time since their last screen which may lead to self-report bias ${ }^{61}$.

- The results of the study may not be entirely representative of women elsewhere in the country as only women in WV were surveyed.

- Causality among the study variables cannot be established due to the cross-sectional study design. 


\section{REFERENCES}

1. American Cancer Society: Breast Cancer Facts and Figures 2012. Atlanta, Ga: American Cancer Society, 2012. http://www.cancer.org/Cancer/BreastCancer/DetailedGuide/breastcancer-key-statistics Accessed August 1, 2012.

2. Siegel R, Naishadham D, Jemal A. Cancer statistics, 2012. CA cancer J Clin. 2012; 62(1):10-29.

3. Nelson HD, Tyne K, Naik A, Bougatsos C, Chan BK, Humphrey L, U.S. Preventive Services Task Force. Screening for breast cancer: an update for the U.S. Preventive Services Task Force. Ann Intern Med. 2009; 151(10):727-37, W237-42.

4. Tabar L, Yen MF, Vitak B, Chen HH, Smith RA, Duffy SW. Mammography service screening and mortality in breast cancer patients: 20-year follow-up before and after introduction of screening. Lancet. 2003; 361(9367):1405-1410.

5. Fletcher SW, Elmore JG. Clinical practice: mammographic screening for breast cancer. $\mathrm{N}$ Engl J Med. 2003; 348:1672-1680.

6. Nyström L, Andersson I, Bjurstam N, Frisell J, Nordenskjold B, Rutqvist LE. Long-term effects of mammography screening: updated overview of the Swedish randomised trials. Lancet. 2002;359 (9310): 909-19.

7. Smith-Bindman R, Kerlikowske K, Gebretsadik T, Newman J. Is screening mammography effective in elderly women? Am J Med. 2000; 108:112-119.

8. Taber L, Dean PB. Mammography and breast cancer: The new era. Int J Gynaecol Obstet. 2003; 82:319-326.

9. Hellquist BN, Duffy SW, Abdsaleh S, Bjorneld L, Bordas P, Tabar L, Vitak B, Zackrisson S, Nystrom L, Jonsson H. Effectiveness of population-based service screening with mammography for women ages 40 to 49 years: Evaluation of the Swedish Mammography Screening in young women (SCRY) cohort. Cancer. 2011; 117(4):714722.

10. Gotzsche PC, Nielsen M. Screening for breast cancer with mammography. Cochrane Datasase Syst Rev. 2009; 4:CD001877.

11. Wolf AB, Brem RF. Decreased Mammography Utilization in the United Sates: Why and how can we reverse the trend? AJR. 2009; 192:400-402.

12. Rahman SMM, Digman MB, Shelton BJ. Factors influencing adherence to guidelines for screening mammography among women aged 40 years and older. Ethn Disp. 2003; 13(4):477-484. 
13. Gierisch JM, Earp JA, Brewer NT, Rimer BK. Longitudinal predictors of nonadherence to maintenance of mammography. Cancer Epidemiol Biomarkers Prev. 2010; 19(4):1103-1111.

14. Meissner HI, Breen N, Taubman ML, Vernon SW, Graubard BU. Which women aren't getting mammograms and why? (United States) Cancer Causes Control. 2007; 18:61-70.

15. Coughlin SS, Uhler RJ, Hall I, Briss PA. Non adherence to Breast and Cervical cancer screening: What are the linkages to chronic disease risk? Preventing chronic disease. 2004; 1(1):A04.

16. Borrayo EA, Hines L, Byers T, Risendal B, Slattery ML, Sweeney C, Baumgartner KB, Giuliano A. Characteristics associated with mammography screening among both Hispanic and non-Hispanic white women. Journal of Women's Health. 2009; 18(10): 1585-1594.

17. Zapka JG, Stoddard A, Maul L, Costanza ME. Interval adherence to mammography screening guidelines. Medical Care. 1991; 29(8):697-707.

18. Ulcickas Yood M, McCarthy BD, Lee NC, Jacobsen G, Johnson CC. Patterns and characteristics of repeat mammography among women 50 years and older. Cancer Epidemiol Biomarkers Prev. 1999; 8:595-599.

19. Selvin E, Brett KM. Breast and Cervical cancer screening. Socio-demographic predictors among white, black and Hispanic women. Am J of Public Health. 2003;93(4):618-623.

20. Bobo JK, Shapiro JA, Schulman J, Wolters CL. On-schedule mammography rescreening in the National Breast and Cervical Cancer Early Detection Program. Cancer Epidemiol Biomarkers Prev. 2004; 13:620-630.

21. Rakowski W, Meissner H, Vernon SW, Breen N, Rimer B, Clark MA. Correlates of Repeat and recent mammography for women ages 45 to 75 in the 2002 to 2003 Health Information National Trends Survey (HINTS 2003). Cancer Epidemiol Biomarkers Prev. 2006; 15(11):2093-2101.

22. Frazier EL, Jiles RB, Mayberry R. Use of screening mammography and clinical breast examinations among Black, Hispanic, and White women. Preventive medicine. 1996; 25:118-125.

23. Barr JK, Franks AL, Lee NC, Herther P, Schachter M. Factors associated with continued participation in mammography screening. Preventive medicine. 2007; 33:661-667.

24. Daly MB, Lerman CL, Ross E, Schwartz MD, Sands CB, Masny A. Gail model breast cancer risk components are poor predictors of risk perception and screening behavior. Breast cancer research treatment. 1996; 41(1):59-70. 
25. Zografos GC, Sergentanis TN, Zagouri F, Papadimitriou CA, Domeyer P, Kontogianni PN, Nonni A, Tsigris C, Patsouris E. Breast self-examination and adherence to mammographic follow-up: an intriguing diptych after benign breast biopsy. Eur J Cancer Prevention. 2010; 19(1):71-72.

26. Katapodi MC, Lee KA, Facione NC, Dodd MJ. Predictors of perceived breast cancer risk and the relation between perceived risk and breast cancer screening: a meta-analytic review. Preventive Medicine. 2004; 38:388-402.

27. Magai C, Consedine N, Neugut AI, Hershman DL. Common psychosocial factors underlying breast cancer screening and breast cancer treatment adherence: a conceptual review and synthesis. Journal of Women's Health. 2007; 16(1):11-23.

28. Lyttie NL, Stadelman K. Assessing awareness and knowledge of breast and cervical cancer among Appalachian women. Preventing chronic disease. 2006; 3(4):1-9.

29. Lengerich E.J., Tucker T.C., Powell R.K., Colsher P., Lehman E.,Ward, A. J., et. al. Cancer incidence in Kentucky, Pennsylvania, and West Virginia: disparities in Appalachia. Journal of Rural Health. 2005; 21: 39-47.

30. U.S. Census Bureau. (2010). Persons 25 years old and over with a bachelor's degree or more, 2008. Washington, DC: U.S. Census Bureau. http://www.census.gov/compendia/statab/2010/ranks/rank19.html, Accessed August 1, 2012.

31. U.S. Census Bureau. (2010). Persons below the poverty level, 2008. Washington, DC: U.S. Census Bureau. http://www.census.gov/compendia/statab/2010/ranks/rank34.html, Accessed August 1, 2012.

32. Kaiser State Health Facts. (2009). Overweight and obesity rates for adults by sex, 2009. Menlo Park, CA: Kaiser Family Foundation. http://www.statehealthfacts.org, Accessed August 1, 2012.

33. Kaiser State Health Facts. (2008). Percent of adults who smoke by sex, 2008. Menlo Park, CA: Kaiser Family Foundation. http://www.statehealthfacts.org, Accessed August $1,2012$.

34. Wingo PA, Tucker TC, Jamison PM, Martin H, McLaughlin C, Bayakly R, BolickAldrich S, Colsher P, Indian R, Knight K, Neloms S, Wilson R, Richards TB. Cancer in Appalachia, 2001-2003. Cancer. 2007; 112,181-192.

35. Lengerich EJ, Chase GA, Beiler J, Darnell M. Increased risk of unknown stage cancer from residence in a rural area: health disparities with poverty and minority status. Hershey, PA: Pennsylvania State University and the Penn State Cancer Institute, Department of Health Evaluation Sciences 2005. 
36. State Cancer Profiles. (2010). Incidence and mortality rate reports for West Virginia by county. Bethesda, MD: National Cancer Institute. http://statecancerprofiles.cancer.gov/, Accessed August 1, 2012.

37. United States Cancer Statistics (USCS). (2010). Rankings by state: 2006, male and female, all cancer sites combined. Atlanta, GA: Centers for Disease Control and Prevention (CDC). http://apps.nccd.cdc.gov/uscs/, Accessed August 1, 2012.

38. United States Cancer Statistics (USCS). (2010). State vs. national rates: 2006, female, West Virginia. Atlanta, GA: Centers for Disease Control and Prevention (CDC). http://apps.nccd.cdc.gov/uscs/, Accessed August 1, 2012.

39. Khanna R, Bhanegaonkar A, Colsher P, Madhavan S, Halverson J. Breast cancer screening, incidence and mortality in West Virginia. WV Med J. 2009. Special CME Issue, 25-32.

40. Kaiser State Health Facts. (2010). Percent of women age 40 and older who report having had a mammogram within the last two years, 2008. Menlo Park, CA: Kaiser Family Foundation. http://statehealthfacts.org, Accessed August 1, 2012.

41. Bhanegaonkar A, Madhavan S, Khanna R, Remick SC. Declining mammography screening in a State Medicaid Fee-for-Service Program: 1999-2008. Journal of Women's Health. 2012, May 8, (Epub ahead of print)

42. Dubard, CA, Schmid D, Yow A. Recommendation for and receipt of cancer screenings among Medicaid recipients 50 years and older. Arch Intern Med. 2008; 168(18) :20142021.

43. Welsh AL. Sauaia A, Jacobellis J, Min SJ, Byers T. The effect of two church-based interventions on breast cancer screening rates among Medicaid-insured Latinas. Prev Chronic Dis. 2005; 2:A07.

44. Roetzheim RG, Pal N, Tennant C, Voti L, Ayanian JZ, Schwabe A, Krischer JP._Effects of health insurance and race on early detection of cancer. J Natl Cancer Inst. 1999; 91:1409-1415.

45. Ayanian JZ, Kohler BA, Abe T, Epstein AM. The relation between health insurance coverage and clinical outcomes among women with breast cancer. N Engl J Med. 1993; 329:326-331.

46. Halpern MT, Bian J, Ward EM, Schrag NM, Chen AY. Insurance status and stage of cancer at diagnosis among women with breast cancer. Cancer. 2007; 110:403-411.

47. Bryant $\mathrm{H}$, Mah Z. Breast cancer screening attitudes and behaviors of rural and urban women. Prev Med. 1992; 21:405-418. 
48. Calle EE, Flanders WD, Thun MJ, Martin LM. Demographic predictors of mammography and pap smear screening in US women. American Journal of Public Health. 1993;.83:53-60.

49. Kratzke C, Wilson S, Vilchis H. Reaching rural women: breast cancer prevention information seeking behaviors and interest in internet, cell phone, and text use. Journal of community health. 2012; (Epub ahead of print)

50. Sohl SJ, Moyer A. Tailored interventions to promote mammography screening: A metaanalytic review. Preventive medicine. 2007; 45:252-261.

51. Flax VL, Earp JL. Counseled women's perspectives on their interactions with lay health advisors: a feasibility study. Health Education Research. 1999; 14(1):15-24.

52. Eng E, Smith J. Natural helping functions of lay health advisors in breast cancer education. Breast Cancer Res Treatment. 1995; 35(1):23-29.

53. Bonfill CX, Marzo CM, Pladevall VM, Marti J, Emparanza JI. Strategies for increasing the participation of women in community breast cancer screening (Review). The Cochrane Library. 2009; 1.

54. Dale J, Caramlau IO, Lindenmeyer A, Williams SM. Peer support telephone calls for improving health (Review). The Cochrane Library. 2009; 1.

55. DeBruhl N, Bassett LW, Jessop NW, Mason AM. Mobile mammography: results of a national survey. Radiology. 1996; 201(2):433-437.

56. Buzek N. Mobile mammography for underserved women: What does evidence say? Advance Nurse practice. 2010; 18(5):29-32.

57. Reuben DB, Bassett LW, Hirsch SH, Jackson CA, Bastani R. A randomized clinical trial to assess the benefit of offering on-site mobile mammography in addition to health education for older women. AJR. 2002; 179:1509-1514.

58. Flynn B, Gavin P, Worden JK, Ashikaga T, Gautam S, Carpenter J. Community education to promote mammography participation in rural New York state. Prev Med. 1997; 26(1):102-108.

59. Derose K, Duan N, Fox SA. Women's receptivity to church-based mobile mammography. J Health Care Poor Underserved. 2002; 13(2):199-213.

60. Vyas A, Madhavan S, Lemasters T, Atkins E, Gainor S, Kennedy S, Kelly K, VonaDavis L, Remick S. Factors influencing adherence to mammography screening guidelines in Appalachian Women participating in a mobile mammography program. Journal of community health. 2012; 37(3):632-646. 
61. Vacek P, Mickey R, Worden J. Reliability of self reported breast screening information in a survey of lower income women. Preventive Medicine. 1997; 26, 287-291. 
CHAPTER 2 


\section{CHAPTER 2}

\section{PREDICTORS OF SELF-REPORTED ADHERENCE TO MAMMOGRAPHY SCREENING GUIDELINES IN WEST VIRGINIA WOMEN}

\section{INTRODUCTION}

Breast cancer $(\mathrm{BC})$ is the most common cancer among women and is the second leading cause of cancer deaths among women in the United States ${ }^{1}$. In 2012, it is estimated that 226,870 new cases of $\mathrm{BC}$ and 39,510 deaths due to $\mathrm{BC}$ will occur in women ${ }^{1,2}$. Early BC detection can lead to long-term survival and improved quality of life in women. Mammography screening is considered to be the 'gold standard' for women at an average risk to detect BC early thereby reducing mortality ${ }^{3,4}$. Several clinical trials have shown that mammography screening reduces BC-related mortality by $20-35 \%$ in women age $40-69$ years of age ${ }^{5-9}$. Also, a recent Cochrane Review has reported that mammography screening reduces the relative risk in mortality by $15 \%$ with $0.05 \%$ reduction in absolute risk ${ }^{10}$. Thus, adherence to mammography screening guidelines should be fostered in women age 40 years and above to reduce mortality due to BC.

\section{Mammography Screening in West Virginia}

West Virginia (WV), the only state that lies entirely within Appalachia has 34 out of its 55 counties categorized as rural ${ }^{11,12}$. Moreover, 48 of WV's 55 counties are wholly or partially designated as Medically Underserved Areas (MUAs) by the Health Resource and Services Administration (HRSA) ${ }^{13}$. Appalachia is a predominantly rural, medically underserved region in the United States characterized by poverty, low levels of education, high rates of chronic disease, and poor health behaviors ${ }^{14-17}$. Despite the higher prevalence of chronic diseases, and higher rates than national averages of all-cancer incidence and mortality, WV has a lower incidence but higher rates of advanced and unstaged $\mathrm{BC}^{12,18-22}$. The lower incidence but higher rates of late 
and unstaged $\mathrm{BC}$ has been attributed to lower mammography screening rates in women in $\mathrm{WV}^{12}$, 23. In 2010, WV was ranked $48^{\text {th }}$ among other states of the United States for women having mammography screening within the past two years ${ }^{24}$. A study on screening, incidence, and mortality associated with BC in WV using different data sources such as the 2006 Centers for Disease Control and Prevention (CDC) Behavioral Risk Factor and Surveillance System Survey (BRFSS), WV Cancer Registry (WVCR), and the CDC Wide-ranging Online Data for Epidemiologic Research (WONDER) indicated that $74.5 \%$ of WV women had a mammogram in the past two years compared to $76.6 \%$ women nationally ${ }^{23}$. The significant predictors of adherence to mammography screening guidelines reported in this study were older age, higher income, having health insurance, and visit to a primary care provider in the past one year ${ }^{23}$. A recent study about mammography screening in WV Medicaid fee-for-service women indicated that less than $40 \%$ women had a mammogram related billing in 2007-2008 within the previous two years although mammography screening services are covered under Medicaid programs ${ }^{25}$. The authors of this study suggested that there may be factors other than insurance coverage and financial constraints, such as lack of knowledge about mammography, cultural influences, views and attitudes about mammography, lack of physician recommendation, lack of transportation, which may influence screening rates in the Medicaid population. This coincides with the findings of other studies that have reported that women enrolled in state Medicaid programs have lower mammography screening rates ${ }^{26,27}$ and are more likely to be diagnosed with advanced stage $\mathrm{BC}^{28-30}$. Thus, the studies highlight the need for interventions targeted at vulnerable women to increase mammography screening rates and adherence to mammography screening guidelines.

Factors Influencing Adherence to Mammography Screening 
Mammography screening rates have declined or have stagnated nationally since 2000 after seeing remarkable increases since $1987^{31}$. This poses a fundamental challenge to breast health ${ }^{31}$. The lack of adherence to mammography screening guidelines varies by demographic, socioeconomic, cultural, geographical, access and psychosocial factors in women age 40 years and above. Several studies have recognized demographic characteristics such as older age ${ }^{32-37}$, being married or partnered ${ }^{35,36,38}$, being employed ${ }^{35}$, and having higher education ${ }^{32,34,35,39,40}$ as the predictors of women's adherence to mammography screening guidelines. Socio-economic and access factors such as higher income ${ }^{32,34,35,37,38,41}$, having health insurance ${ }^{32,37,41}$, visit to a primary care provider in past one year ${ }^{34,35,37}$, and visit to an obstetrician/gynecologist $(\mathrm{OB} / \mathrm{GYN})$ in past one year ${ }^{42,43}$ are also associated with women's adherence to mammography screening guidelines. Various health-related behavioral factors such as not smoking ${ }^{35,36,39,41}$, not consuming alcohol ${ }^{35}$, having good to excellent self-reported health ${ }^{33,35,40}$, participating in other screening tests such as clinical breast exam (CBE), Pap test, cholesterol or blood pressure check $^{35}$, and not being overweight or morbidly obese ${ }^{35}$ have been associated with adherence to mammography screening guidelines in women. Having a family history of $\mathrm{BC}^{32,34,36,37}$, having had breast problems ${ }^{37,40}$, and having had a breast biopsy ${ }^{44,45}$ are also significantly associated with adherence to mammography screening guidelines in women. Studies have shown that psychosocial factors such as having higher perceived risk of developing $\mathrm{BC}^{46,47}$, having knowledge of BC and mammography screening ${ }^{47,48}$, and having positive views and beliefs about mammography screening ${ }^{47}$ as being associated with women's adherence to mammography screening guidelines.

\section{Interventions to overcome Barriers to Mammography Screening}


Several studies have reported interventions such as physician's letter and/or booklets along with telephone counseling, use of printed educational materials, and tailored telephone counseling that have been effective to reduce disparities related to mammography screening ${ }^{49-53}$. One such intervention that has been in use for more than two decades to overcome barriers and increase mammography screening rates in rural and hard-to-reach populations is mobile mammography ${ }^{54}$. Mobile mammography programs offer low cost or free mammography screening to rural and hard-to-reach women populations. Several studies have demonstrated that mobile mammography reduce access barriers thereby increasing mammography utilization in vulnerable populations ${ }^{55-57}$. Rural women who have to travel long distances to get a mammogram, who do not have insurance and who have an inconsistent history of previous screenings are more likely to get screened if they have access to mobile mammography services $^{58}$. Hence, mobile mammography screening programs increase accessibility for women by providing services closer to home, at work sites, health clinics, health fairs, churches and community centers.

\section{Bonnie Wells Wilson Mobile Mammography Program}

The ‘Bonnie Wells Wilson Mobile Mammography Program' (called Bonnie’s Bus hereafter) was established in 2009 with the long term goal of increasing adherence and persistence of mammography screening in underserved women in rural WV. It is a program of the Mary Babb Randolph Cancer Center (MBRCC) in partnership with West Virginia University Healthcare. Bonnie's Bus was established to provide BC screening services to women in WV, especially those in rural parts of the state with limited or no access to screening mammography. More details about the program are described elsewhere ${ }^{59}$. 
Before Bonnie's Bus was established, women in WV typically utilized mammography screening services from the stationary facilities such as the Betty Puskar Breast Care Center (BPBCC), Montgomery General Hospital, Advanced Women's Imaging by Saint Francis Hospital and a few other such facilities located throughout WV. The BPBCC is the largest mammogram and $\mathrm{BC}$ treatment facility in $\mathrm{WV}$ and is housed at the MBRCC that launched and operates Bonnie's Bus. The BPBCC provides a comprehensive program for breast care, offering the best available expertise, educational tools, and technology aimed at the early detection of $\mathrm{BC}$ in Morgantown, WV. The center sees approximately 10,000-12,000 women every year.

Mobile mammography programs have been in service for more than twenty years, however there have been very few studies about their effectiveness. A recent study which described the women who utilize mobile mammography unit (Bonnie's Bus) and what factors influence their adherence to mammography screening guidelines ${ }^{59}$ may be useful to develop effective intervention strategies aimed at increasing mammography screening rates and persistence in these women. However, this study did not determine how women who utilize mobile mammography units for screening may be different from women who get their routine screening done at a stationary facility. Understanding the characteristics and hence predictors of adherence in women who utilize mobile mammography unit to get a mammogram and compare those to women who utilize a stationary facility, can help to identify the determinant characteristics of these women to facilitate the development of targeted educational programs and interventions to increase mammography screening rates. Moreover, in a rural, underserved, geographically and socio-economically challenged state, the 'standard' approach of providing screening at fixed facilities is not the only solution to improve screening rates. Hence, the objectives of this research study are to identify the characteristics of women age 40 years and 
above who utilize Bonnie's Bus mobile mammography service and those women age 40 years and above who obtain mammography screening at a stationary facility such as the BPBCC, and to determine the predictors of self-reported adherence in these two study populations.

\section{CONCEPTUAL FRAMEWORK}

To achieve the objectives of the research study, the 'expanded' version of Andersen Behavioral Model for Health Services Utilization (Andersen model) ${ }^{60}$ is utilized as the conceptual model (Figure 1). This model is one of the most frequently used conceptual frameworks for analyzing patient utilization of health care services. Also, the data on all the factors included in this conceptual framework is well captured by the Mammography Screening and Preventive Care Survey which has been used to collect data since the establishment of Bonnie's Bus in 2009. The reasons for the choice of this model and its details are explained elsewhere ${ }^{59}$. Predisposing factors such as age, education, employment status, body mass index (BMI), smoking status, alcohol consumption, and enabling factors such as marital status, household income, insurance coverage, visit to doctor and obstetrician/gynecologist (OB/GYN) in past year, problems in performing routine and instrumental activities of daily living, and delay in care due to transportation are included in the model. Need-related factors included in the model are self-rated health status, family history of $\mathrm{BC}$, adherence to $\mathrm{CBE}$ and Pap test, having had breast problems, having had breast biopsy, history of cancer, and other screening tests for cholesterol, blood pressure, bone mineral density and glucose. Psychosocial factors such as perceived five year and lifetime risks of developing $\mathrm{BC}$, knowledge about mammography screening and views on mammography screening are also included in the model. Use of this expanded version of the Andersen model of healthcare services utilization provides a strong 
theoretical framework to identify the factors that influence adherence to mammography screening guidelines in the two study samples.

\section{METHODS}

\section{Study Design}

This research study used a cross-sectional study design.

\section{Participants}

Participants for this research study comprised of women throughout WV who utilized mammography screening at the Bonnie's Bus in the years 2009, 2010 and 2011 and those who had mammography screening at the BPBCC at least once in the past 10 years and completed the survey.

Out of a total of 2,447 women who utilized mammography services at the Bonnie's Bus, 1,313 women consented to participate in the survey. Out of 1,313 women, six women did not report age, seven women did not report time since last mammogram, and seventy-nine women already had a mammogram at the Bonnie's Bus before and hence were not included in the sample. Sixty women were under the age of 40 years and were not included in the study to be consistent with the mammography screening guidelines, which recommends mammography screening in women age 40 years and above ${ }^{61-63}$. Therefore, the final sample size for the Bonnie's Bus was 1,161 (50.59\%).

A total of 16,687 women age 40 years and above utilized BPBCC to get a screening mammogram at least once in the past ten years (from August 2001 to July 2011). Out of these, 2,505 women were randomly selected and invited to participate in the study. Out of 2,505 women contacted, 246 women did not receive the survey due to bad address and 4 women died during the ten-year period and thus were not included in the study. Hence, a total of 2,255 
women were assumed to have received the survey. Out of these, 1,104 women $(48.96 \%)$ completed and returned the survey which comprised the final sample size for the BPBCC sample.

The BPBCC was chosen as a representative stationary site for comparing the Bonnie's Bus women because it is the largest mammography screening facility in the state and $60 \%$ of its coverage area overlaps with the Bonnie's Bus coverage area.

\section{Survey Instrument}

For this study, data were collected using the West Virginia University Institutional Review Board (WVU-IRB) approved Mammography Screening and Preventive Care Survey (Appendix A) from women who utilized Bonnie's Bus to get a mammogram and those who utilized BPBCC at least once in the past ten years to get a mammogram. The survey questionnaire was pilot tested in a small group of women to assess its reliability and validity. It

had several sections including personal health history, menstrual and pregnancy history, family history of cancer, cancer risk assessment and screening history, views on BC screening, BC awareness, preventive care and wellness history, nutrition and exercise history, dental, smoking and alcohol consumption history, and demographics.

\section{Survey Administration and Data Collection}

Women who utilize Bonnie's Bus to get a mammogram are typically provided study information and requested to participate in research survey. Women agreeing to participate in the research study are required to sign the consent and Health Insurance Portability and Accountability Act form before completing the survey. This informed consent form is used to seek their consent to use their survey data for research, and also contact them, if necessary, for the current or any other study for which they may be eligible in the future. 
A survey, a cover letter (Appendix B) and a prepaid business reply envelope from the radiologist at the $\mathrm{BPBCC}$ were sent to 2,505 randomly selected women who were screened at the BPBCC at least once in the past ten years. At the three week interval, a cover letter (Appendix C) and the survey were mailed again to those who had not responded to maximize the response rate. Those who completed and returned the survey were assumed to have given their consent to participate in the study. A thank you letter (Appendix D) with $\$ 5$ gift-card was mailed to all women who completed and returned the survey to acknowledge their participation and time.

\section{Dependent Variable - Self-Reported On-Schedule Adherence to Mammography Screening}

\section{Guidelines}

The main outcome of interest was self-reported on-schedule adherence to mammography screening guidelines, defined as having had a mammogram in the past one to two years in women $^{64}$.

For this study, we focused on the United States Preventive Services Task Force (USPSTF) 2002 recommendations which advocates mammography screening every 1-2 years for women age 40 years and above ${ }^{61,65}$ which are in general agreement with current recommendations from several professional organizations such as Centers for Disease Control \& Prevention (for BRFSS, National Health Interview Survey, National Center for Health Statistics) and Healthy People 2010 \& 2020 objectives. Moreover, data from the BPBCC sample is from women who have had at least one mammogram from 2001 to 2011 during which USPSTF 2002 recommendations were being followed by clinicians. The recommendations are consistent with the Medicare and Medicaid coverage for screening mammograms as well.

The dependent variable, self-reported adherence to mammography screening guidelines, was dichotomized into adherent $(=1)$ and non-adherent $(=0)$ groups. Women who reported 
having had a mammogram in the past 1 to 2 years were considered adherent while those who never have had a mammogram and those who had their last mammogram more than 2 years prior were considered non-adherent to mammography screening guidelines.

\section{Independent Variables}

Our analyses of the factors influencing adherence to mammography screening guidelines in women age 40 years and above was guided by the extended version of Andersen model where the utilization of healthcare services is considered as the function of an individual's predisposition to use services, factors which enable or impede use, need for care and various psychosocial factors.

\section{Predisposing factors}

Various socio-demographic variables were utilized: age (40-49, 50-64, 65and above); education level (less than high school, some high school/high school graduate, GED/Tech, some college/graduate); and employment status (employed, unemployed); health-related variables such as body mass index (BMI) (underweight/normal weight BMI $<25 \mathrm{~kg} / \mathrm{m}^{2}$, overweight $25 \mathrm{~kg} / \mathrm{m}^{2}$ $<=$ BMI $<30 \mathrm{~kg} / \mathrm{m}^{2}$, obese $30 \mathrm{~kg} / \mathrm{m}^{2}<=$ BMI $<35 \mathrm{~kg} / \mathrm{m}^{2}$, extremely obese $35 \mathrm{~kg} / \mathrm{m}^{2}<=$ BMI < $40 \mathrm{~kg} / \mathrm{m} 2$, morbidly obese BMI >= $40 \mathrm{~kg} / \mathrm{m}^{2}$ ); smoking status (never, former, current); and alcohol consumption (yes, no).

\section{Enabling factors}

Several variables that may impede or enable women to utilize mammography screening as per the guidelines were utilized: marital status (married/partnered, single/divorced/widowed); household income (less than $\$ 25,000, \$ 25,000-\$ 50,000, \$ 50,000-\$ 75,000$, more than $\$ 75,000$ ); health insurance (yes, no); visit to physician in the past year (yes, no); visit to OB/GYN in the 
past year (yes, no); delay in medical care due to transportation (yes, no); problems in performing activities of daily living (ADL), and instrumental activities of daily living (IADL) (yes, no).

\section{Need-related factors}

Health-related and medical history variables were also explored: self-reported health status (poor/fair, good/very good/excellent); family history of BC (yes, no); breast problems in the past (yes, no); breast biopsy in the past (yes, no); adherence to clinical breast exam (CBE) (yes, no); adherence to Pap test (yes, no); having had any cancer (yes, no); a composite score of having had other screening tests such as blood glucose test, bone mineral density test, cholesterol test, high blood pressure test (possible scores $0,1,2,3$, or 4). The composite scores were grouped in two groups, those with score 0-3 and those with score 4. A woman who would have all the four screening tests in past two years was given the score of 4 while a woman who would not have any of these screening tests in past two years was given the score of 0 . A woman was considered adherent to $\mathrm{CBE}$ if she had $\mathrm{CBE}$ in past one year as per recommended guidelines ${ }^{62}$ and adherent to Pap test if she had Pap test within past two years as per recommended guidelines $^{62}$.

\section{$\underline{\text { Psychosocial factors }}$}

Perceived five-year risk and perceived lifetime risk of developing $\mathrm{BC}$ where women were asked to rate their level of risk in comparison to the risk of other women of their age in the general population (lower, similar, higher); views towards mammography screening; and knowledge about BC and mammography screening were used. Views towards mammography screening were measured using eight statements for which participants had to indicate their extent of agreement or disagreement with each statement using a 7-point Likert scale where $1=$ strongly agree and $7=$ strongly disagree. Four statements reflected positive views about 
mammography screening while four other statements reflected negative views about mammography screening. For example, a positive view statement was 'Having mammography screening would reassure me that everything is $\mathrm{OK}$ ' and a negative view statement was 'Having mammography screening would be painful'. Internal consistency for positive and negative views statements was evaluated using Cronbach's alpha co-efficient. For the Bonnie's Bus data, the Cronbach's alpha was 0.758 for a set of positive views and 0.713 for a set of negative views which indicated sufficient internal consistency. While for the BPBCC data, the Cronbach's alpha was 0.756 for a set of positive views and 0.678 for the set of negative views which again indicated sufficient internal consistency. Knowledge about BC and mammography screening was assessed by summing correct responses to six BC and mammography screening related statements. Correct responses were assigned score of 1 and hence maximum possible knowledge score was 6. Participants' total knowledge scores were analyzed by three groupings (0-2, 3-4, and 5-6). The knowledge statements were validated by two WVU clinicians and three researchers overseeing the project.

\section{Non-Response Bias Assessment}

To determine whether or not women who did not participate in the study were different from women who participated, non-response bias was assessed in both the study samples. Women who utilized Bonnie's Bus to get a mammogram and did not consent to participate in the survey were asked to provide their basic information such as their age, race, marital status, employment status, health insurance coverage, BMI and if it was their first mammogram at the Bonnie's Bus. The survey response rate for the Bonnie's Bus was 50.59\%. Survey respondents were compared to non-respondents on selected demographic and access factors as noted above. Non-respondents were significantly older $(64.4 \%$ in age group $>=65$ years, $p<0.0001)$, from 
other minority race $(64.3 \%, \mathrm{p}=0.009)$, single/widowed $(53.9 \%, \mathrm{p}=0.002)$, unemployed $(52.2 \%$, $\mathrm{p}=0.001)$, overweight and morbidly obese $(54.0 \%$ and $51.2 \%$ respectively, $\mathrm{p}<0.0001)$ and with some kind of insurance coverage $(51.7 \%, \mathrm{p}=0.007)$.

The survey response rate for the BPBCC study sample was 48.96\%. From those who did not complete and mail back the survey, 400 women were randomly selected and mailed a WVUIRB approved a brief non-response bias assessment survey (Appendix F) along with a cover letter (Appendix E). This survey was developed by selecting key questions from the Mammography Screening and Preventive Care Survey. These included possible reasons for nonparticipation, time since last mammogram, a positive view statement about mammography screening, a knowledge item about mammography screening, and other demographic and access questions. A total of 100 women completed and mailed back this survey. Twenty-eight percent of women said that they misplaced the survey, and $26 \%$ mentioned that they do not respond to mail surveys in general. Another $12 \%$ of women specified that they had no time to complete and mail back the survey, and participate in the study, while $9 \%$ mentioned other reasons for not participating in the study. Survey respondents were compared to non-respondents on the selected information collected using the non-response bias assessment survey. Non-respondents were significantly more likely to be unemployed $(54.0 \%, \mathrm{p}=0.026)$, and have less than college education $(51.0 \%, \mathrm{p}=0.013)$ and worry sometimes about getting $\mathrm{BC}(53 \%, \mathrm{p}<0.0001)$.

\section{Statistical Analyses}

Descriptive statistics were used to separately describe the characteristics of women age 40 years and above who utilized mobile mammography services and the stationary facility to get a mammogram and also completed the Mammography Screening and Preventive Care Survey. Chi-square statistics for categorical variables and t-tests for continuous variables were used 
separately in both the study samples to determine significant differences between self-reported adherent and non-adherent groups. Logistic regressions were also performed to analyze the relationship between self-reported adherence with all the constructs of Andersen model, after controlling for predisposing, enabling, need-related and psychosocial factors, separately for both the study samples. We entered variables in sequential blocks for logistic regressions for both the study populations. Model 1 included only predisposing factors as independent variables. Model 2 added enabling factors to model 1 . Model 3 added need-related factors in addition to variables mentioned in model 2. Model 4 included psychosocial factors in addition to variables specified in model 3 thereby making model 4 the completely "adjusted model". In all regressions models, 'non-adherent group' was the reference group for the dependent variable. Resulting odds ratios and their corresponding 95\% confidence intervals were examined. The findings that were significant with p-values less than 0.05 levels are discussed. SAS 9.2 software program was used for the statistical analyses.

\section{RESULTS}

\section{Characteristics of the Mobile Mammography Study Sample}

The left panel of Table 1 describes the characteristics of 1,161 women age 40 years and above who utilized Bonnie's Bus to get a mammogram from 2009 to 2011 and completed the Mammography Screening and Preventive Care Survey. Women in this study sample were on average of age 54.5 years. A majority (57\%) of the women were in the age group 50-64 years, while $31 \%$ were in age group $40-49$ years and only $12 \%$ were age 65 and above. A majority $(65 \%)$ were married or partnered, had less than college level education (70\%), were unemployed (52\%), were overwhelmingly overweight to morbidly obese (82\%), had a household income of less than $\$ 25,000(67 \%)$, were insured (57\%), and reported their health status as good to 
excellent $(76 \%)$. Twenty-five percent of the women were current smokers and a majority $(75 \%)$ did not consume alcohol. Fifty-eight percent of the women had visited a doctor in the past year while only $35 \%$ had visited an OB/GYN in the past year. Sixteen percent of the women reported a family history of BC, $13 \%$ reported breast problems and $19 \%$ had a breast biopsy in the past. Sixty-nine percent of women reported having had a Pap test in the past two years while only $47 \%$ reported having had a CBE in the past year. Only $14 \%$ of the study sample had all the four screenings such as blood glucose test, bone mineral density test, cholesterol test and high blood pressure test in the past two years. A low percentage of women perceived their five-year risk (12\%) and lifetime risk (14\%) to be higher than other women in the general population. Almost equal proportion of women (47\%) had moderate knowledge (scores 3 and 4) and higher (scores 5 and 6) knowledge about $\mathrm{BC}$ and mammography screening. The mean score for the positive views statements was $1.741(1=$ Strongly agree and $7=$ Strongly disagree $)$ and that for the negative views statements was $5.509(1=$ Strongly agree and $7=$ Strongly disagree $)$. Out of 1,161 women, 559 women (48.15\%) reported adherence to mammography screening guidelines i.e. having had a mammogram in the past 1-2 years.

\section{Characteristics of the Stationary Facility Study Sample}

The right panel of Table 1 describes the characteristics of 1,104 women age 40 years and above who had at least one mammogram at the BPBCC in the past ten years and completed the Mammography Screening and Preventive Care Survey. Women in this study sample were on average of age 57.8 years. A majority (57\%) of the women was in the age group 50-64 years, while $23 \%$ were age 65 and above and $20 \%$ were in the age group $40-49$ years. A majority (77\%) were married or partnered, had at least some college level education (62\%), were employed (58\%), overweight to morbidly obese (68\%), had household income more than 
$\$ 50,000$ (55\%), were insured (95\%), and reported their health status as good to excellent (85\%). Ten percent of women were current smokers and a majority (52\%) did not consume alcohol. Seventy-three percent of women had visited a doctor in the past year while 53\% had visited an $\mathrm{OB} / \mathrm{GYN}$ in the past year. Twenty percent of women reported a family history of $\mathrm{BC}$ and $23 \%$ reported breast problems. One-third of the study sample had breast biopsy in the past, and 14\% reported any cancer. Seventy percent of women reported having had a Pap test in the past two years and $63 \%$ reported having had a CBE in the past year. Only $32 \%$ of the study sample had all the four screenings such as blood glucose test, bone mineral density test, cholesterol test and high blood pressure test in the past two years. A low percentage of women perceived their fiveyear risk (16\%) and lifetime risk (18\%) to be higher than other women in the general population. A majority (62\%) of the women had moderate knowledge (scores 3 and 4) while $31 \%$ reported higher knowledge (scores 5 and 6 ) about $\mathrm{BC}$ and mammography screening. The mean score for the positive views statements was $1.975(1=$ Strongly agree and $7=$ Strongly disagree $)$ and that for the negative views statements was $5.822(1=$ Strongly agree and $7=$ Strongly disagree $)$. Out of 1,104 women, 1,019 women (92.3\%) reported adherence to mammography screening guidelines i.e. having had a mammogram in the past 1-2 years.

\section{Results of Bivariate Analyses}

Table 2 details the independent variables that were significantly different between women who were adherent and non-adherent to mammography screening guidelines in the study sample who utilized mobile mammography unit. The average age of women in the adherent group was 56.03 years while that in the non-adherent group was 53.03 years. Self-reported adherence to mammography screening guidelines was higher in older women $\left(\chi^{2}=23.914, \mathrm{p}<0.0001\right)$, women who were unemployed $\left(\chi^{2}=5.903, p=0.0151\right)$, women who were never or former 
smokers $\left(\chi^{2}=9.661, \mathrm{p}=0.008\right)$, those who had visited a doctor $\left(\chi^{2}=5.616, \mathrm{p}=0.018\right)$ and $/$ or OB/GYN $\left(\chi^{2}=11.072, p=0.0009\right)$ in the past year, those who reported a family history of BC $\left(\chi^{2}=9.603, \mathrm{p}=0.0019\right)$, those who had breast problems $\left(\chi^{2}=10.734, \mathrm{p}=0.0011\right)$, those who had a breast biopsy in the past $\left(\chi^{2}=18.547, \mathrm{p}<0.0001\right)$, and those who were adherent to CBE $\left(\chi^{2}=6.153, \mathrm{p}=0.0131\right)$ and Pap test $\left(\chi^{2}=107.362, \mathrm{p}<0.0001\right)$ and those who reported all the four routine screenings in the past two years $\left(\chi^{2}=9.930, \mathrm{p}=0.0016\right)$.

Table 3 details the independent variables that were significantly different between women who were adherent and non-adherent to mammography screening guidelines in the study sample who utilized stationary mammography facility. The average age of women in the adherent group was 57.89 years while that in the non-adherent group was 56.77 years. Self-reported adherence to mammography screening guidelines was higher in women with at least some college-level education $\left(\chi^{2}=10.942, \mathrm{p}=0.0120\right)$, women who were underweight, normal weight, or overweight $\left(\chi^{2}=9.873, \mathrm{p}=0.0425\right)$, women who were never smokers $\left(\chi^{2}=16.433, \mathrm{p}=0.0003\right)$, those who were married/partnered $\left(\chi^{2}=9.121, \mathrm{p}=0.0046\right)$, those who had higher household income $\left(\chi^{2}=17.325, \mathrm{p}=0.0006\right)$, those who had health insurance $\left(\chi^{2}=57.110, \mathrm{p}<0.0001\right)$, those who had visited a doctor $\left(\chi^{2}=31.180, \mathrm{p}<0.0001\right)$ and/or OB/GYN $\left(\chi^{2}=26.605, \mathrm{p}<\right.$ $0.0001)$ in the past year, those who reported no problems in getting care due to transportation $\left(\chi^{2}\right.$ $=12.370, \mathrm{p}=0.0031)$, those who rated their health status as good to excellent $\left(\chi^{2}=10.0086, \mathrm{p}=\right.$ $0.0041)$, those who had breast problems $\left(\chi^{2}=5.675, \mathrm{p}=0.0162\right)$, those who had a breast biopsy in the past $\left(\chi^{2}=4.997, \mathrm{p}=0.0305\right)$, those who were adherent to $\operatorname{CBE}\left(\chi^{2}=71.717, \mathrm{p}<0.0001\right)$ and Pap test $\left(\chi^{2}=81.441, \mathrm{p}<0.0001\right)$, and those who reported all the four routine screenings in the past two years $\left(\chi^{2}=23.569, \mathrm{p}<0.0001\right)$, those who perceived their lifetime risk of 
developing $\mathrm{BC}$ as higher $\left(\chi^{2}=6.298, \mathrm{p}=0.0429\right)$, those who reported higher knowledge of $\mathrm{BC}$ and mammography screening $\left(\chi^{2}=6.006, \mathrm{p}=0.0496\right)$ and those who strongly agreed with the positive views, $(\mathrm{F}=4.98, \mathrm{p}<0.0001)$ and strongly disagreed with the negative views $(\mathrm{F}=-2.80$, $\mathrm{p}=0.0053)$ about mammography screening.

\section{Results of Multivariate Analyses for the Mobile Mammography Study Sample}

The multivariate analyses in model 1 (data not shown) indicated that when predisposing factors were controlled, women in the age groups 50-64 years and 65 years and above were more likely to be adherent to mammography screening guidelines than women age 40-49 years. The adjusted odds ratio (AOR) were $1.711(95 \% \mathrm{CI}=1.306-2.242)$ and $1.916(95 \% \mathrm{CI}=1.255-$ 2.926), respectively. Also women who were smokers were $26 \%$ less likely to be adherent to mammography screening guidelines than those who never smoked $(\mathrm{AOR}=0.735,95 \% \mathrm{CI}=$ 0.548-0.986). When enabling factors were added in model 1 (data not shown), the AORs remained significant for the two age groups. Women who were not employed were significantly more likely to be adherent to mammography screening guidelines than those who were employed $(\mathrm{AOR}=1.308,95 \% \mathrm{CI}=1.005-1.703)$. Women who did not visit $\mathrm{OB} / \mathrm{GYN}$ in the past year were $41 \%$ less likely to be adherent to mammography screening guidelines as compared to those who visited $\mathrm{OB} / \mathrm{GYN}$ in the past year $(\mathrm{AOR}=0.591,95 \% \mathrm{CI}=0.457-0.763)$. In model 3 (data not shown), when need-related factors were added, the AORs remained significant for the two age groups and for women who were not employed. Women who were extremely and morbidly obese were more likely to be adherent to mammography screening guidelines as compared to women who were under weight or with normal weight. The AORs were 1.891 (95\% CI $=1.170$ 3.058) and $1.856(95 \% \mathrm{CI}=1.097-3.139)$, respectively. Moreover, women who reported delayed medical care due to transportation problem were $49 \%$ less likely to be adherent to 
mammography screening guidelines than those who did not have delayed care due to transportation problems $(\mathrm{AOR}=0.508,95 \% \mathrm{CI}=0.274-0.944)$. Women who had a family history of $\mathrm{BC}(\mathrm{AOR}=1.605,95 \% \mathrm{CI}=1.128-2.283)$, who had a breast biopsy in the past $(\mathrm{AOR}$ $=1.652,95 \% \mathrm{CI}=1.140-2.393$ ) were significantly more likely to be adherent to mammography screening guidelines. Women who were not adherent to Pap test $(\mathrm{AOR}=0.172,95 \% \mathrm{CI}=$ 0.124-0.238) and who did not have all the four screenings in the past two years ( $\mathrm{AOR}=0.607$, 95\% CI $=0.413-0.893$ ) were significantly less likely to be adherent to mammography screening guidelines. When psychosocial factors were added to model 3 to form the fully adjusted model (left panel of Table 4), women in the age groups 50-64 years and those 65 years and above remained significantly more likely to be adherent to mammography screening guidelines than women age 40-49 years. The AORs were $2.025(95 \% \mathrm{CI}=1.489-2.754)$ and $3.181(95 \% \mathrm{CI}=$ 1.904-5.314), respectively. Women who were not employed $(\mathrm{AOR}=1.371,95 \% \mathrm{CI}=1.028$ 1.829), who were extremely obese $(\mathrm{AOR}=1.880,95 \% \mathrm{CI}=1.161-3.046)$ and morbidly obese $(\mathrm{AOR}=1.918,95 \% \mathrm{CI}=1.128-3.261)$ were more likely to be adherent to mammography screening guidelines. Moreover, women reported delayed medical care due to transportation problems were $50 \%$ less likely to be adherent to mammography screening guidelines ( $\mathrm{AOR}=$ $0.503,95 \% \mathrm{CI}=0.269-0.941)$ than those who did not report delayed care due to transportation problems. In addition, women who had a family history of $\mathrm{BC}(\mathrm{AOR}=1.541,95 \% \mathrm{CI}=1.067$ 2.225) and women who had breast biopsy in the past $(\mathrm{AOR}=1.661,95 \% \mathrm{CI}=1.143-2.413)$ were also more likely to be adherent to mammography screening guidelines. Women who were not adherent to Pap test $(\mathrm{AOR}=0.170,95 \% \mathrm{CI}=0.122-0.236)$ and who did not have all the four screenings $(\mathrm{AOR}=0.613,95 \% \mathrm{CI}=0.416-0.904)$ were less likely to be adherent to mammography screening guidelines. 


\section{Results of Multivariate Analyses for the Stationary Facility Study Sample}

The multivariate analyses in model 1 (data not shown) indicated that when predisposing factors were controlled, women who were former and current smokers were significantly less likely to report adherence to mammography screening guidelines than women who never smoked and the AOR were $0.516(95 \% \mathrm{CI}=0.307-0.869)$ and $0.363(0.193-0.682)$, respectively. In model 2 (data not shown), when predisposing and enabling factors were controlled, the AOR remained significant for the former smokers only. Also women who did not have an insurance were $82 \%$ less likely to be adherent to mammography screening guidelines as compared to those who had insurance coverage $(\mathrm{AOR}=0.178,95 \% \mathrm{CI}=0.084-0.380)$. Women who did not visit a doctor in the past year $(\mathrm{AOR}=0.396,95 \% \mathrm{CI}=0.242-0.649)$ and who did not visit an $\mathrm{OB} / \mathrm{GYN}$ in the past year $(\mathrm{AOR}=0.363,95 \% \mathrm{CI}=0.211-0.625)$ were significantly less likely to be adherent to mammography screening guidelines. When need-related factors were added in model 3 (data not shown), women who were overweight were significantly more likely to be adherent to mammography screening guidelines as compared to those who were under weight or with normal weight $(\mathrm{AOR}=2.599,95 \% \mathrm{CI}=1.171-5.769)$. Also, women who did not have health insurance, who were not adherent to CBE and Pap test, and who did not have all the four screenings in the past two years were significantly less likely to be adherent to mammography screening guidelines. The AORs were $0.219(95 \% \mathrm{CI}=0.093-0.512), 0.284(95 \% \mathrm{CI}=0.143$ $0.562), 0.181(95 \% \mathrm{CI}=0.097-0.337)$ and $0.287(95 \% \mathrm{CI}=0.121-0.680)$, respectively. When psychosocial factors were added to model 3 to form a fully adjusted model (right panel of Table 4), women who were overweight remained significantly more likely to be adherent to mammography screening guidelines $(\mathrm{AOR}=3.046,95 \% \mathrm{CI}=1.315-7.060)$. Also, those who did not have health insurance remained significantly less likely to be adherent to mammography 
screening guidelines $(\mathrm{AOR}=0.203,95 \% \mathrm{CI}=0.084-0.492)$. Those who reported delayed medical care due to transportation problem were $70 \%$ less likely to be adherent to mammography screening guidelines $(\mathrm{AOR}=0.299,95 \% \mathrm{CI}=0.090-0.989)$. Furthermore, women were not adherent to CBE and Pap test, and who did not have all the four screenings in the past two years were significantly less likely to be adherent to mammography screening guidelines. The AORs were $0.257(95 \% \mathrm{CI}=0.125-0.525), 0.176(95 \% \mathrm{CI}=0.092-0.338)$ and $0.329(95 \% \mathrm{CI}=0.135$ 0.801), respectively. In addition, women whose level of agreement towards positive views about mammography screening reduced by one point on the agreement scale, were $33 \%$ less likely to be adherent to mammography screening guidelines $(\mathrm{AOR}=0.672,95 \% \mathrm{CI}=0.550-0.822$ ).

\section{DISCUSSION}

In this study, the characteristics and predictors of self-reported adherence to mammography screening guidelines in women age 40 years and above who utilized mobile mammography services and those who utilized a stationary mammography facility were determined. The findings indicated that stationary mammography facilities in WV may typically attract women with higher levels of education, higher income, health insurance, who visit a doctor and/or an OB/GYN regularly, and who are adherent to CBE, Pap test and other screenings. Hence, women routinely utilizing the stationary facility such as BPBCC may not have or have already overcome barriers to mammography screening and may not be considered underserved. The study results also showed that mobile mammography unit in WV may typically attract women with lower levels of education, lower income, who are overweight to morbidly obese, who do not visit an $\mathrm{OB} / \mathrm{GYN}$ regularly and who are not adherent to CBE. Hence, it may be concluded that through mobile mammography program in WV, women with comparatively lower levels of education, lower income, who are overweight to morbidly obese and with access problems in terms of no 
regular visit to $\mathrm{OB} / \mathrm{GYN}$ are able to get mammography screening. This suggests that the mobile unit is indeed reaching a rural vulnerable population who may not routinely have access to preventive health services such as mammography screening. Therefore, through the introduction of the Bonnie's Bus, underserved women in WV are able to get access to low-cost or free-of-cost mammography screening.

Among women who utilized mobile mammography unit, only $48.15 \%$ were adherent to mammography screening guidelines and among women who utilized stationary mammography facility, an overwhelming $92.3 \%$ were adherent to mammography screening guidelines. The mammography screening rate for women who utilized mobile unit is significantly below the national Healthy People 2010 goals for mammography screening ${ }^{66}$, WV screening rate of $72.3 \%{ }^{67}$ and the national screening rate of $75.4 \%$ in $2010^{68}$. Thus, as suggested by a previous study the mobile mammography program may be more likely to provide mammography screening to those women who are not screened or who are long overdue (at least 2 years) to undergo mammography screening ${ }^{55}$. Furthermore, the high mammography screening rate among women who utilized stationary facility suggests that these women never have had or have overcome the barriers to mammography screening. The broad difference in adherence in WV women utilizing a mobile unit and a stationary facility suggests disparities in mammography screening within WV.

Among predisposing factors, age 50 years and above was associated with adherence to mammography screening in women who utilized mobile mammography unit. Younger women in age group 40-49 years may be less likely to be adherent to mammography screening as screening in this age group has been controversial. Older women age 65 and above have Medicare coverage for mammograms which increases the likelihood that they will be adherent to 
mammography screening guidelines. However, age was not a significant predictor of adherence in women who utilized stationary unit indicating that women in all age groups are equally likely to be adherent to mammography screening. In contrast to previous study by Coughlin et al. ${ }^{35}$, employed women who utilized mobile unit were less likely to be adherent to mammography screening guidelines. Due to their jobs (a competing priority), these women may have difficulty in getting mammograms. Extremely and morbidly obese women who utilized mobile unit were significantly more likely to be adherent to mammography screening guidelines than women who were normal or underweight. These women may have comorbidities such as diabetes, hypertension, and other such chronic conditions, which results in frequent visits to primary care physicians which increases the likelihood of being advised to have a mammogram. Among enabling factors, having insurance was a significant predictor of adherence to mammography screening in women who utilized the stationary facility. However, it was not a significant predictor of adherence in women who utilized the mobile mammography unit which suggests that there may be factors other than insurance coverage, such as attitudes and views, cultural influences, and physical access problem, which may influence screening rates in this rural and underserved population. Also, a reported delay in medical care due to transportation problems made women more likely to be non-adherent to mammography screening for both the study populations indicating that transportation is a key issue in the geographically challenging state, WV.

Among need-related factors, family history of BC increased the likelihood of women who utilized mobile mammography of being adherent to mammography screening guidelines ${ }^{32,34,36}$ which suggests that these women are sensitive to the need of being screened. Having had a breast biopsy in the past was also associated with adherence to mammography screening in 
women who utilized mobile mammography unit which may be due to higher concern and anxiety about BC, and greater likelihood of being advised by their physicians to have regular screening ${ }^{69}$. Preventive behaviors such as CBE, Pap test and other tests for blood glucose, blood cholesterol, bone mineral density, and blood pressure strongly predicted adherence to mammography screening guidelines in both the study populations thus indicating that women who follow such preventative behaviors are sufficiently knowledgeable about the importance of preventive health to overcome any barriers they encountered to screening. Among psychosocial factors, having strong positive views about mammography screening was associated with adherence to mammography screening in women who utilized stationary facility. However, psychosocial factors did not significantly predict adherence to mammography screening guidelines in women who utilized mobile mammography unit.

Overall, for women who utilized the mobile mammography unit, predisposing and needrelated factors had a strong influence on adherence to mammography screening guidelines. Hence, interventions targeted at younger women who have not experienced any BC-related event may be beneficial to increase screenings. While for women who utilized the stationary mammography facility, enabling factors, need-related factors, and positive views about mammography screening had a strong influence on adherence to mammography screening guidelines. Thus, access barriers are an issue in this population, and these women need education about preventive behaviors.

The survey captured all the factors included in the Andersen model which was the theoretical framework used in the study.

There are several limitations of the study. One limitation is the response rate; $49 \%$ of women who utilized mobile mammography services and $51 \%$ of women who utilized stationary 
mammography facility did not respond to the surveys. A non-respondents analysis indicated that non-respondents for mobile mammography unit were significantly older, single/widowed, morbidly obese and with insurance coverage. Moreover, non-respondents analysis for women who utilized the stationary facility indicated that non-respondents were significantly unemployed and with lower levels of education. Hence, these should be taken into consideration while extrapolating the findings of the study. Another limitation is that survey data is self-reported which may be different from mammography screening data obtained from medical records. Individuals are more likely to over-report their use of screening and to underreport the time since their last screening leading to self-report $\operatorname{bias}^{70}$. Moreover, data from both the study populations were collected using different methods, so there may be some bias related to mode effects. In addition, the findings of this study cannot be generalized to women residing outside of WV. The results of the study may be helpful in developing interventions to increase mammography screening in women in WV.

\section{CONCLUSION}

The number of women age 40 years and above who had not received a mammogram in the past two years was significantly higher for women who utilized mobile mammography services than those who utilized the stationary facility. BC-related events such as family history of BC and having had a biopsy, and adherence to other screening tests were associated with adherence to mammography screening guidelines in older women who utilized the mobile mammography service. Access factors, adherence to other screening tests such as CBE, Pap test and having strong positive views about mammography screening were associated with adherence to mammography screening guidelines in women who utilized the stationary mammography facility. 


\section{ACKNOWLEDGEMENTS}

This research study is funded by Susan G. Komen For the Cure, Claude Worthington Benedum Foundation, and AHRQ grant \# R24HS018622-03. 


\section{REFERENCES}

1. American Cancer Society: Breast Cancer Facts and Figures 2012. Atlanta, Ga: American Cancer Society, 2012. http://www.cancer.org/Cancer/BreastCancer/DetailedGuide/breastcancer-key-statistics Accessed August 1, 2012.

2. Siegel R., Naishadham D, Jemal A. Cancer statistics, 2012. CA cancer J Clin. 2012; 62(1):10-29.

3. Nelson HD, Tyne K, Naik A, Bougatsos C, Chan BK, Humphrey L, U.S. Preventive Services Task Force. Screening for breast cancer: an update for the U.S. Preventive Services Task Force. Ann Intern Med. 2009; 151(10):727-37, W237-42.

4. Tabar L, Yen MF, Vitak B, Chen HH, Smith RA, Duffy SW. Mammography service screening and mortality in breast cancer patients: 20-year follow-up before and after introduction of screening. Lancet. 2003; 361(9367):1405-1410.

5. Fletcher SW, Elmore JG. Clinical practice: mammographic screening for breast cancer. $\mathrm{N}$ Engl J Med. 2003; 348:1672-1680.

6. Nyström L, Andersson I, Bjurstam N, Frisell J, Nordenskjold B, Rutqvist LE. Long-term effects of mammography screening: updated overview of the Swedish randomised trials. Lancet. 2002;359 (9310): 909-19.

7. Smith-Bindman R, Kerlikowske K, Gebretsadik T, Newman J. Is screening mammography effective in elderly women? Am J Med. 2000;108:112-119.

8. Taber L, Dean PB. Mammography and breast cancer: The new era. Int J Gynaecol Obstet. 2003; 82:319-326.

9. Hellquist BN, Duffy SW, Abdsaleh S, Bjorneld L, Bordas P, Tabar L, Vitak B, Zackrisson S, Nystrom L, Jonsson H. Effectiveness of population-based service screening with mammography for women ages 40 to 49 years: Evaluation of the Swedish Mammography Screening in young women (SCRY) cohort. Cancer. 2011; 117(4):714722.

10. Gotzsche PC, Nielsen M. Screening for breast cancer with mammography. Cochrane Datasase Syst Rev. 2009; 4:CD001877.

11. Health Resource and Services Administration (HRSA). List of Rural Counties and Designated Eligible Census Tracts in Metropolitan Counties, 2009. ftp://ftp.hrsa.gov/ruralhealth/eligibility2005.pdf Accessed August 1, 2012

12. Lengerich EJ, Tucker TC, Powell RK, Colsher P, Lehman E,Ward, A J, et. al. Cancer incidence in Kentucky, Pennsylvania, and West Virginia: disparities in Appalachia. Journal of Rural Health. 2005; 21: 39-47. 
13. Health Resource and Services Administration (HRSA). West Virginia Needs Assessment 2010. US Department of Health and Human Services, 2010. Accessed August 1, 2012 http://www.wvochs.org/dr/shortageareas.aspx

14. U.S. Census Bureau. (2010). Persons 25 years old and over with a bachelor's degree or more, 2008. Washington, DC: U.S. Census Bureau. http://www.census.gov/compendia/statab/2010/ranks/rank19.html, Accessed August 1, 2012.

15. U.S. Census Bureau. (2010). Persons below the poverty level, 2008. Washington, DC: U.S. Census Bureau. http://www.census.gov/compendia/statab/2010/ranks/rank34.html, Accessed August 1, 2012.

16. Kaiser State Health Facts. (2009). Overweight and obesity rates for adults by sex, 2009. Menlo Park, CA: Kaiser Family Foundation. http://www.statehealthfacts.org, Accessed August 1, 2012.

17. Kaiser State Health Facts. (2008). Percent of adults who smoke by sex, 2008. Menlo Park, CA: Kaiser Family Foundation. http://www.statehealthfacts.org, Accessed August $1,2012$.

18. Wingo PA, Tucker TC, Jamison PM, Martin H, McLaughlin C, Bayakly R, BolickAldrich S, Colsher P, Indian R, Knight K, Neloms S, Wilson R, Richards TB. Cancer in Appalachia, 2001- 2003. Cancer. 2007; 112,181-192.

19. Lengerich EJ, Chase GA, Beiler J, Darnell M. Increased risk of unknown stage cancer from residence in a rural area: health disparities with poverty and minority status. Hershey, PA: Pennsylvania State University and the Penn State Cancer Institute, Department of Health Evaluation Sciences 2005.

20. State Cancer Profiles. (2010). Incidence and mortality rate reports for West Virginia by county. Bethesda, MD: National Cancer Institute. http://statecancerprofiles.cancer.gov/, Accessed August 1, 2012.

21. United States Cancer Statistics (USCS). (2010). Rankings by state: 2006, male and female, all cancer sites combined. Atlanta, GA: Centers for Disease Control and Prevention (CDC). http://apps.nccd.cdc.gov/uscs/, Accessed August 1, 2012.

22. United States Cancer Statistics (USCS). (2010). State vs. national rates: 2006, female, West Virginia. Atlanta, GA: Centers for Disease Control and Prevention (CDC). http://apps.nccd.cdc.gov/uscs/, Accessed August 1, 2012

23. Khanna R, Bhanegaonkar A, Colsher P, Madhavan S, Halverson J. Breast cancer screening, incidence and mortality in West Virginia. WV Med J. 2009. Special CME Issue, 25-32. 
24. Kaiser State Health Facts. (2010). Percent of women age 40 and older who report having had a mammogram within the last two years, 2008. Menlo Park, CA: Kaiser Family Foundation. http://statehealthfacts.org, Accessed August 1, 2012.

25. Bhanegaonkar A, Madhavan S, Khanna R, Remick SC. Declining mammography screening in a State Medicaid Fee-for-Service Program: 1999-2008. Journal of Women's Health. 2012, May 8, (Epub ahead of print)

26. Dubard, CA, Schmid D, Yow A. Recommendation for and receipt of cancer screenings among Medicaid recipients 50 years and older. Arch Intern Med. 2008; 168(18):2014:2021.

27. Welsh AL. Sauaia A, Jacobellis J, Min SJ, Byers T. The effect of two church-based interventions on breast cancer screening rates among Medicaid-insured Latinas. Prev Chronic Dis. 2005; 2:A07.

28. Roetzheim RG, Pal N, Tennant C, Voti L, Ayanian JZ, Schwabe A, Krischer JP._Effects of health insurance and race on early detection of cancer. J Natl Cancer Inst. 1999; 91:1409-1415.

29. Ayanian JZ, Kohler BA, Abe T, Epstein AM. The relation between health insurance coverage and clinical outcomes among women with breast cancer. N Engl J Med. 1993; 329:326-31.

30. Halpern MT, Bian J, Ward EM, Schrag NM, Chen AY. Insurance status and stage of cancer at diagnosis among women with breast cancer. Cancer. 2007; 110:403-411.

31. Wolf AB, Brem RF. Decreased Mammography Utilization in the United Sates: Why and how can we reverse the trend? AJR. 2009; 192:400-402.

32. Rahman SMM, Digman MB, Shelton BJ. Factors influencing adherence to guidelines for screening mammography among women aged 40 years and older. Ethn Disp. 2003; 13(4):477-484.

33. Gierisch JM, Earp JA, Brewer NT, Rimer BK. Longitudinal predictors of nonadherence to maintenance of mammography. Cancer Epidemiol Biomarkers Prev. 2010; 19(4):1103-1111.

34. Meissner HI, Breen N, Taubman ML, Vernon SW, Graubard BU. Which women aren't getting mammograms and why? (United States) Cancer Causes Control. 2007; 18:61-70.

35. Coughlin SS, Uhler RJ, Hall I, Briss PA. Non adherence to Breast and Cervical cancer screening: What are the linkages to chronic disease risk? Preventing chronic disease. 2004; 1(1):A04.

36. Borrayo EA, Hines L, Byers T, Risendal B, Slattery ML, Sweeney C, Baumgartner KB, Giuliano A. Characteristics associated with mammography screening among both 
Hispanic and non-Hispanic white women. Journal of Women's Health. 2009; 18(10): 1585-1594.

37. Zapka JG, Stoddard A, Maul L, Costanza ME. Interval adherence to mammography screening guidelines. Medical Care. 1991; 29(8):697-707.

38. Ulcickas Yood M, McCarthy BD, Lee NC, Jacobsen G, Johnson CC. Patterns and characteristics of repeat mammography among women 50 years and older. Cancer Epidemiol Biomarkers Prev. 1999; 8:595-599.

39. Selvin E, Brett KM. Breast and Cervical cancer screening. Socio-demographic predictors among white, black and Hispanic women. Am J of Public Health. 2003;93(4):618-623.

40. Bobo JK, Shapiro JA, Schulman J, Wolters CL. On-schedule mammography rescreening in the National Breast and Cervical Cancer Early Detection Program. Cancer Epidemiol Biomarkers Prev. 2004; 13:620-630.

41. Rakowski W, Meissner H, Vernon SW, Breen N, Rimer B, Clark MA. Correlates of Repeat and recent mammography for women ages 45 to 75 in the 2002 to 2003 Health Information National Trends Survey (HINTS 2003). Cancer Epidemiol Biomarkers Prev. 2006; 15(11):2093-2101.

42. Frazier EL, Jiles RB, Mayberry R. Use of screening mammography and clinical breast examinations among Black, Hispanic, and White women. Preventive medicine. 1996; 25:118-125.

43. Barr JK, Franks AL, Lee NC, Herther P, Schachter M. Factors associated with continued participation in mammography screening. Preventive medicine. 2007; 33:661-667.

44. Daly MB, Lerman CL, Ross E, Schwartz MD, Sands CB, Masny A. Gail model breast cancer risk components are poor predictors of risk perception and screening behavior. Breast cancer research treatment. 1996; 41(1):59-70.

45. Zografos GC, Sergentanis TN, Zagouri F, Papadimitriou CA, Domeyer P, Kontogianni PN, Nonni A, Tsigris C, Patsouris E. Breast self-examination and adherence to mammographic follow-up: an intriguing diptych after benign breast biopsy. Eur J Cancer Prevention. 2010; 19(1):71-72.

46. Katapodi MC, Lee KA, Facione NC, Dodd MJ. Predictors of perceived breast cancer risk and the relation between perceived risk and breast cancer screening: a meta-analytic review. Preventive Medicine. 2004; 38:388-402.

47. Magai C, Consedine N, Neugut AI, Hershman DL. Common psychosocial factors underlying breast cancer screening and breast cancer treatment adherence: a conceptual review and synthesis. Journal of Women's Health. 2007; 16(1):11-23. 
48. Lyttie NL, Stadelman K. Assessing awareness and knowledge of breast and cervical cancer among Appalachian women. Preventing chronic disease. 2006; 3(4):1-9.

49. Sohl SJ, Moyer A. Tailored interventions to promote mammography screening: A metaanalytic review. Preventive medicine. 2007; 45:252-261.

50. Flax VL, Earp JL. Counseled women's perspectives on their interactions with lay health advisors: a feasibility study. Health Education Research. 1999; 14(1):15-24.

51. Eng E, Smith J. Natural helping functions of lay health advisors in breast cancer education. Breast Cancer Res Treatment. 1995; 35(1):23-29.

52. Bonfill CX, Marzo CM, Pladevall VM, Marti J, Emparanza JI. Strategies for increasing the participation of women in community breast cancer screening (Review). The Cochrane Library. 2009; 1.

53. Dale J, Caramlau IO, Lindenmeyer A, Williams SM. Peer support telephone calls for improving health (Review). The Cochrane Library. 2009;1.

54. DeBruhl N, Bassett LW, Jessop NW, Mason AM. Mobile mammography: results of a national survey. Radiology. 1996; 201(2):433-437.

55. Reuben DB, Bassett LW, Hirsch SH, Jackson CA, Bastani R. A randomized clinical trial to assess the benefit of offering on-site mobile mammography in addition to health education for older women. AJR. 2002; 179:1509-1514.

56. Flynn B, Gavin P, Worden JK, Ashikaga T, Gautam S, Carpenter J. Community education to promote mammography participation in rural New York state. Prev Med. 1997; 26(1):102-108.

57. Derose K, Duan N, Fox SA. Women's receptivity to church-based mobile mammography. J Health Care Poor Underserved. 2002; 13(2):199-213.

58. Buzek N. Mobile mammography for underserved women: What does evidence say? Advance Nurse practice. 2010; 18(5):29-32.

59. Vyas A, Madhavan S, Lemasters T, Atkins E, Gainor S, Kennedy S, Kelly K, VonaDavis L, Remick S. Factors influencing adherence to mammography screening guidelines in Appalachian Women participating in a mobile mammography program. Journal of community health. 2012; 37(3):632-646.

60. Bradley EH, McGraw SA, Curry L, Buckser A, King KL, Kasl SV, Andersen RM. Expanding the Andersen Model: The role of psychosocial factors in long-term care use. Health Services Research. 2002; 37(5):1221-1242.

61. U.S. Preventive Services Task Force. Screening for breast cancer: recommendations and rationale. Ann Intern Med. 2002; 137(5):344-346. 
62. Smith RA, Cokkinides V, Brawley O. Cancer screening in the United States, 2012: A review of current American Cancer Society Guidelines and current issues in cancer screening. CA:A Cancer Journal for Clinicians. 2012; 62:129-142.

63. Hirsch BR, Lyman GH. Breast cancer screening with mammography. Curr Oncol Rep. 2011; 13:63-70.

64. Gierisch JM, Reiter PL, Rimer BK, Brewer NT. Standard definitions of Adherence for infrequent yet repeated health behaviors. American Journal of Health Behavior. 2010; 34(6):669-679.

65. Humphrey LL, Helfand M, Chan BK, Woolf SH. Breast cancer screening: a summary of the evidence for the U.S. Preventive Services Task Force. Ann Intern Med. 2002; 137(5):347-360.

66. United States Department of Health and Human Services 2010. Healthy people 2010: Understanding and improving health. Washington DC: US department of Health and Human Services.

67. National Cancer Institute 2010. State cancer profiles screening and risk factors report 2010 http://statecancerprofiles.cancer.gov/risk/index.php?risk=06\&type=risk\&stateFIPS=00\&s ortVariableName $=$ default\&sortOrder $=$ default Accessed August 1, 2012

68. National Cancer Institute 2010. Cancer trends progress reports 2009/2010 updates http://progressreport.cancer.gov/doc_detail.asp?pid=1\&did=2009\&chid=92\&coid=916\& $\underline{\text { mid }}=$ Accessed August 1, 2012

69. Lerman C, Trock B, Rimer B, Jepson C, Brody D, Boyce A. Psychological side effects of breast cancer screening. Health Psychology. 1991; 10: 259-267.

70. Vacek P, Mickey R, Worden J. Reliability of self-reported breast screening information in a survey of lower income women. Preventive medicine. 1997; 26:287-291. 


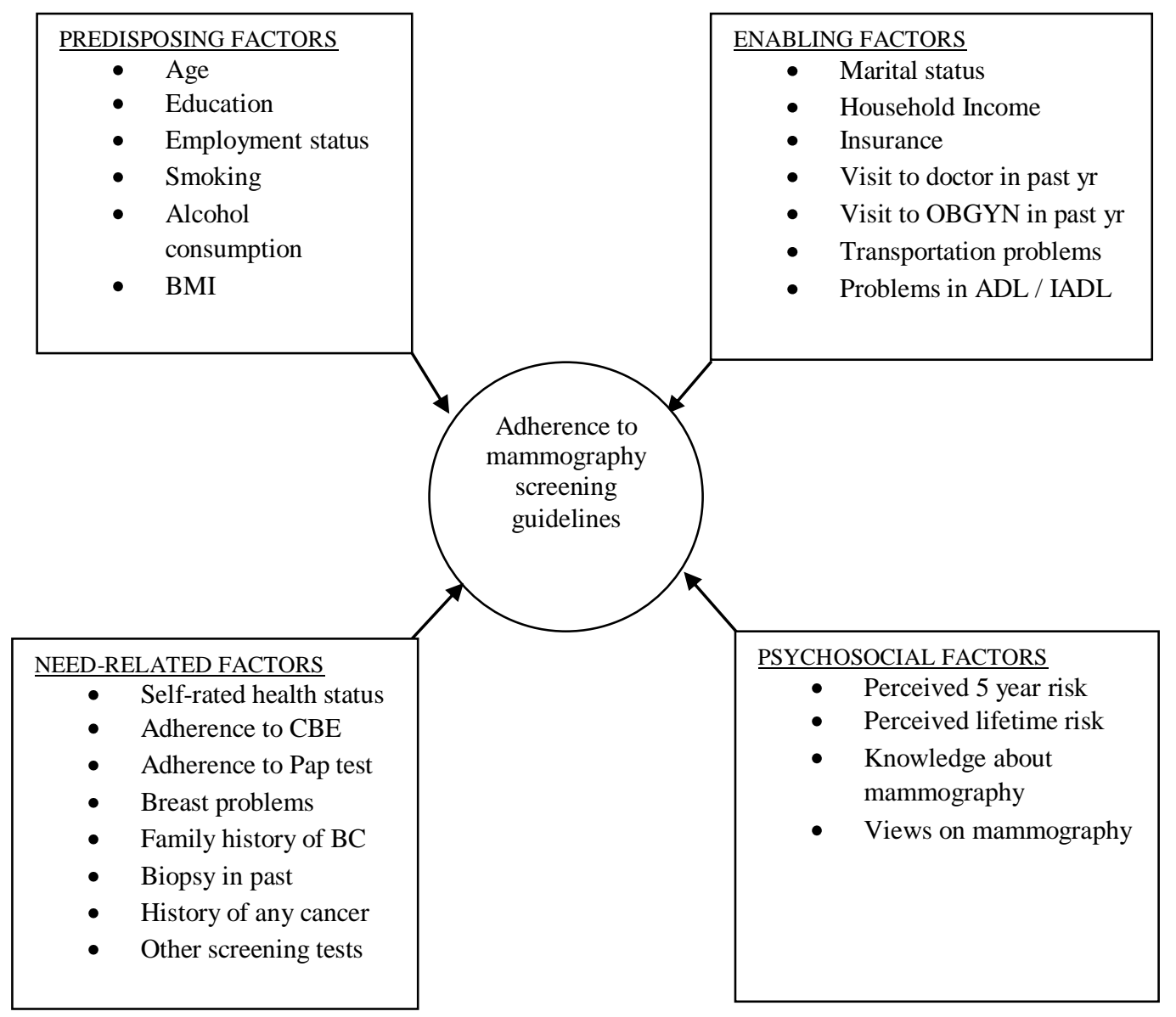

Figure 1. Conceptual model illustrating the constructs of expanded version of Andersen Behavioral Model of Healthcare Services Utilization in predicting adherence to screening mammography guidelines 
Table 1

Description of the Study Samples of WV Women age 40 years and above

\begin{tabular}{|c|c|c|c|c|c|c|}
\hline & & & \multicolumn{2}{|l|}{ BBMMP } & \multicolumn{2}{|l|}{ ВPBCC } \\
\hline \multicolumn{7}{|c|}{ PREDISPOSING FACTORS } \\
\hline Age & & & $\mathbf{N}(\mathbf{1 , 1 6 1 )}$ & $\%$ & $\mathbf{N}(\mathbf{1 , 1 0 4 )}$ & $\%$ \\
\hline & $40-49$ & & 361 & 31.09 & 217 & 19.66 \\
\hline & $50-64$ & & 662 & 57.02 & 630 & 57.07 \\
\hline & $65 \&$ above & & 138 & 11.89 & 257 & 23.28 \\
\hline & & Mean & 54.469 & & 57.799 & \\
\hline \multicolumn{7}{|c|}{ Education } \\
\hline & Less than HS & & 43 & 3.70 & 15 & 1.36 \\
\hline & Some HS/HS grad & & 522 & 44.96 & 273 & 24.73 \\
\hline & GED/Tech & & 247 & 21.27 & 135 & 12.23 \\
\hline & Some college/Graduate & & 349 & 30.06 & 681 & 61.68 \\
\hline \multicolumn{7}{|c|}{ Employment status } \\
\hline & Employed & & 558 & 48.06 & 635 & 57.52 \\
\hline & Unemployed & & 603 & 51.94 & 469 & 42.48 \\
\hline \multicolumn{7}{|c|}{ Body Mass Index } \\
\hline & Underweight/Normal weight & & 205 & 17.66 & 351 & 31.79 \\
\hline & Overweight & & 280 & 24.12 & 327 & 29.62 \\
\hline & Obese & & 393 & 33.85 & 214 & 19.38 \\
\hline & Extremely Obese & & 163 & 14.04 & 126 & 11.41 \\
\hline & Morbidly Obese & & 120 & 10.34 & 86 & 7.79 \\
\hline \multicolumn{7}{|c|}{ Smoking status } \\
\hline & Never & & 630 & 54.26 & 729 & 66.03 \\
\hline & Former & & 236 & 20.33 & 267 & 24.18 \\
\hline & Current & & 295 & 25.41 & 108 & 9.78 \\
\hline \multicolumn{7}{|c|}{ Alcohol consumption } \\
\hline & Yes & & 287 & 24.72 & 526 & 47.64 \\
\hline & No & & 874 & 75.28 & 578 & 52.36 \\
\hline
\end{tabular}

ENABLING FACTORS

Marital Status

Married/Partnered

Single

$\begin{array}{cccc}757 & 65.20 & 848 & 76.81 \\ 404 & 34.80 & 256 & 23.19 \\ & & & \\ 777 & 66.93 & 232 & 21.01 \\ 242 & 20.84 & 270 & 24.46 \\ 83 & 7.15 & 220 & 19.93 \\ 59 & 5.08 & 382 & 34.60\end{array}$

......Continued

$$
\begin{aligned}
& \text { Less than } \$ 25,000 \\
& \$ 25,000-\$ 50,000 \\
& \$ 50,000-\$ 75,000 \\
& \text { More than } \$ 75,000
\end{aligned}
$$

382

34.60 
Table 1

Description of the Study Samples of WV Women age 40 years and above

\begin{tabular}{ccccc}
\hline & BBMMP & \multicolumn{3}{c}{ BPBCC } \\
\hline Health Insurance & 660 & 56.85 & 1,048 & 94.93 \\
Yes & 501 & 43.15 & 56 & 5.07 \\
No & & & & \\
Visit to doctor in past year & 671 & 57.80 & 805 & 72.92 \\
Yes & 490 & 42.20 & 299 & 27.08 \\
No & & & & \\
Yes & 405 & 34.88 & 582 & 52.72 \\
No & 756 & 65.12 & 522 & 47.28 \\
Visit to OB/GYN in past year & & & & \\
Yes & 35 & 3.01 & 15 & 1.36 \\
No & 1,126 & 96.99 & 1,089 & 98.64 \\
Problems with ADL & & & & \\
Yes & 106 & 9.13 & 75 & 6.79 \\
No & 1,055 & 90.87 & 1,029 & 93.21 \\
Problems with IADL & & & & \\
Yes & 58 & 5.00 & 34 & 3.08 \\
No & 1,103 & 95.00 & 1,070 & 96.92 \\
& & & &
\end{tabular}

NEED-RELATED FACTORS

Self-rated Health Status

$\begin{array}{llllr}\text { Fair/Poor } & 273 & 23.51 & 168 & 15.22 \\ \text { Excellent/V.good/Good } & 888 & 76.49 & 936 & 84.78\end{array}$

Family History of BC

$\begin{array}{rrrrr}\text { Yes } & 190 & 16.37 & 216 & 19.57 \\ \text { No } & 971 & 83.63 & 888 & 80.43\end{array}$

Breast problems

$\begin{array}{lrrrr}\text { Yes } & 152 & 13.09 & 259 & 23.46 \\ \text { No } & 1,009 & 86.91 & 845 & 76.54\end{array}$

Breast biopsy in past

Yes

18.52

$368 \quad 33.33$

$\begin{array}{llll}946 & 81.48 & 736 & 66.67\end{array}$

Adherence to CBE

Yes

544

46.86

$692 \quad 62.68$

$617 \quad 53.14$

$412 \quad 37.32$

Adherence to PAP test

$\begin{array}{lllll}\text { Yes } & 798 & 68.73 & 774 & 70.11 \\ \text { No } & 363 & 31.27 & 330 & 29.89\end{array}$

......Continued 
Table 1

Description of the Study Samples of WV Women age 40 years and above

\begin{tabular}{cccccc}
\hline & BBMMP & \multicolumn{3}{c}{ BPBCC } \\
\hline History of Cancer & & & & & \\
Yes & 84 & 7.24 & 150 & 13.59 \\
No & 1,077 & 92.76 & 954 & 86.41 \\
Total score of screenings & & & & \\
$0-3$ & 1,002 & 86.30 & 753 & 68.21 \\
4 & 159 & 13.70 & 351 & 31.79 \\
\hline
\end{tabular}

PSYCHOSOCIAL FACTORS

\section{Perceived 5 year risk}

$\begin{array}{lllll}\text { Lower } & 513 & 44.19 & 391 & 35.42 \\ \text { Similar } & 508 & 43.76 & 541 & 49.00 \\ \text { Higher } & 140 & 12.06 & 172 & 15.58\end{array}$

Perceived Lifetime risk

$\begin{array}{lllll}\text { Lower } & 440 & 37.90 & 337 & 30.53 \\ \text { Similar } & 560 & 48.23 & 571 & 51.72 \\ \text { Higher } & 161 & 13.87 & 196 & 17.75\end{array}$

Knowledge Score

$\begin{array}{ccccc}0-2 & 73 & 6.29 & 75 & 6.79 \\ 3-4 & 541 & 46.60 & 683 & 61.87 \\ 5-6 & 547 & 47.11 & 346 & 31.34\end{array}$

Views

\begin{tabular}{llll} 
Positive Views & Mean & 1.741 & 1.975 \\
Negative Views & Mean & 5.509 & 5.822 \\
\hline
\end{tabular}

BBMMP: Bonnie's Bus Mobile Mammography Program (mobile unit); BPBCC: Betty Puskar Breast Care Center (stationary facility); HS: high school; V.good: very good, OB/GYN: obstetrician/gynecologist, ADL: activities of daily living; IADL: instrumental activities of daily living. For views, score 1 is equal to strongly agree and score 7 is equal to strongly disagree on the scale of 1 to 7 . 
Table 2

Description of the Study Sample of Women age 40 and above

By Self-Reported Adherence to Mammography Guidelines

Bonnie's Bus Mobile Mammography Program (BBMMP)

\begin{tabular}{|c|c|c|c|c|c|c|c|c|c|}
\hline & & & \multicolumn{2}{|c|}{ Adherent } & \multicolumn{2}{|c|}{ Non-Adherent } & \multirow[t]{2}{*}{ Chisqr/t-test } & \multirow[t]{2}{*}{ P-value } & \multirow[t]{2}{*}{ Sig } \\
\hline & & & $\mathbf{N}(559)$ & $\%$ & $\mathrm{~N}(602)$ & $\%$ & & & \\
\hline \multicolumn{10}{|c|}{ PREDISPOSING FACTORS } \\
\hline \multirow[t]{5}{*}{ Age } & & & & & & & 23.9142 & $<0.0001$ & $* * *$ \\
\hline & $40-49$ & & 136 & 37.7 & 225 & 62.3 & & & \\
\hline & $50-64$ & & 345 & 52.1 & 317 & 47.9 & & & \\
\hline & $65 \&$ above & & 78 & 56.5 & 60 & 43.5 & & & \\
\hline & & Mean & 56.025 & & 53.025 & & -5.83 & $<0.0001$ & $* * *$ \\
\hline \multirow[t]{5}{*}{ Education } & & & & & & & 2.7607 & 0.4300 & \\
\hline & Less than HS & & 26 & 60.5 & 17 & 39.5 & & & \\
\hline & Some HS/HS grad & & 249 & 47.7 & 273 & 52.3 & & & \\
\hline & GED/Tech & & 119 & 48.2 & 128 & 51.8 & & & \\
\hline & Some college/Graduate & & 165 & 47.3 & 184 & 52.7 & & & \\
\hline \multicolumn{3}{|c|}{ Employment status } & & & & & 5.9031 & 0.0151 & $*$ \\
\hline & Employed & & 248 & 44.4 & 310 & 55.6 & & & \\
\hline & Unemployed & & 311 & 51.6 & 292 & 48.4 & & & \\
\hline \multicolumn{3}{|c|}{ Body Mass Index } & & & & & 5.460 & 0.2433 & \\
\hline & Underweight/Normal weight & & 89 & 43.4 & 116 & 56.6 & & & \\
\hline & Overweight & & 129 & 46.1 & 151 & 53.9 & & & \\
\hline & Obese & & 190 & 48.4 & 203 & 51.7 & & & \\
\hline & Extremely Obese & & 86 & 52.8 & 77 & 47.2 & & & \\
\hline & Morbidly Obese & & 65 & 54.2 & 55 & 45.8 & & & \\
\hline \multicolumn{3}{|c|}{ Smoking status } & & & & & 9.6607 & 0.0080 & $* *$ \\
\hline & Never & & 320 & 50.8 & 310 & 49.2 & & & \\
\hline & Former & & 120 & 50.9 & 116 & 49.2 & & & \\
\hline & Current & & 119 & 40.3 & 176 & 59.7 & & & \\
\hline \multicolumn{3}{|c|}{ Alcohol consumption } & & & & & 2.319 & 0.1278 & \\
\hline & Yes & & 127 & 44.3 & 160 & 55.8 & & & \\
\hline & No & & 432 & 49.4 & 442 & 50.6 & & & \\
\hline \multicolumn{10}{|c|}{ ENABLING FACTORS } \\
\hline \multirow[t]{3}{*}{ Marital Statu } & & & & & & & 0.0964 & 0.7561 & \\
\hline & Married/Partnered & & 367 & 48.5 & 390 & 51.5 & & & \\
\hline & Single & & 192 & 47.5 & 212 & 52.5 & & & \\
\hline
\end{tabular}


Table 2

Description of the Study Sample of Women age 40 and above

By Self-Reported Adherence to Mammography Guidelines

Bonnie's Bus Mobile Mammography Program (BBMMP)

\begin{tabular}{|c|c|c|c|c|c|c|c|}
\hline & \multicolumn{2}{|c|}{ Adherent } & \multicolumn{2}{|c|}{ Non-Adherent } & \multirow[t]{2}{*}{ Chisqr/t-test } & \multirow[t]{2}{*}{ P-value } & \multirow[t]{2}{*}{ Sig } \\
\hline & N (559) & $\%$ & $\mathbf{N}(\mathbf{6 0 2})$ & $\%$ & & & \\
\hline Household Income & & & & & 2.0877 & 0.5544 & \\
\hline Less than $\$ 25,000$ & 376 & 48.4 & 401 & 51.6 & & & \\
\hline$\$ 25,000-\$ 50,000$ & 116 & 47.9 & 126 & 52.1 & & & \\
\hline$\$ 50,000-\$ 75,000$ & 35 & 42.2 & 48 & 57.8 & & & \\
\hline More than $\$ 75,000$ & 32 & 54.2 & 27 & 45.8 & & & \\
\hline Health Insurance & & & & & 0.2507 & 0.6166 & \\
\hline Yes & 322 & 48.8 & 338 & 51.2 & & & \\
\hline No & 237 & 47.3 & 264 & 52.7 & & & \\
\hline Visit to doctor in past year & & & & & 5.6157 & 0.0178 & $*$ \\
\hline Yes & 343 & 51.1 & 328 & 48.9 & & & \\
\hline No & 216 & 44.1 & 274 & 55.9 & & & \\
\hline Visit to $\mathrm{OB} / \mathrm{GYN}$ in past year & & & & & 11.0723 & 0.0009 & $* * *$ \\
\hline Yes & 222 & 54.8 & 183 & 45.2 & & & \\
\hline No & 337 & 44.6 & 419 & 55.4 & & & \\
\hline Problems with ADL & & & & & 1.7507 & 0.2295 & \\
\hline Yes & 13 & 37.1 & 22 & 62.9 & & & \\
\hline No & 546 & 48.5 & 580 & 51.5 & & & \\
\hline Problems with IADL & & & & & 1.0551 & 0.3101 & \\
\hline Yes & 46 & 43.4 & 60 & 56.6 & & & \\
\hline No & 513 & 48.6 & 542 & 51.4 & & & \\
\hline Delayed care due to transportation problem & & & & & 2.5527 & 0.1376 & \\
\hline Yes & 22 & 37.9 & 36 & 62.1 & & & \\
\hline No & 537 & 48.7 & 566 & 51.3 & & & \\
\hline \multicolumn{8}{|l|}{ NEED-RELATED FACTORS } \\
\hline Self-rated Health Status & & & & & 1.7516 & 0.1857 & \\
\hline Fair/Poor & 141 & 51.7 & 132 & 48.4 & & & \\
\hline Excellent/V.good/Good & 418 & 47.1 & 470 & 52.9 & & & \\
\hline Family History of BC & & & & & 9.6031 & 0.0019 & $* *$ \\
\hline Yes & 111 & 58.4 & 79 & 41.6 & & & \\
\hline No & 448 & 46.1 & 523 & 53.9 & & & \\
\hline Breast problems & & & & & 10.7338 & 0.0011 & $* *$ \\
\hline Yes & 92 & 60.5 & 60 & 39.5 & & & \\
\hline No & 467 & 46.3 & 542 & 53.7 & & & \\
\hline
\end{tabular}

......Continued 
Table 2

Description of the Study Sample of Women age 40 and above By Self-Reported Adherence to Mammography Guidelines Bonnie's Bus Mobile Mammography Program (BBMMP)

\begin{tabular}{|c|c|c|c|c|c|c|c|c|}
\hline & & \multicolumn{2}{|c|}{ Adherent } & \multicolumn{2}{|c|}{ Non-Adherent } & \multirow[t]{2}{*}{ Chisqr/t-test } & \multirow[t]{2}{*}{ P-value } & \multirow[t]{2}{*}{ Sig } \\
\hline & & $\mathbf{N}(\mathbf{5 5 9})$ & $\%$ & $\mathbf{N}(602)$ & $\%$ & & & \\
\hline Breast biopsy in past & & & & & & 18.5474 & $<0.0001$ & $* * *$ \\
\hline Yes & & 132 & 61.4 & 83 & 38.6 & & & \\
\hline No & & 427 & 45.1 & 519 & 54.9 & & & \\
\hline Adherence to CBE & & & & & & 6.1532 & 0.0131 & $* *$ \\
\hline Yes & & 283 & 52.0 & 261 & 48.0 & & & \\
\hline No & & 276 & 44.7 & 341 & 55.3 & & & \\
\hline Adherence to PAP test & & & & & & 107.3617 & $<0.0001$ & $* * *$ \\
\hline Yes & & 466 & 58.4 & 332 & 41.6 & & & \\
\hline No & & 93 & 25.6 & 270 & 74.4 & & & \\
\hline History of Cancer & & & & & & 0.0102 & 0.9197 & \\
\hline Yes & & 40 & 47.6 & 44 & 52.4 & & & \\
\hline No & & 519 & 48.2 & 558 & 51.8 & & & \\
\hline Total score of screenings & & & & & & 9.9301 & 0.0016 & $* *$ \\
\hline $0-3$ & & 464 & 46.3 & 538 & 53.7 & & & \\
\hline 4 & & 95 & 59.8 & 64 & 40.3 & & & \\
\hline \multicolumn{9}{|l|}{ PSYCHOSOCIAL FACTORS } \\
\hline Perceived 5 year risk & & & & & & 3.0042 & 0.2227 & \\
\hline Lower & & 243 & 47.4 & 270 & 52.6 & & & \\
\hline Similar & & 239 & 47.1 & 269 & 53.0 & & & \\
\hline Higher & & 77 & 55.0 & 63 & 45.0 & & & \\
\hline Perceived Lifetime risk & & & & & & 1.6519 & 0.4378 & \\
\hline Lower & & 218 & 49.6 & 222 & 50.5 & & & \\
\hline Similar & & 259 & 46.3 & 301 & 53.8 & & & \\
\hline Higher & & 82 & 50.9 & 79 & 49.1 & & & \\
\hline Knowledge Score & & & & & & 1.0387 & 0.5949 & \\
\hline $0-2$ & & 31 & 42.5 & 42 & 57.5 & & & \\
\hline $3-4$ & & 264 & 48.8 & 277 & 51.2 & & & \\
\hline $5-6$ & & 264 & 48.3 & 283 & 51.7 & & & \\
\hline \multicolumn{9}{|l|}{ Views } \\
\hline Positive Views & Mean & 1.7406 & & 1.7421 & & 0.0200 & 0.9827 & \\
\hline Negative Views & Mean & 5.523 & & 5.497 & & -0.2900 & 0.7691 & \\
\hline
\end{tabular}

BBMMP: Bonnie's Bus Mobile Mammography Program (mobile unit); BPBCC: Betty Puskar Breast Care Center (stationary facility); HS: high school; V.good: very good, OB/GYN: obstetrician/gynecologist, ADL: activities of daily living; IADL: instrumental activities of daily living. For views, score 1 is equal to strongly agree and score 7 is equal to strongly disagree on the scale of 1 to 7 .

$* * * \mathrm{P}<0.001 ; * * 0.001=<\mathrm{P}<0.01 ; * 0.01=<\mathrm{P}<0.05$ 
Table 3

Description of the Study Sample of Women age 40 and above

By Self-Reported Adherence to Mammography Guidelines

Betty Puskar Breast Care Center (BPBCC)

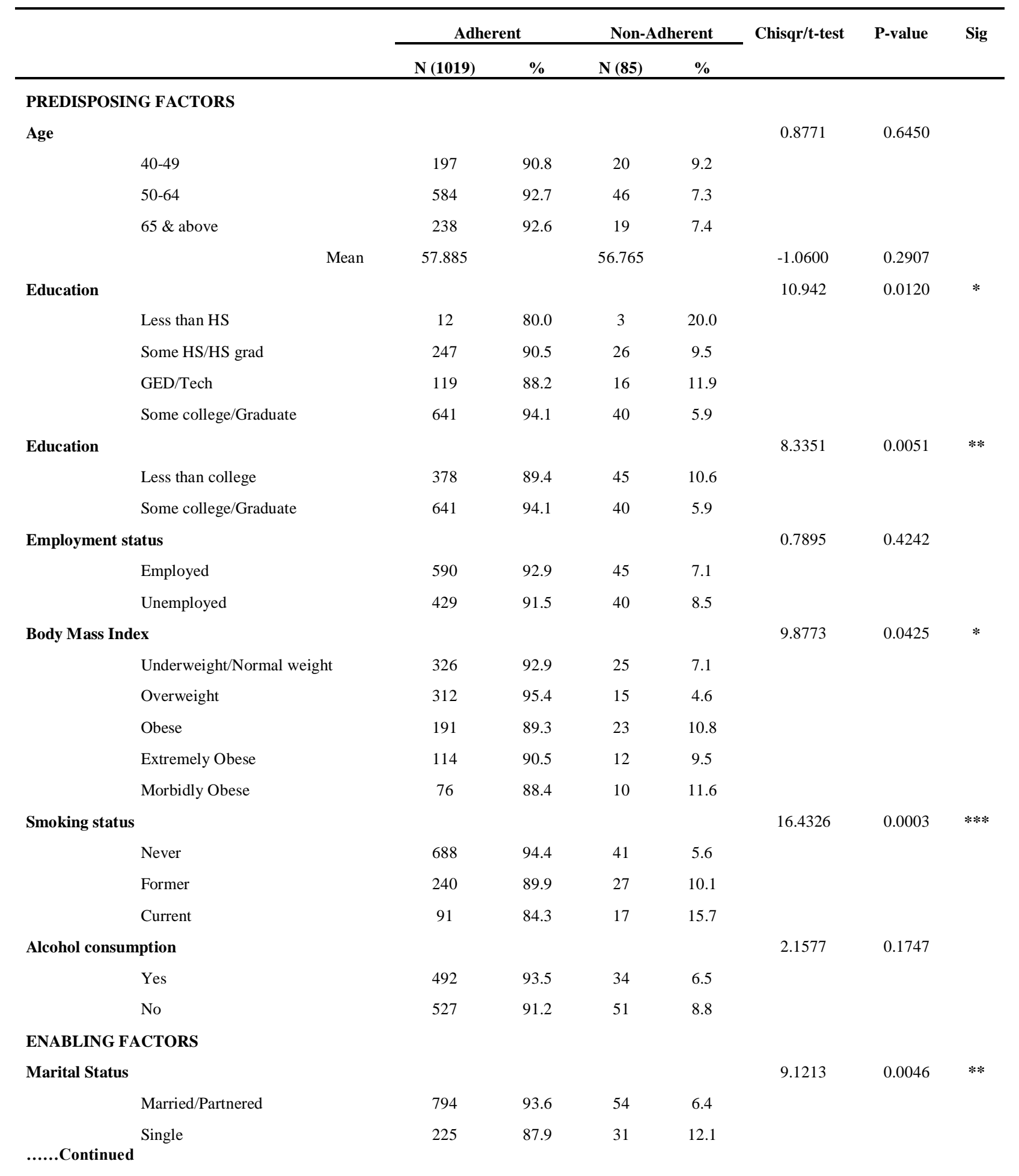


Table 3

Description of the Study Sample of Women age 40 and above

By Self-Reported Adherence to Mammography Guidelines

Betty Puskar Breast Care Center (BPBCC)

\begin{tabular}{|c|c|c|c|c|c|c|c|}
\hline & \multicolumn{2}{|c|}{ Adherent } & \multicolumn{2}{|c|}{ Non-Adherent } & \multirow[t]{2}{*}{ Chisqr/t-test } & \multirow[t]{2}{*}{ P-value } & \multirow[t]{2}{*}{ Sig } \\
\hline & $\mathbf{N}(\mathbf{1 0 1 9})$ & $\%$ & $\mathbf{N}(\mathbf{8 5})$ & $\%$ & & & \\
\hline Household Income & & & & & 17.3252 & 0.0006 & $* * *$ \\
\hline Less than $\$ 25,000$ & 200 & 86.2 & 32 & 13.8 & & & \\
\hline$\$ 25,000-\$ 50,000$ & 252 & 93.3 & 18 & 6.7 & & & \\
\hline$\$ 50,000-\$ 75,000$ & 203 & 92.3 & 17 & 7.7 & & & \\
\hline More than $\$ 75,000$ & 364 & 95.3 & 18 & 4.7 & & & \\
\hline Health Insurance & & & & & 57.1103 & $<0.0001$ & $* * *$ \\
\hline Yes & 982 & 93.7 & 66 & 6.3 & & & \\
\hline No & 37 & 66.1 & 19 & 33.9 & & & \\
\hline Visit to doctor in past year & & & & & 31.1795 & $<0.0001$ & $* * *$ \\
\hline Yes & 765 & 95.0 & 40 & 5.0 & & & \\
\hline No & 254 & 85.0 & 45 & 15.1 & & & \\
\hline Visit to $\mathrm{OB} / \mathrm{GYN}$ in past year & & & & & 26.6050 & $<0.0001$ & $* * *$ \\
\hline Yes & 560 & 96.2 & 22 & 3.8 & & & \\
\hline No & 459 & 87.9 & 63 & 12.1 & & & \\
\hline Problems with ADL & & & & & 3.2377 & 0.1022 & \\
\hline Yes & 12 & 80.0 & 3 & 20.0 & & & \\
\hline No & 1007 & 92.5 & 82 & 7.5 & & & \\
\hline Problems with IADL & & & & & 3.5942 & 0.0701 & \\
\hline Yes & 65 & 86.7 & 10 & 13.3 & & & \\
\hline No & 954 & 92.7 & 75 & 7.3 & & & \\
\hline Delayed care due to transportation problem & & & & & 12.3703 & 0.0031 & $* *$ \\
\hline Yes & 26 & 76.5 & 8 & 23.5 & & & \\
\hline No & 993 & 92.8 & 77 & 7.2 & & & \\
\hline \multicolumn{8}{|l|}{ NEED-RELATED FACTORS } \\
\hline Self-rated Health Status & & & & & 10.0086 & 0.0041 & $* *$ \\
\hline Fair/Poor & 145 & 86.3 & 23 & 13.7 & & & \\
\hline Excellent/V.good/Good & 874 & 93.4 & 62 & 6.6 & & & \\
\hline Family History of BC & & & & & 0.5604 & 0.5689 & \\
\hline Yes & 202 & 93.5 & 14 & 6.5 & & & \\
\hline No & 817 & 92.0 & 71 & 8.0 & & & \\
\hline Breast problems & & & & & 5.6747 & 0.0162 & $*$ \\
\hline Yes & 248 & 95.8 & 11 & 4.3 & & & \\
\hline No & 771 & 91.2 & 74 & 8.8 & & & \\
\hline
\end{tabular}

......Continued 
Table 3

Description of the Study Sample of Women age 40 and above

By Self-Reported Adherence to Mammography Guidelines

Betty Puskar Breast Care Center (BPBCC)

\begin{tabular}{|c|c|c|c|c|c|c|c|c|}
\hline & & \multicolumn{2}{|c|}{ Adherent } & \multicolumn{2}{|c|}{ Non-Adherent } & \multirow[t]{2}{*}{ Chisqr/t-test } & \multirow[t]{2}{*}{ P-value } & \multirow[t]{2}{*}{ Sig } \\
\hline & & $N(1019)$ & $\%$ & $\mathbf{N}(\mathbf{8 5})$ & $\%$ & & & \\
\hline Breast biopsy in past & & & & & & 4.9965 & 0.0305 & $*$ \\
\hline Yes & & 349 & 94.8 & 19 & 5.2 & & & \\
\hline No & & 670 & 91.0 & 66 & 9.0 & & & \\
\hline Adherence to CBE & & & & & & 71.7168 & $<0.0001$ & $* * *$ \\
\hline Yes & & 675 & 97.5 & 17 & 2.5 & & & \\
\hline No & & 344 & 83.5 & 68 & 16.5 & & & \\
\hline Adherence to PAP test & & & & & & 81.4406 & $<0.0001$ & $* * *$ \\
\hline Yes & & 751 & 97.0 & 23 & 3.0 & & & \\
\hline No & & 268 & 81.2 & 62 & 18.8 & & & \\
\hline History of Cancer & & & & & & 0.0221 & 0.8693 & \\
\hline Yes & & 138 & 92.0 & 12 & 8.0 & & & \\
\hline No & & 881 & 92.4 & 73 & 7.7 & & & \\
\hline Total score of screenings & & & & & & 23.5686 & $<0.0001$ & $* * *$ \\
\hline $0-3$ & & 675 & 89.6 & 78 & 10.4 & & & \\
\hline 4 & & 344 & 98.0 & 7 & 2.0 & & & \\
\hline \multicolumn{9}{|l|}{ PSYCHOSOCIAL FACTORS } \\
\hline Perceived 5 year risk & & & & & & 2.9188 & 0.2324 & \\
\hline Lower & & 354 & 90.5 & 37 & 9.5 & & & \\
\hline Similar & & 503 & 93.0 & 38 & 7.0 & & & \\
\hline Higher & & 162 & 94.2 & 10 & 5.8 & & & \\
\hline Perceived Lifetime risk & & & & & & 6.2979 & 0.0429 & $*$ \\
\hline Lower & & 301 & 89.3 & 36 & 10.7 & & & \\
\hline Similar & & 533 & 93.4 & 38 & 6.7 & & & \\
\hline Higher & & 185 & 94.4 & 11 & 5.6 & & & \\
\hline Knowledge Score & & & & & & 6.0057 & 0.0496 & $*$ \\
\hline $0-2$ & & 64 & 85.3 & 11 & 14.7 & & & \\
\hline $3-4$ & & 631 & 92.4 & 52 & 7.6 & & & \\
\hline $5-6$ & & 324 & 93.6 & 22 & 6.4 & & & \\
\hline \multicolumn{9}{|l|}{ Views } \\
\hline Positive Views & Mean & 1.926 & & 2.568 & & 4.9800 & $<0.0001$ & $* * *$ \\
\hline Negative Views & Mean & 5.853 & & 5.456 & & -2.8000 & 0.0053 & $* *$ \\
\hline
\end{tabular}

BBMMP: Bonnie's Bus Mobile Mammography Program (mobile unit); BPBCC: Betty Puskar Breast Care Center (stationary facility); HS: high school; V.good: very good, OB/GYN: obstetrician/gynecologist, ADL: activities of daily living; IADL: instrumental activities of daily living. For views, score 1 is equal to strongly agree and score 7 is equal to strongly disagree on the scale of 1 to 7 .

$* * * \mathrm{P}<0.001 ; * * 0.001=<\mathrm{P}<0.01 ; * 0.01=<\mathrm{P}<0.05$ 
Table 4

Adjusted Odds Ratios and 95\% Confidence Interval from Logistic Regression Of Self-Reported Adherence to Mammography Guidelines

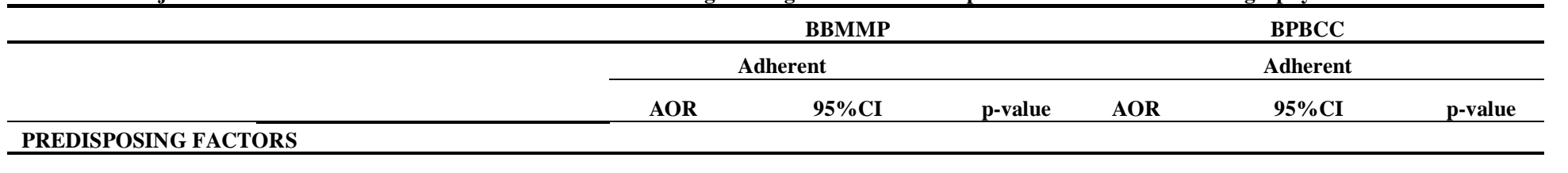

Age

40-49

50-64

2.025

$[1.489,2.754]$

$<0.0001$

\section{1}

$65 \&$ above

$3.181 \quad[1.904,5.314]$

$<0.0001$

1.999

$[0.973,4.106]$

0.0592

Education

$$
\text { Less than HS }
$$

1

Some HS/HS grad

GED/Tech

0.741

$[0.367,1.495]$

0.789

$[0.379,1.644]$

0.849

$[0.406,1.776]$

2.585

$[0.956,6.987]$

0.0612

Some college/Graduate

1

Employed

Unemployed

1.371

$[1.028,1.829]$

0.0319

$[0.627,2.502]$

0.5232

Body Mass Index

Underweight/Normal weight

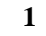

Overweight

1

Obese

1.280

$[0.848,1.933]$

1.295

[0.874, 1.917]

Extremely Obese

1.880

[1.161, 3.046]

0.4023

1.735

[0.303, 9.928]

0.5359

$0.5274-1.587$

[0.261, 9.639]

0.6158

Morbidly Obese

1.918

$[1.128,3.261]$

$\begin{array}{cc} & \mathbf{1} \\ 0.2394 & 3.046 \\ 0.1973 & 1.088 \\ 0.0103 & 1.665 \\ 0.0161 & 1.089\end{array}$

[1.315, 7.060]

0.0094

[0.513, 2.307]

0.8268

[0.650, 4.269]

0.2883

[0.376, 3.153]

0.8753

Smoking status

Never
Former
Current

1

0.995

0.776

[0.707, 1.400]

$[0.558,1.080]$

0.9776

\section{1}

0.571

[0.301, 1.083]

0.0861

0.1330

0.536

$[0.243,1.184]$

0.1229

Alcohol consumption

Yes

0.922

$[0.672,1.265]$

0.6162

0.971

$[0.528,1.788]$

0.9250

1

\section{ENABLING FACTORS}

\section{Marital Status}

Married/Partnered

Less than $\$ 25,000$
$\$ 25,000-\$ 50,000$
$\$ 50,000-\$ 75,000$

\section{1}

0.991

1

1.088

0.977

1.794
Single/Divorced

Household Income

More than $\$ 75,000$
$[0.769,1.539]$

$[0.562,1.700]$

[0.943, 3.412]
$[0.744,1.320]$

0.9482

0.743

$[0.382,1.444]$

0.3813

......Continued 
Table 4

Adjusted Odds Ratios and 95\% Confidence Interval from Logistic Regression Of Self-Reported Adherence to Mammography Guidelines

\begin{tabular}{|c|c|c|c|c|c|c|}
\hline & \multicolumn{3}{|c|}{ BВMMP } & \multicolumn{3}{|c|}{ BPBCC } \\
\hline & \multicolumn{2}{|c|}{ Adherent } & \multirow[b]{2}{*}{ p-value } & \multicolumn{3}{|c|}{ Adherent } \\
\hline & AOR & $95 \% \mathrm{CI}$ & & AOR & $95 \% \mathrm{CI}$ & p-value \\
\hline \multicolumn{7}{|l|}{ Health Insurance } \\
\hline Yes & 1 & & & 1 & & \\
\hline \multicolumn{7}{|l|}{ Visit to doctor in past year } \\
\hline Yes & 1 & & & 1 & & \\
\hline No & 0.933 & {$[0.703,1.239]$} & 0.6320 & 0.898 & {$[0.478,1.685]$} & 0.7366 \\
\hline \multicolumn{7}{|l|}{ Visit to $\mathrm{OB} / \mathrm{GYN}$ in past year } \\
\hline Yes & 1 & & & 1 & & \\
\hline No & 0.814 & {$[0.613,1.082]$} & 0.1563 & 0.790 & {$[0.406,1.536]$} & 0.4863 \\
\hline \multicolumn{7}{|l|}{ Problems with ADL } \\
\hline Yes & 0.604 & {$[0.246,1.483]$} & 0.2713 & 0.892 & {$[0.133,6.006]$} & 0.9068 \\
\hline No & 1 & & & 1 & & \\
\hline \multicolumn{7}{|l|}{ Problems with IADL } \\
\hline Yes & 0.636 & {$[0.360,1.123]$} & 0.1186 & 0.904 & {$[0.278,2.945]$} & 0.8671 \\
\hline No & 1 & & & 1 & & \\
\hline \multicolumn{7}{|c|}{ Delayed care due to transportation problem } \\
\hline Yes & 0.503 & {$[0.269,0.941]$} & 0.0316 & 0.299 & {$[0.090,0.989]$} & 0.0479 \\
\hline No & 1 & & & 1 & & \\
\hline
\end{tabular}

NEED-RELATED FACTORS

Self-rated Health Status

Fair/Poor
Excellent/V.good/Good

Family History of BC

$$
\text { Yes }
$$$$
\text { No }
$$

Breast problems

Yes
No

Breast biopsy in past

Yes
No

Adherence to CBE

Yes
No

1.244

1

\begin{abstract}
1.541
\end{abstract}
[1.067, 2.225]

0.0212

1.617

1

1

\begin{abstract}
1.434
\end{abstract}
$[0.931,2.209]$

1

$$
1.661
$$

1

[1.143, 2.413]

0.0077

1.213

1

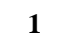

1.236

$[0.922,1.656]$

0.1566

1

0.257

$[0.125,0.525]$

0.0002

......Continued 
Table 4

Adjusted Odds Ratios and 95\% Confidence Interval from Logistic Regression Of Self-Reported Adherence to Mammography Guidelines

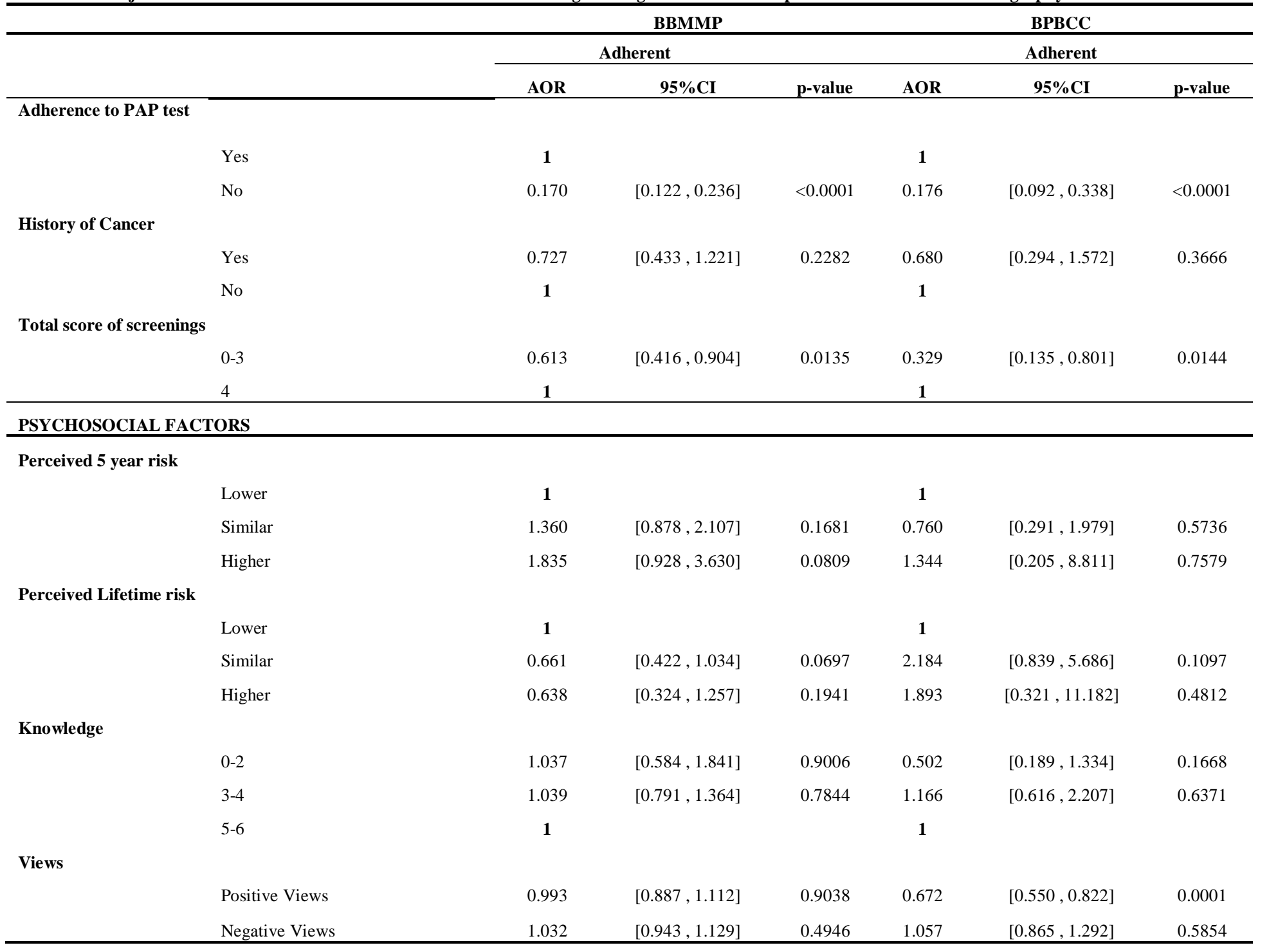

BBMMP: Bonnie's Bus Mobile Mammography Program (mobile unit); BPBCC: Betty Puskar Breast Care Center (stationary facility); HS: high school; V.good: very good, OB/GYN: obstetrician/gynecologist, ADL: activities of daily living; IADL: instrumental activities of daily living. For views, score 1 is equal to strongly agree and score 7 is equal to strongly disagree on the scale of 1 to 7 .

The regressions also include intercept terms and parameter estimates for other variables controlled are not presented. Asterisks represent statistically significant group differences compared to the reference group. "Non-adherence to mammography screening" is the reference group for the dependent variable for respective study samples. 
CHAPTER 3 


\section{CHAPTER 3}

\section{PREFERENCES OF WOMEN FOR INTERVENTIONS STRATEGIES IN A MOBILE MAMMOGRAPHY PROGRAM}

\section{INTRODUCTION}

West Virginia (WV) is the only state that lies entirely within the Appalachian region and has 34 out of its 55 counties classified as rural ${ }^{1,2}$. The Appalachian region, as well as WV, is largely rural, and demographically homogenous. Moreover, WV is a medically underserved state characterized by higher than national median age, lower education levels, higher poverty rates, higher rates of chronic diseases, poor health behaviors and significant health care disparities $^{3-6}$. In spite of higher than national rates of all-cancer incidence and mortality, WV has a lower incidence but higher rates of advanced and unstaged $\mathrm{BC}^{2,7-11}$. The lower incidence but higher rates of late and unstaged $\mathrm{BC}$ is due to lower mammography screening rates in women in $\mathrm{WV}^{2,12}$. In 2010, WV was ranked $48^{\text {th }}$ among other states of the United States for women having mammography screening within the past two years ${ }^{13}$. A recent study on WV Medicaid fee-for-service women indicated that fewer than $40 \%$ women had a mammogram related billing in 2007-2008 within the previous two years even though mammography screening is covered under the WV Medicaid program ${ }^{14}$. Thus, the authors concluded that there may be factors other than health insurance coverage and socio-economic factors, such as lack of knowledge about mammography, cultural influences, views and attitudes about mammography, lack of physician's recommendation, and transportation problems, which may be responsible for the low screening rates in the Medicaid population. Few studies have indicated that rural residence is associated with lower mammography use, with women residing in rural areas significantly less likely to ever have had a mammogram ${ }^{15,16}$. 
According to the American Cancer Society (ACS), mammography screening is the single most effective method of detecting breast cancer $(\mathrm{BC})$ early ${ }^{17}$ which reduces $\mathrm{BC}$-related mortality by $20-35 \%$ in women age $40-69$ years of age ${ }^{18-22}$. Accessible health and BC prevention information sources are exceptionally important for the rural and underserved women to learn about benefits of mammography screening. Rural women in WV seek information related to mammography screening mostly from doctors or obstetricians/gynecologists $(\mathrm{OB} / \mathrm{GYN})^{23-24}$. A recent study documented that interpersonal sources of information such as doctors, nurses, friends and channel sources such as television, magazines and internet were among the most preferred information sources for women residing in rural areas ${ }^{25}$. Moreover, the authors of the study suggested that multiple channels including the internet and text messages via cell-phones may become regular BC prevention information sources and health educators may use these when developing an educational intervention to increase mammography screening rates in rural areas. However, this study surveyed all women regardless of whether or not they were adherent to mammography screening guidelines. Hence, the sources of information utilized by women who were not adherent to mammography screening guidelines or who never have had a mammogram before were obscured in the results.

A recent study of women age 40 years and above who utilized Bonnie's Bus to get a mammogram reported that only $46 \%$ had a mammogram within the past two years ${ }^{26}$ which is below the national Healthy People 2010 goals for mammography screening ${ }^{27}$ and the WV screening rate of $73.7 \%^{28}$. Of the women who were not adherent to mammography screening guidelines, approximately $21 \%$ reported not ever having had a mammogram before having it at the Bonnie's Bus (data not reported). The authors also reported that younger women in the age group 40-49 years with no experience of BC-related events were significantly less likely to 
report having had a mammogram within the past two years. Such substantially lower adherence to mammography screening in these women who utilized the Bonnie's Bus and with such a high proportion of women obtaining their first ever mammogram at a mobile mammography service, raises questions about what type of community-based or individually targeted interventions are most likely to attract women to get screened and become adherent to mammography screening guidelines.

Various interventions have been developed around mobile mammography since the inception of mobile mammography to improve preventive behavior. A study reported that when health care agents visited and educated women about BC and mammography screening prior to the mobile mammography van visit to the community, the screening rates improved significantly ${ }^{29}$. Another study documented that an educational program resulted in an increase in screening rates when coupled with low-cost mobile mammography screening ${ }^{30}$. A randomized clinical trial that assessed the benefit of on-site mobile mammography coupled with health education for older women reported that offering on-site mammography at community-based sites where older women gather is an effective method of increasing breast cancer screening rates $^{31}$. However, there are very few studies that have looked at the barriers and facilitators to mammography screening among women who have never had a mammogram before ${ }^{32-35}$. This is a segment of the women population that is very hard to identify and determine their reasons for not obtaining regular mammograms. As suggested by a recent study ${ }^{14}$, it is vital to understand their views and attitudes, barriers and facilitators for mammography screening especially when they are rural and underserved. Additionally, it is important to determine the information sources and channels these women use, and whose advice they seek related to health care behaviors. Also, not much has been reported about what types of intervention strategies linked 
with mobile mammography are likely to improve screening rates thereby the effectiveness of a mobile mammography program in such a population. Although there are many effective interventions reported in the literature, it is important to determine from the perspective of women at whom these interventions are targeted, their receptiveness towards these interventions and perception of likelihood of interventions' success with their peers and in their communities. Thus, the objectives of this research study are to determine the barriers and facilitators to mammography screening among WV women age 40 years and above who have had their first mammogram at the Bonnie's Bus, to examine their mammography screening information seeking behaviors and to identify from their perspective the intervention strategies that are most likely to be effective in increasing mammography screening rates when linked to mobile mammography with their peers and in their community.

\section{METHODS}

\section{Study Design}

The present study reports data from Phase II of the two-phase research project. A structured telephone interview was conducted in early 2012 of women age 40 years and above residing in WV who reported never having had a mammogram prior to getting one through the Bonnie's Bus. The study was approved by the Institutional Review Board at the West Virginia University, USA.

\section{Setting}

The ‘Bonnie Wells Wilson Mobile Mammography Program' (called Bonnie's Bus hereafter) was established in 2009 with the goal of increasing persistence of mammography screening in underserved women in rural WV. It is a joint venture of the Mary Babb Randolph Cancer Center (MBRCC) and West Virginia University Healthcare and a statewide partnership 
of women's groups, clinicians, public health professionals and other community leaders all working toward reducing BC-mortality in WV. Bonnie's Bus was put into practice to provide $\mathrm{BC}$ screening services to women in WV, especially those in rural parts of the state with limited or no access to screening mammography. Although the program requires a referral from the physician, walk-ins acceptable too for which the provider on staff can write the referral. Mammograms are billed to third-party payers, and the program works closely with the West Virginia Breast and Cervical Cancer Screening Program (CDC) to provide service to women who are uninsured. Funding from grants and donations also help in providing mammograms to the uninsured women and those with income at or below $200 \%$ of the federal poverty level.

\section{Study Population}

An exhaustive sample of 77 women age 40 years and above who reported having had their first mammogram at the Bonnie's Bus in 2010 or 2011 and who had consented to participate in future research was identified.

\section{Participant Recruitment}

Each of the 77 women was mailed an informational letter (Appendix G) along with a telephone interview schedule (Appendix H) and a self-addressed business reply envelope. The informational letter explained the purpose of the research study, the voluntary participation, the confidentiality of the information to be collected, and the purpose of the attached 'telephone interview schedule'. They were asked to identify convenient time slots for conducting a telephone interview in the telephone interview schedule sheet and return it in a self-addressed business reply envelope. Return of the schedule implied consent for participation in the research study. Eighteen women mailed back the completed telephone interview schedule and confirmed their interest to participate in the study. 


\section{Interview Guide}

A structured interview guide (Appendix I) was developed and refined by the research team prior to conducting the telephone interviews. It contained five main topic areas: views about mammography screening, barriers and facilitators of mammography screening, information seeking behavior, preferences for community-based and personal interventions that could be developed around the mobile mammography unit, and the acceptance of social media and cell-phones to receive information about mammography screening. The interventions about whose preferences were to be determined were chosen based on their effectiveness as reported in the literature ${ }^{36,37}$. The interview guide included both open-ended and close-ended questions. Probing questions were utilized to encourage participants to elaborate on their responses, describe their views and preferences in their own words and from their own perspective (e.g. Can you add more to your answer? Anything else you can think of?).

\section{Interview}

Based on the convenient times identified by each woman, telephone calls were made to complete the interviews. Two women were not reached in spite of efforts at different times of the day. Hence, the final sample for this study consisted of 16 women. All the telephone interviews commenced with a general introduction about the study purpose, procedures and maintenance of confidentiality of the interviews. With the permission of participants, all telephone interviews were audio recorded. These interviews were conducted by the same researcher (AV) and averaged 23 minutes in duration (range: 12-33 minutes). Participants received a $\$ 25$ gift card with a thank you letter (Appendix J) by mail as a token of appreciation for their time and participation.

\section{Analysis}


Data on women's demographic characteristics, socio-economic and access factors, health-related behavioral factors, medical history and psychosocial factors were collected during their visit at the Bonnie's Bus to obtain a mammogram. These data were analyzed using SPSS 20.0 to describe the study sample.

The audio-recordings of the telephone interviews were transcribed verbatim. The transcript was coded by two researchers working independently to reduce bias. Dissimilar interpretations and coding of the data were discussed to arrive at the consensus on the codes.

Thematic analysis of data was conducted using the process summarized by Braun and Clarke ${ }^{38}$ to identify women's barriers and facilitators to mammography screening and their receptiveness to various interventions. Analysis of qualitative data was performed using the NVIVO 9.3 software package $^{39}$. Results were organized by theme and sub-theme and quotes describing the themes extracted. Data from closed-ended questions on likelihood of interventions and use of social media and cell-phones were analyzed using SPSS 20.0.

\section{Non-Response Bias Assessment}

To determine whether or not women who did not participate in the study were different from women who participated, we assessed non-response bias. The participation rate was $20.8 \%$. Women who did not participate in the telephone interviews were compared to women who participated in the telephone interviews on selected demographic, socio-economic, and psychosocial factor (views about mammography screening) using data from the Mammography Screening and Preventive Care Survey that they had all completed during their visit to the mobile mammography unit. There were no significant differences between respondents and nonrespondents on these factors.

\section{RESULTS}




\section{Characteristics of the Participants}

Table 1 describes the characteristics of women who have had their first mammogram at the Bonnie's Bus. Women in this study sample were on average of age 46.4 years. Majority (75.0\%) of women were in the age group 40-49 years and $25.0 \%$ were in age group 50-59 years. Majority were married/partnered (62.5\%), employed (68.8\%), had less than college level education (62.5\%), with household income of less than $\$ 25,000$ (68.8\%) and with no health insurance coverage (68.8\%). Also majority of them were adherent to clinical breast exam (CBE) (56.3\%) and Pap test (87.5\%). A lower proportion of women (37.5\%) preferred to receive health information via texts on cell-phone while majority (56.3\%) indicated a preference for using networking sites to get health information.

\section{Barriers and Facilitators to Mammography Screening}

Table 2 outlines the themes and subthemes of barriers and facilitators to mammography screening as described by the participants. Each theme with a subtheme was described and exemplified by a representative quotation.

Three primary themes related to barriers and facilitators to mammography screening emerged in the analysis; accessibility, attitudes and beliefs, and social network experience.

\section{Accessibility}

In terms of accessibility, the major barriers that prevented women from getting a mammogram in the past were lack of insurance coverage, followed by costs of the procedure. A 48-year old woman mentioned "I did not have health insurance and so it was one of those things that I just kind of put off even though I passed the age I should have had". This indicates that rural women in WV may not be able to access preventive services such as screening due to lack 
of insurance coverage. Only one woman mentioned lack of transportation as a barrier to mammography screening.

On the other hand, free and/or discounted mammography screening, convenient and close location of mammography screening service were the major facilitators to mammography screening related to accessibility as reported by women. Statements such as "I had found out that it [Bonnie's Bus] was going to be near me and it was free for someone who did not have insurance so lot of it was the fact that I can have that [mammogram] free" and "It [mammogram] was free, and its location [close]" were common, further exemplifying the availability of free and/or discounted mammograms at a place near the residence for women. Having health insurance was also mentioned by one woman as the facilitator to mammography screening.

$\underline{\text { Attitudes and beliefs }}$

The attitudes and beliefs identified as barriers to mammography screening included fear of pain or unpleasantness from procedure, lack of knowledge about screening or BC itself, and lower perceived risk of developing BC. For instance, a 44-year old woman said, "I always heard that it [mammography screening] is painful". While another woman 43 years of age said, "I haven't thought about it [mammography screening].... never had no issues so I never thought of going [for a mammogram]". Hence these rural women need to be educated about mammography procedures and its importance.

However, the attitudes and beliefs identified as facilitators to mammography screening included knowledge about mammography screening and having had breast problems. A 43-year old woman said, “...I should do it as I am 40”. Another 44-year old woman mentioned, 
"Basically I recently got one [mammogram] as I had lump in my breast and a leaky nipple in my right breast".

Social network experience

The only barrier in regards to social network experience reported by a 49-year old woman was delayed recommendation from the gynecologist. She said, “...I did yearly health check ups, did screenings [breast self exam] at home, it was matter of listening to doctor and gynecologist and she [gynecologist] was like you are okay, you do not have a history, just delaying due to no recommendation from the gynecologist". This indicates that the doctors and $\mathrm{OB} / \mathrm{GYNs}$ need to be targeted with interventions that would focus on the importance of recommending mammography screening for the women in their community.

While in terms of social network experience, the facilitators to mammography screening as reported by women were recommendation from doctor/gynecologist, recommendation from friends and/or family, family history of $\mathrm{BC}$, knowing people with $\mathrm{BC}$ and who died of $\mathrm{BC}$, and advertisement of Bonnie's Bus. A 51-year old woman said, "I happened to go down for the Pap smear and they [physician at health department] recommended Bonnie's Bus, the physician at the health department recommended to go to the Bonnie's Bus", while a 49-year old woman mentioned, “...my gynecologist recommended it". A 52-year old woman mentioned that she got a recommendation from her friend, while a 48-year old mentioned that her friends who worked at the place where the Bonnie's Bus was to visit recommended her about having a mammogram. Another 57-year old woman got a recommendation of having a mammogram at the Bonnie's Bus from her customer whose daughter-in-law died of BC. A 44-year old woman who had breast problem due to which she had a mammogram at the Bonnie's Bus mentioned, "I had watched my cousin, she was in her 50's when she died of BC'. Hence, getting family and friends and women 
with BC play an important role in motivating other women in their community to get screened

for BC. A few women reported that they saw the advertisement of the Bonnie's Bus at the health center, post office, and in the newspaper.

\section{Sources and Channels of Information}

Figure 1 shows the sources and channels of information about health and mammography screening used by rural women who had their first mammogram at the Bonnie's Bus. These included doctors or OB/GYN (81.25\%), materials from library $(43.75 \%)$, health fairs $(37.50 \%)$, internet $(37.50 \%)$, health center $(25.0 \%)$, nurses (18.75\%), hospital $(6.25 \%)$ and senior center (6.25\%). A majority $(81.25 \%)$ of the women reported the highest likelihood of seeking advice about mammography screening from the doctors, and $31.25 \%$ women were most likely to seek advice about mammography screening from their mothers (data not shown). Sister (25.00\%) and friends (18.75\%) were also referred to as the most likely sources from which to seek advice about mammography screening (data not shown). Approximately $19 \%$ of women reported the internet as an equally likely option in seeking advice about mammography screening.

\section{Acceptance of Social Media and Cell-Phones to Receive Information}

More than half of the women (56\%) specified using social media such as Facebook, Linkedin and e-mail (data not shown). Eight women showed their interest to be friends with the Bonnie's Bus on its Facebook page (data not shown). As mentioned in table 1, only 6 women (38\%) indicated the preference to receive health related information about mammography screening via text messages on their cell-phones. Nine women $(56 \%)$ indicated their preference to receive information about mammography screening through the networking websites.

\section{Preferences for Interventions}


Table 3 demonstrates the mean scores of the likelihood for community-based and individual-level interventions that would be helpful to women, on the likelihood scale of 1 to 5 where 1 corresponds to least likely and 5 corresponds to most likely. Among the communitybased interventions, community-based health educational programs that could be held at public places such as library or church or work-sites was perceived to be the most helpful intervention (mean score $(\mathrm{M})=4.625$, standard deviation $(\mathrm{SD})=0.885)$ and also for other women in their community $(\mathrm{M}=4.438, \mathrm{SD}=0.964)$. However, other community-based intervention, use of community health educators, received a mean preference score of $4.063(\mathrm{SD}=1.063)$ for self and $4.250(\mathrm{SD}=0.856)$ for other women in the community. Among the individual-level interventions, mailed educational material about BC and mammography screening was perceived to be the most helpful intervention $(\mathrm{M}=4.125, \mathrm{SD}=1.258)$, followed by telephone counseling with a letter from a physician $(M=3.625, \mathrm{SD}=1.668)$, telephone counseling with mailed educational materials $(\mathrm{M}=3.250, \mathrm{SD}=1.770)$, and receiving information about $\mathrm{BC}$ and mammography screening on the cell-phones in the form of texts $(\mathrm{M}=3.063, \mathrm{SD}=1.652)$. While for other women in their community, women in this study sample perceived that individually targeted intervention such as telephone counseling with a letter from a physician (M $=4.063, \mathrm{SD}=1.436)$ would be the most helpful intervention, followed by mailed educational material about $\mathrm{BC}$ and mammography screening $(\mathrm{M}=3.938, \mathrm{SD}=1.237)$.

Table 4 outlines the reasons stated by women for perceiving community-based educational programs and individually-targeted mailed educational materials as the most helpful approaches to increase their participation and adherence in the mammography screening. Each reason was described and exemplified by a representative quotation. 
Among community-based interventions, women perceived community-based educational programs as the most helpful approach for them to encourage them to participate in mammography screening. Women perceived that such programs may increase accessibility to getting information about mammography screening in the community. A 49-year old woman mentioned "I think you mention about library, I think that [educational program] would be easier if it opens to the public and information is readily available". They also perceived that such programs would be informative, and increase knowledge about mammography screening in women. A 43-year old woman said, "People will hear more about situations and its [educational programs] got to be more helpful for them". Lack of such community-based educational programs and close and convenient location for such programs were also mentioned by women for such programs to be helpful to them. A few women mentioned that such programs would be more helpful to the rural women. A 52-year old woman stated that such community-based educational programs will be highly helpful to her based on the experiences of her friends and mother, who also took advantage of such programs. She said, ""Because of my past experience with my best friends, with my mother...My mother used such a program".

Among individual-based interventions, women perceived receiving educational materials in the mail as the most helpful approach for them to encourage them to participate in mammography screening. Women perceived that such an approach may be more helpful to them as it would be convenient, personal and would increase the likelihood of being read of such health-related materials. A 41-year old woman said, "Because in the mail, it is personally suggested, you are going to open it and read it....it is a more personal approach". Women also mentioned that such an approach would increase knowledge about mammography screening and 
be more informative. A 52-year old woman said, "Some women do not know anything about it [mammography screening], so mail will be helpful".

\section{DISCUSSION}

The study examined the barriers and facilitators to mammography screening in women who have had their first mammogram at the mobile mammography program in WV, their mammography screening information seeking behaviors and identified from their perspective the intervention strategies that are most likely to be effective in increasing mammography screening rates when linked to mobile mammography. To our knowledge, it is the first study which explored the perceptions and receptiveness of women who never have had a mammogram about various intervention strategies that could be linked to the mobile mammography program which may assist in increasing mammography screening rates in women in WV.

Consistent with the literature, the major barriers to mammography screening which restricted women in WV to ever get a mammogram before they got one at the mobile mammography program were related to access factors (health insurance and cost of the procedure) ${ }^{32-34}$, and attitudes and beliefs about mammography screening (perception that the mammogram is painful, lower perceived risk and lack of knowledge about mammography screening $)^{32,33,35}$. The lack of health insurance is the major obstacle for rural women of WV and should be addressed to increase their use of mammography screening services. Again, consistent with published literature, the major facilitators which made women obtain mammography screening at the mobile mammography program in WV were free and/or discounted service ${ }^{34}$ at close and/or convenient location, followed by recommendation from a doctor or OB/GYN ${ }^{33,34}$, friends and family ${ }^{33,35}$, and having had family history of $\mathrm{BC}$, and knowing people with $\mathrm{BC}^{35}$. 
Putting up advertisements about the mammography screening services at public places in the community also encouraged women to obtain mammograms as seen in a previous study ${ }^{40}$.

Consistent with the literature, a majority of rural women in WV seek information related to health and mammography screening from doctors or $\mathrm{OB} / \mathrm{GYNs}^{23-25}$, highlighting the important role of health professionals in encouraging women for mammography screening. Moreover, library and health fairs were important places of information by these rural women, which indicates that availability of educational materials at these places can be beneficial to increase awareness about mammography screening in these women. Internet use is rapidly increasing as a source of information about BC and mammography screening, and the findings support previous studies ${ }^{24,41,42}$. Internet use among the study women to seek information about mammography screening indicated an alteration to the traditional 'two-step flow theory' developed by Katz and Lazersfeld ${ }^{43}$ which suggests that information flows from media to opinion leaders to the public. Moreover, while the many information sources available to the women is a good trend, it is vital that these sources and channels of information be also valid and accurate. The internet, particularly, is known for biased and inaccurate information and therefore these women should be provided with addresses of credible and accurate websites. The findings on the likelihood of receiving text messages about mammography screening suggested that rural women may have network problems, use cell phones less, or did not prefer receiving information by this means. Thus, incorporating use of cell phones and texts as one of the intervention strategy to increase mammography screening in women in WV may not be a successful strategy.

The most helpful interventions as perceived by women to encourage them to utilize and adhere to mammography screening were community-based educational programs and mailed educational materials. This is consistent with the study on mobile mammography in underserved 
women, which recommended adding education programs to mobile mammography programs to increase their effectiveness ${ }^{44}$. Also, a few studies have demonstrated that community-based educational programs increase screening rates in women who utilized mobile mammography units $^{31,45,46}$. A study on the perceptions and beliefs of Appalachian women about communitybased educational campaigns suggested that an educational campaign would increase awareness and knowledge about mammography screening ${ }^{32}$. Moreover, this study also reported that women preferred the direct mailed materials to be colorful, bold, and interesting to persuade women to utilize mammography screening ${ }^{32}$. Another study has reported that mailed educational material is one of the mroe effective intervention strategies to increase screening rates in women $^{37}$.

One of the limitations of this study is that the sample of the study was relatively small for the telephone interviews of women who had obtained a mammogram for the first time which may not have resulted in the full saturation of the findings in the telephone interviews. Moreover, the findings cannot be generalized to women who are adherent to mammography screening guidelines, residing outside of WV, and who do not use mobile mammography services.

Nonetheless, despite these limitations, there are some important strengths of this study. To our knowledge, it is the first study of its kinds to identify from the perspective of women, the intervention strategies that could be linked to mobile mammography unit to increase mammography screening rates in rural women. Another strength is the use of qualitative methods to investigate the perceptions and preferences of women about various intervention strategies that could be linked to mobile mammography unit. Using this methodology, it was possible to explore and discuss with participants why they preferred a particular intervention 
strategy. The results of the study may be helpful in developing interventions that could be coupled with the mobile mammography program to increase mammography screening in women in WV.

\section{CONCLUSION}

This qualitative study identified the community-based and individual-based intervention strategies that could be developed along with the mobile mammography unit that may be better received and therefore more likely to be effective in attracting rural and underserved women in WV to mobile mammography. Also, to gain access to a population that is traditionally hard to reach, information sources such as doctors and/or OB/GYNs, family and friends, and channels such as the internet are vital to increase mammography screening rates in rural women.

\section{ACKNOWLEDGEMENTS}

This research study is funded by Susan G. Komen For the Cure, Claude Worthington Benedum Foundation, and AHRQ grant \# R24HS018622-03. 


\section{REFERENCES}

1. Health Resource and Services Administration (HRSA). List of Rural Counties and Designated Eligible Census Tracts in Metropolitan Counties, 2009.

ftp://ftp.hrsa.gov/ruralhealth/eligibility2005.pdf Accessed August 1, 2012

2. Lengerich E.J., Tucker T.C., Powell R.K., Colsher P., Lehman E.,Ward, A. J., et. al. Cancer incidence in Kentucky, Pennsylvania, and West Virginia: disparities in Appalachia. J Rural Health. 2005; 21, 39 - 47.

3. Kaiser State Health Facts. (2009). Overweight and obesity rates for adults by sex, 2009. Menlo Park, CA: Kaiser Family Foundation. http://www.statehealthfacts.org, Accessed August 1, 2012.

4. Kaiser State Health Facts. (2008). Percent of adults who smoke by sex, 2008. Menlo Park, CA: Kaiser Family Foundation. http://www.statehealthfacts.org, Accessed August $1,2012$.

5. U.S. Census Bureau. (2010). Persons 25 years old and over with a bachelor's degree or more, 2008. Washington, DC: U.S. Census Bureau. http://www.census.gov/compendia/statab/2010/ranks/rank19.html, Accessed August 1, 2012.

6. U.S. Census Bureau. (2010). Persons below the poverty level, 2008. Washington, DC: U.S. Census Bureau. http://www.census.gov/compendia/statab/2010/ranks/rank34.html, Accessed August 1, 2012.

7. Wingo PA, Tucker TC, Jamison PM, Martin H, McLaughlin C, Bayakly R, BolickAldrich S, Colsher P, Indian R, Knight K, Neloms S, Wilson R, Richards TB. Cancer in Appalachia, 2001-2003. Cancer. 2007; 112, 181 - 192.

8. Lengerich EJ, Chase GA, Beiler J, Darnell M. Increased risk of unknown stage cancer from residence in a rural area: health disparities with poverty and minority status. Hershey, PA: Pennsylvania State University and the Penn State Cancer Institute, Department of Health Evaluation Sciences 2005.

9. State Cancer Profiles. (2010). Incidence and mortality rate reports for West Virginia by county. Bethesda, MD: National Cancer Institute. http://statecancerprofiles.cancer.gov/, Accessed August 1, 2012.

10. United States Cancer Statistics (USCS). (2010). Rankings by state: 2006, male and female, all cancer sites combined. Atlanta, GA: Centers for Disease Control and Prevention (CDC). http://apps.nccd.cdc.gov/uscs/, Accessed August 1, 2012.

11. United States Cancer Statistics (USCS). (2010). State vs. national rates: 2006, female, West Virginia. Atlanta, GA: Centers for Disease Control and Prevention (CDC). http://apps.nccd.cdc.gov/uscs/, Accessed August 1, 2012. 
12. Khanna R, Bhanegaonkar A, Colsher P, Madhavan S, Halverson J. Breast cancer screening, incidence and mortality in West Virginia. WV Med J. 2009. Special CME Issue, 25-32.

13. Kaiser State Health Facts. (2010). Percent of women age 40 and older who report having had a mammogram within the last two years, 2008. Menlo Park, CA: Kaiser Family Foundation. http://statehealthfacts.org, Accessed August 1, 2012.

14. Bhanegaonkar A, Madhavan SS, Khanna R, Remick SC. Declining mammography screening in a state Medicaid fee-for-service program: 1999-2008. Journal of Womens Health. 2012; May 8: (Epub ahead of print)

15. Bryant $\mathrm{H}$, Mah $\mathrm{Z}$. Breast cancer screening attitudes and behaviors of rural and urban women. Prev Med. 1992; 21:405-418.

16. Calle EE, Flanders WD, Thun MJ, Martin LM. Demographic predictors of mammography and pap smear screening in US women. American Journal of Public Health. 1993;:83:53-60.

17. American Cancer Society: Breast Cancer Facts and Figures 2012. Atlanta, Ga: American Cancer Society, 2012. http://www.cancer.org/Cancer/BreastCancer/DetailedGuide/breastcancer-key-statistics Accessed August 1, 2012.

18. Fletcher SW, Elmore JG. Clinical practice: mammographic screening for breast cancer. N Engl J Med. 2003; 348:1672-1680.

19. Nyström L, Andersson I, Bjurstam N, Frisell J, Nordenskjold B, Rutqvist LE. Long-term effects of mammography screening: updated overview of the Swedish randomised trials. Lancet. 2002; 359 (9310): 909-919.

20. Smith-Bindman R, Kerlikowske K, Gebretsadik T, Newman J. Is screening mammography effective in elderly women? Am J Med. 2000;108:112-119.

21. Taber L, Dean PB. Mammography and breast cancer: The new era. Int J Gynaecol Obstet. 2003;82:319-326.

22. Hellquist BN, Duffy SW, Abdsaleh S, Bjorneld L, Bordas P, Tabar L, Vitak B, Zackrisson S, Nystrom L, Jonsson H. Effectiveness of population-based service screening with mammography for women ages 40 to 49 years: Evaluation of the Swedish Mammography Screening in young women (SCRY) cohort. Cancer. 2011; 117(4):71422.

23. Nekhlyudov L, Li R, Fletcher SW. Information and involvement preferences of women in their 40s before their first screening mammogram. Archives of internal medicine. 2005; 165:1370-1374. 
24. Kelly KM, Sturm A, Kemp K, Holland J, Ferketich A. How can we reach them? Information seeking and preferences for a cancer family history campaign in underserved communities. Journal of community health. 2009; 14: 573-589.

25. Kratzke C, Wilson S, Vilchis $\mathrm{H}$. Reaching rural women: breast cancer prevention information seeking behaviors and interest in internet, cell phone, and text use. Journal of community health. 2012; (Epub ahead of print)

26. Vyas A, Madhavan S, Lemasters T, Atkins E, Gainor S, Kennedy S, Kelly K, VonaDavis L, Remick S. Factors influencing adherence to mammography screening guidelines in Appalachian Women participating in a mobile mammography program. Journal of community health. 2012;37(3):632-646.

27. United States Department of Health, Human Services (2010). Healthy people 2010: Understanding and improving health. Washington, DC: US Department of Health and Human Services.

28. National Cancer Institute (2008). State cancer profiles screening and risk factors report 2008, Accessed August 1, 2012. http://statecancerprofiles.cancer.gov/risk/index.php?risk $=06 \&$ type $=$ risk \&stateFIPS $=00 \& s$ ortVariableName=default\&sortOrder=default

29. Mauad EC, Nicolau SM, Moreira LF, Haikel RL, Longatto-Filho A, Baracat EC. Adherence to cervical and breast cancer programs is crucial to improving screening performance. Rural Remote Health. 2009; 9 (3): 1241.

30. Kim YH, Sarna L. An intervention to increase mammography use by Korean American women. Oncology Nursing Forum. 2004; 31(1):105-110.

31. Reuben DB, Bassett LW, Hirsch SH, Jackson CA, Bastani R. A randomized clinical trial to assess the benefit of offering on-site mobile mammography in addition to health education for older women. AJR. 2002;179:1509-1514.

32. Lyttle NL, Stadelman K. Assessing awareness and knowledge of breast and cervical cancer among Appalachian women. Preventing chronic disease. 2006; 3(4):A125

33. Tejeda S, Thompson B, Coronado GD, Martin DP. Barriers and facilitators related to mammography screening use among lower educated Mexican women in the USA. Social Science and Medicine. 2009; 68:832-839.

34. Lee-Lin F, Menon U, Nail L, Lutz KF. Findings from focus groups indicating what Chinese American immigrant women think about breast cancer and breast cancer screening. Journal of Obstetric, Gynecologic and neonatal nursing. 2012 April 26.

35. Ogedegbe G, Cassells AN, Robinson CM, DuHamel K, Tobin JN, Sox CH, Dietrich AJ. Perceptions of barriers and facilitators of cancer early detection among low-income 
minority women in community health centers. Journal of the national medical association. 2005; 97(2):162-170.

36. Sohl SJ, Moyer A. Tailored interventions to promote mammography screening: A metaanalytic review. Preventive medicine. 2007;45:252-261.

37. Bonfill CX, Marzo CM, Pladevall VM, Marti J, Emparanza JI. Strategies for increasing the participation of women in community breast cancer screening (Review). The Cochrane Library. 2009;1.

38. Braun V, Clarke V. Using thematic analysis in psychology. Qualitative Research in Psychology. 2006; 3(2):77-101.

39. NVIVO software 2012. QSR International: Victoria, Australia.

40. Williams GA, Abbott RR. Using focus group methodology to develop breast cancer screening programs that recruit African American women. Journal of community health. 1997;.22(1):45-56.

41. Colby S, Johnson A, Eickhoff A, Johnson L. Promoting community health resources: Preferred communication strategies. Health Promotion Practice. 2011;.12(2):271-279.

42. Kowalczyk N, Draper LJ. Trends in patient information preferences and acquisition. Radiologic Technology. 2012; 83(4):316-324.

43. Katz E, Lazersfeld P. The two-step flow of communication: An up-to-date report on an hypothesis. Public Opinion Quaterly, 21:61-78.

44. Buzek N. Mobile mammography for underserved women. Advance for nurse practitioners. 2010; 18(5):29-32.

45. Flynn B, et al. Community education to promote mammography participation in rural New York state. Prev Med. 1997;26(1):102-108.

46. Derose K, et al. Women's receptivity to church-based mobile mammography. Journal of health care for poor and underserved. 2002; 13(2): 199-213. 
Figure 1: Sources and Channels of Information for Mammography Screening

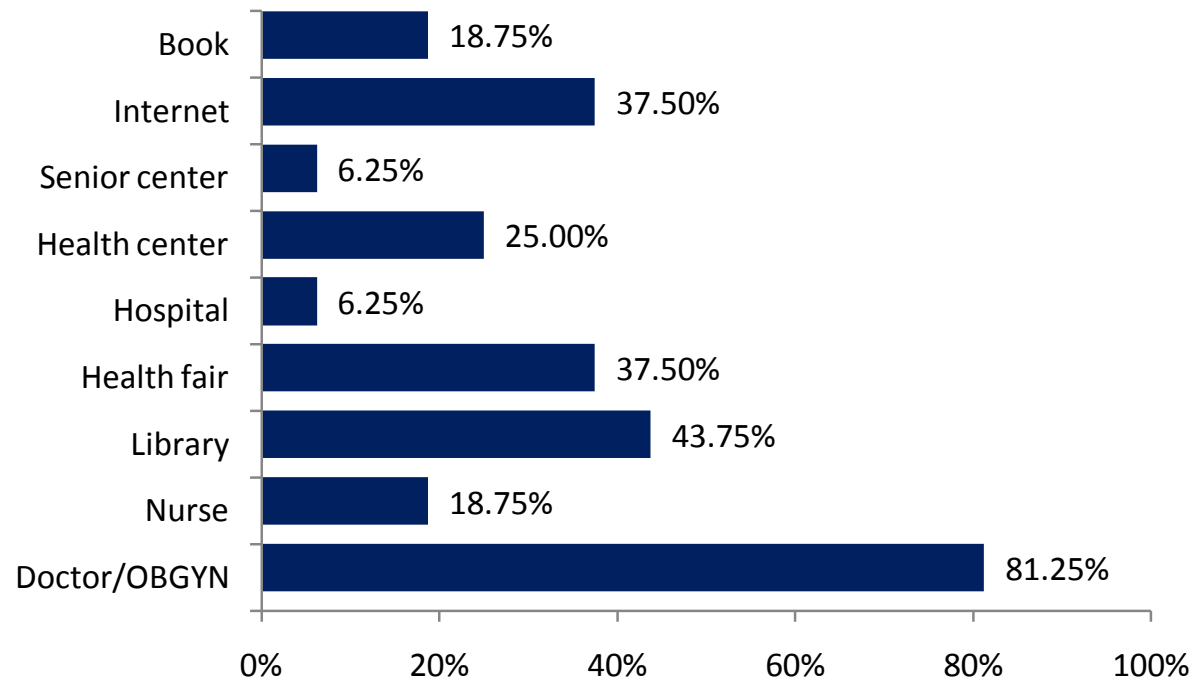


Table 1

Characteristics of the Study participants $(N=16)$

\begin{tabular}{|c|c|c|c|}
\hline Variables & & $\mathbf{N}$ & $\%$ \\
\hline \multicolumn{4}{|l|}{ Age } \\
\hline & $40-49$ & 12 & 75.00 \\
\hline & $50-59$ & 4 & 25.00 \\
\hline & Mean & 46.44 & \\
\hline & Median & 45 & \\
\hline & Range & $(41,57)$ & \\
\hline \multicolumn{4}{|l|}{ Education } \\
\hline & Less than college & 10 & 62.50 \\
\hline & Some college/Graduate & 6 & 37.50 \\
\hline \multicolumn{4}{|c|}{ Employment status } \\
\hline & Employed & 11 & 68.75 \\
\hline & Unemployed & 5 & 31.25 \\
\hline \multicolumn{4}{|c|}{ Marital Status } \\
\hline & Married/Partnered & 10 & 62.50 \\
\hline & Single/Divorced & 6 & 37.50 \\
\hline \multicolumn{4}{|c|}{ Household Income } \\
\hline & Less than $\$ 25,000$ & 11 & 68.75 \\
\hline & $\$ 25,000-\$ 50,000$ & 4 & 25.00 \\
\hline & $\$ 50,000-\$ 75,000$ & 1 & 6.25 \\
\hline \multicolumn{4}{|c|}{ Health Insurance } \\
\hline & Yes & 5 & 31.25 \\
\hline & No & 11 & 68.75 \\
\hline \multicolumn{4}{|c|}{ Adherence to CBE } \\
\hline & Yes & 9 & 56.25 \\
\hline & No & 7 & 43.75 \\
\hline \multicolumn{4}{|c|}{ Adherence to PAP test } \\
\hline & Yes & 14 & 87.50 \\
\hline & No & 2 & 12.50 \\
\hline \multicolumn{4}{|c|}{ Prefer texts about health information } \\
\hline & Yes & 6 & 37.50 \\
\hline & No & 10 & 62.50 \\
\hline \multicolumn{4}{|c|}{ Prefer networking sites for health information } \\
\hline & Yes & 9 & 56.25 \\
\hline & No & 7 & 43.75 \\
\hline
\end{tabular}


Table 2

Barriers and Facilitators to Mammography Screening

Reported by Women who had their first mammogram at the Bonnie's Bus

\begin{tabular}{|c|c|c|}
\hline Themes & Subthemes & Quotes \\
\hline \multicolumn{3}{|l|}{ Barriers } \\
\hline \multirow[t]{3}{*}{ Accessibility } & Lack of health insurance coverage & $\begin{array}{l}\text { "I did not have health insurance and so it was one of } \\
\text { those things that I just kind of put off even though I } \\
\text { passed the age I should have had" }\end{array}$ \\
\hline & Cost of test & "I could not afford one [mammogram]" \\
\hline & Lack of transportation & "Problem with transportation" \\
\hline \multirow[t]{2}{*}{$\begin{array}{l}\text { Attitudes \& } \\
\text { Beliefs }\end{array}$} & $\begin{array}{l}\text { Fear of pain or unpleasantness from } \\
\text { procedure } \\
\text { Lack of knowledge }\end{array}$ & $\begin{array}{l}\text { "I always heard that it [mammography screening] is } \\
\text { painful" } \\
\text { "I haven't thought about it [mammography } \\
\text { screening] .... I never had no issues so I never thought } \\
\text { of going [for a mammogram]" }\end{array}$ \\
\hline & Low perceived risk & \\
\hline $\begin{array}{l}\text { Social Network } \\
\text { Experience }\end{array}$ & $\begin{array}{l}\text { Delayed recommendation from } \\
\text { doctor }\end{array}$ & $\begin{array}{l}\text { ".....just delaying due to no recommendation from the } \\
\text { gynecologist" }\end{array}$ \\
\hline \multicolumn{3}{|l|}{ Facilitators } \\
\hline \multirow[t]{3}{*}{ Accessibility } & Free/Discounted service & $\begin{array}{l}\text { "It had discount on it. It is a smart thing that they pay } \\
\text { for it [mammogram]" }\end{array}$ \\
\hline & $\begin{array}{l}\text { Convenient and close location of } \\
\text { screening service }\end{array}$ & "It was local, it was close.." \\
\hline & Availability of insurance & $\begin{array}{l}\text { "...I had an insurance then so I got it [mammography } \\
\text { screening]" }\end{array}$ \\
\hline \multirow{2}{*}{$\begin{array}{l}\text { Attitudes \& } \\
\text { Beliefs }\end{array}$} & Knowledge about guidelines & "...I should do it as I am 40" \\
\hline & Breast problem & $\begin{array}{l}\text { "Basically I recently got one [mammogram] as I had } \\
\text { lump in my breast and a leaky nipple in my right } \\
\text { breast" }\end{array}$ \\
\hline \multirow[t]{5}{*}{$\begin{array}{l}\text { Social Network } \\
\text { Experience }\end{array}$} & $\begin{array}{l}\text { Recommendation from } \\
\text { doctor/OBGYN }\end{array}$ & $\begin{array}{l}\text { "My gynecologist recommended it [mammography } \\
\text { screening at the Bonnie's Bus]" }\end{array}$ \\
\hline & $\begin{array}{l}\text { Recommendation from } \\
\text { friends/family }\end{array}$ & $\begin{array}{l}\text { "Also got recommendation [for mammography } \\
\text { screening ]from friend" }\end{array}$ \\
\hline & Family history of BC & $\begin{array}{l}\text { "I thought well when my sister has those tumors [in } \\
\text { breast], they [her breasts] should be checked out" }\end{array}$ \\
\hline & Knowing people with cancer & $\begin{array}{l}\text { "I had watched my cousin, she was in her 50's when } \\
\text { she died of } B C^{\prime \prime}\end{array}$ \\
\hline & Advertisement & $\begin{array}{l}\text { "Health center had put out bulletins at our post office } \\
\text { where I first found about it [Bonnie's Bus]" }\end{array}$ \\
\hline
\end{tabular}


Table 3

Preferences for Interventions to be developed around Bonnie's Bus

By Women who had their First Mammogram at the Bonnie's Bus

\begin{tabular}{|c|c|c|}
\hline Interventions & Mean likelihood $^{\mathrm{a}}$ (SD) & Mean likelihood $^{\mathrm{b}}$ (SD) \\
\hline \multicolumn{3}{|l|}{ Community-based } \\
\hline Health educators & $4.063(1.063)$ & $4.250(0.856)$ \\
\hline Educational programs & $4.625(0.885)$ & $4.438(0.964)$ \\
\hline \multicolumn{3}{|l|}{ Individual-level } \\
\hline $\begin{array}{l}\text { Telephone counseling + Educational } \\
\text { material }\end{array}$ & $3.250(1.770)$ & $3.750(1.483)$ \\
\hline $\begin{array}{l}\text { Telephone counseling + Letter from } \\
\text { physician }\end{array}$ & $3.625(1.668)$ & $4.063(1.436)$ \\
\hline Mailed educational material & $4.125(1.258)$ & $3.938(1.237)$ \\
\hline Text messages & $3.063(1.652)$ & $3.500(1.557)$ \\
\hline
\end{tabular}

For mean likelihood score, score 5 is equal to most likely and score 1 is equal to least likely on the scale of 1 to 5.

SD: Standard deviation

a : Mean score for self

${ }^{\mathrm{b}}$ : Mean score for other women in community 
Table 4

Reasons for the Preferences of Interventions

As reported by Women who had their first mammogram at the Bonnie's Bus

\section{Community-based educational program}

\begin{tabular}{|c|c|}
\hline Reasons & Quotes \\
\hline Increased accessibility & $\begin{array}{l}\text { "I think you mention about library, I think that [educational program] would } \\
\text { be easier if it opens to the public and information is readily available" }\end{array}$ \\
\hline Informative & "You can never get enough information about it, all the information is helpful" \\
\hline Close/Convenient & "It will be close to people and it will be easier and much more convenient" \\
\hline $\begin{array}{l}\text { Lack of community-based } \\
\text { programs for women }\end{array}$ & $\begin{array}{l}\text { "In our area there is not a lot of things out there for women to go to or helpful, } \\
\text { I think workshops on any women thing will be helpful" }\end{array}$ \\
\hline Increase in knowledge & $\begin{array}{l}\text { "People will hear more about situations and its got to be more helpful for } \\
\text { them" }\end{array}$ \\
\hline More helpful to rural women & "They need to come to the smaller plains where I live in..." \\
\hline $\begin{array}{l}\text { Past experiences from such } \\
\text { programs }\end{array}$ & $\begin{array}{l}\text { "Because of my past experience with my best friends, with my mother...My } \\
\text { mother used such a program" }\end{array}$ \\
\hline \multicolumn{2}{|c|}{ Individual-based mailed educational materials } \\
\hline Reasons & Quotes \\
\hline Increased readability & "People look at the mail" \\
\hline Convenient & "That is the way you get most of the stuff through mail" \\
\hline Informative & $\begin{array}{l}\text { "Some women do not know anything about it [mammography screening], so } \\
\text { mail will be helpful" }\end{array}$ \\
\hline Increase in knowledge & $\begin{array}{l}\text { "..That way we know about ways to prevent it [breast cancer], everybody may } \\
\text { not know about it' }\end{array}$ \\
\hline Personal approach & $\begin{array}{l}\text { "Because in the mail, it is personally suggested, you are going to open it and } \\
\text { read it....it is a more personal approach" }\end{array}$ \\
\hline
\end{tabular}


CHAPTER 4 


\section{CHAPTER 4}

\section{GENERAL DISCUSSION}

\section{RATIONALE AND OBJECTIVES}

Since mammography screening rates have stagnated or declined in WV and large segments of rural West Virginia (WV) women remain hard-to-reach, the number of advanced and unstaged $\mathrm{BC}$ cases detected and mortality related to breast cancer $(\mathrm{BC})$ will only increase in the future. Hence, there is an urgent need to increase mammography screening among these rural women in WV. Bonnie's Bus Mobile Mammography Program (called Bonnie's Bus hereafter) is a major effort towards reaching the underserved and rural women and to increase mammography screening rates.

Mobile mammography programs have been in service for more than two decades; however there have been very few studies about their effectiveness. Such programs increased mammography utilization in vulnerable populations by reducing access barriers. No study has determined how women who utilize mobile mammography units for screening may be different from women who get their routine screening done at a stationary facility. Understanding the characteristics and hence predictors of adherence in women who utilize mobile mammography unit to get a mammogram and compare those to women who utilize a stationary facility, can help to identify the determinant characteristics of these women to facilitate the development of targeted educational programs and interventions to increase mammography screening rates.

Very few studies have determined the types of intervention strategies which when linked with mobile mammography that are likely to improve screening rates and the effectiveness of such a program. Although many interventions effective in increasing screening rates have been reported in the literature, no studies have assessed the perspectives of women at whom these 
interventions are targeted, such as their receptiveness towards these interventions and their perception of whether or not they would be successful with their peers and in their communities. Besides determining the information sources used by women for mammography screening and their advice seeking behavior, it is important to consider targeting these rural and underserved women through appropriate sources and channels of information to increase mammography screening rates. Hence, understanding women's' barriers and facilitators for mammography screening, their perception and receptiveness about intervention strategies and the sources of health-related information can be used in developing targeted educational programs and interventions that could be coupled with the Bonnie's Bus to increase mammography screening rates in women in $\mathrm{WV}$.

The objective of the two studies were to determine the predictors of adherence to mammography screening guidelines in women who utilize mobile mammography services and those who utilize a stationary mammography facility, and to identify from the women's perspectives the intervention strategies that could be developed around the Bonnie's Bus to increase mammography screening rates in WV. The research design was cross-sectional for the first study where data was collected using 'Mammography Screening and Preventive Care Survey' and structured telephone interviews were conducted for the second study. The specific aims of the studies were: (1) to identify the characteristics and predictors of self-reported adherence to mammography screening guidelines in women age 40 years and above who utilize Bonnie's Bus in WV and those who utilize a stationary mammography facility, BPBCC, and (2) to examine the information seeking behaviors and to determine what types of targeted educational interventions coupled with mobile mammography are perceived as likely to be acceptable and effective by non-adherent women. 


\section{SUMMARY OF THE FINDINGS}

Predictors of self-reported adherence to mammography screening guidelines in women in

\section{West Virginia women}

In this cross-sectional study, the findings indicated that women who utilize stationary mammography facilities were those with higher levels of education, higher income, health insurance, who visit a doctor and/or an OB/GYN regularly, and who are adherent to CBE, Pap test and other screenings. And, the women who utilize mobile mammography services were those with lower levels of education, lower income, who are overweight to morbidly obese, who did not visit an OB/GYN in the past year, and who are not adherent to CBE. Among women who utilized mobile mammography unit, only $48.15 \%$ were adherent to mammography screening guidelines and among women who utilized stationary mammography facility, an overwhelming $92.3 \%$ were adherent to mammography screening guidelines. Moreover, the predictors of adherence to mammography screening guidelines in women who utilized stationary mammography facility were health insurance coverage, no reported delay in care due to transportation problem, adherence to CBE, Pap test and other routine screenings, and having strong agreement with the positive views about mammography screening. The predictors of adherence to mammography screening guidelines in women who utilized mobile mammography services were older age, unemployed status, no reported delay in care due to transportation problem, having family history of $\mathrm{BC}$, having had a breast biopsy in the past, and adherence to Pap test and other routine screenings.

\section{Preferences of Women for Intervention Strategies in a Mobile Mammography Program}

The sources of information about health and mammography screening used by rural women who had their first mammogram at the Bonnie's Bus included doctors or OB/GYN, 
materials from libraries, health fairs, internet, and health centers. A majority of women reported the highest likelihood of seeking advice about mammography screening from the doctors, and some were also very likely to seek advice about mammography screening from their mothers. A majority of the women indicated their preference to receive information about mammography screening through networking websites. In addition, community-based health educational programs that could be held at public places such as libraries or churches, or at work-sites and mailed educational materials were perceived to be the most helpful interventions to encourage women obtain mammograms.

\section{SIGNIFICANCE OF THE STUDIES}

Overall, for women who utilized the mobile mammography services, predisposing and need-related factors have a strong influence on adherence to mammography screening guidelines. Hence, interventions targeted at younger women who have not experienced any BCrelated event may be beneficial to increase screenings. While for women who utilized stationary mammography facility, enabling factors, need-related factors, and positive views about mammography screening have a strong influence on adherence to mammography screening guidelines. Thus, access barriers need to be eliminated, along with educating them about preventive behaviors. In addition, intervention strategies such as community-based educational programs and mailed educational materials need to be developed that would complement the mobile mammography services in the rural and underserved communities of WV. These intervention strategies may also involve the preferred information sources such as doctors and OB/GYNs in these communities and also utilize the internet to educate women to improve the effectiveness of the mobile mammography program.

\section{FUTURE RESEARCH}


Persistence to mammography screening guidelines in women in both the study populations should be determined. Interventions for rural and underserved younger women in WV who have not experienced BC-related events can be developed and evaluated to increase mammography screening rates. Randomized controlled trials of community-based educational programs and mailed educational materials can also be conducted to determine their effectiveness in increasing mammography screening rates and persistence rates in the rural and underserved women of WV. 
APPENDICES 


\section{APPENDIX A: Mammography Screening and Preventive Care Survey}

Survey Tracking \#:

Age: years

Current Prescription and Over-the-Counter (OTC) Medications (please list if any?):

Current IIIness (if any):

\section{Personal Health History}

\begin{tabular}{|l|l|l|}
\hline $\begin{array}{l}\text { Has your doctor ever told } \\
\text { you that you had one or } \\
\text { more of the following...? }\end{array}$ & Yes & No \\
\hline Allergies & & \\
\hline Bone Loss (Osteoporosis) & & \\
\hline Seizures/Epilepsy & & \\
\hline Mental Health Issues & & \\
\hline Thyroid Disease & & \\
\hline Breast Problems & & \\
\hline Heart Problems & & \\
\hline $\begin{array}{l}\text { High Blood Pressure } \\
\text { (Hypertension) }\end{array}$ & & \\
\hline Circulatory Problems & & \\
\hline Varicose Veins & & \\
\hline $\begin{array}{l}\text { Lung Problems or } \\
\text { Tuberculosis }\end{array}$ & & \\
\hline Liver Disease/Hepatitis & & \\
\hline Kidney Disease & & \\
\hline Diabetes & & \\
\hline Hormone Problems & & \\
\hline $\begin{array}{l}\text { Ovaries, Tubes, Uterus } \\
\text { problems }\end{array}$ & & \\
\hline Vaginal Infections & & \\
\hline $\begin{array}{l}\text { Sexually Transmitted } \\
\text { Disease }\end{array}$ & & \\
\hline Cancer & & \\
\hline High Cholesterol & \\
\hline
\end{tabular}

\section{Menstrual and Pregnancy History}

Age when period first started? years

Age of Menopause or "change of life" (if applicable)? years How many times have you been pregnant?

How many times have you given live birth?

What was your age at the time of first pregnancy?

How many children have you breast fed?

Previous birth control method(s):

Current birth control methods:

Have you had your uterus removed (Hysterectomy)? $\square$ Yes $\square$ No

Have you had your tubes tied (Tubal Ligation)?

$\square$ Yes $\square$ No

Have you had your ovaries removed (Oophorectomy)? $\square$ Yes $\square$ No Have you had Hormone Replacement Therapy (HRT)?
$\square$ No
$\square$ Yes, in the past
$\square$ Currently taking HRT

\section{Family History of Cancer}

Please tell us if you have a family history of cancer. Please list family members (e.g., father, mother, sister...), type of cancer (e.g., colon cancer, breast cancer, leukemia...), and their age at the time of diagnosis.

(If there is no family history of cancer, then please check this box $\square$ )

\begin{tabular}{|c|c|c|}
\hline Family member & Type of cancer & $\begin{array}{c}\text { Age at time of } \\
\text { diagnosis }\end{array}$ \\
\hline & & \\
\hline & & \\
\hline & & \\
\hline & & \\
\hline
\end{tabular}


1a. Have you been told what your level of risk of developing breast cancer is? (please check one box)
$\square$ Yes
$\square$ No
$\square$ Don't know/Not Sure

1b. If yes, what were you told your level of risk is? (please check one box)

$\square$ Low $\square$ Moderate $\square$ High

2. Has your mother, father, sister, brother, daughter, or son been diagnosed with breast cancer in the past?
Yes
No
Don't know/Not Sure

3. A mammogram is an x-ray of each breast to look for breast cancer. How long has it been since you had your last mammogram?

$\square$ Never had one

Within past 2 years ( 1 year but less than 2 years ago)

$\square$ Within past 5 years (3 years but less than 5 years ago)

Within past year (anytime less than 12 months ago)

$\square$ Within past 3 years (2 years but less than 3 years ago)

Don't know/Not sure

4. What was the reason the last time you got a mammogram?
Routine checkup
Breast problem other than cancer
Had breast cancer
Don't know/Not Sure

5. Have you ever had a breast biopsy (procedure to take tissue to look at under microscope)?

Yes $\quad \square$ No $\quad \square$ Don't know/Not sure (If no, please go to Question 9.)

6. How many breast biopsies (positive or negative) you have ever had?

7. Have you ever had a breast biopsy with atypical hyperplasia (abnormal cells)?
Yes
$\square$ No
Don't know/Not Sure

8. Have you ever been diagnosed with breast cancer, ductal carcinoma in situ (DCIS), or lobular carcinoma in situ (LCIS)? [DCIS and LCIS are non-invasive, but early signs of cancer.]
Yes
No

9. A clinical breast exam is when a doctor, nurse, or other health professional feels the breast for lumps. How long has it been since your last clinical breast exam?

$\square$ Never had one

Within past 2 years ( 1 year but less than 2 years ago)

$\square$ Within past 5 years (3 years but less than 5 years ago)

$\square$ Within past year (anytime less than 12 months ago)

Don't know/Not sure

10. Have you ever performed a breast self-exam?
Yes
$\square$ No

11. Do you have breast implants?
Yes
$\square$ No

12a. A Pap test is a test for cancer of the cervix. How long has it been since you had your last Pap test?

$\square$ Never had one

Within past 2 years ( 1 year but less than 2 years ago)

$\square$ Within past 5 years (3 years but less than 5 years ago)

$\square$ Don't know/Not sure

12b. If you have had a Pap test before, has it ever been abnormal? $\quad \square$ Yes $\quad \square$ No

13. In your opinion, how do you compare your risk of developing breast cancer in the next 5 years to that of any woman of your age in the general population?
Lower risk
$\square$ Similar risk
$\square$ Higher risk
Not sure

14. In your opinion, how do you compare your lifetime risk of developing breast cancer to that of any woman of 


\section{your age in the general population?}
Lower risk
Similar risk
Higher risk
Not sure

15. What do you think the chances are that you will get breast cancer in your lifetime? (0 to 100\%) $\%$

\section{Your Views on Breast Cancer Screening}

16. Please read each of the following statements about breast cancer mammography screening carefully and then circle a number from 1 to 7 on the Agree-Disagree scale provided that best describes your view.

Agree

Disagree

a. Having mammography screening would reassure me that everything was OK.

b. Having mammography screening would be painful.

$\begin{array}{lllllll}1 & 2 & 3 & 4 & 5 & 6 & 7\end{array}$

c. Having mammography screening would make me feel that I am doing

something positive about my risk of breast cancer.

d. Having mammography screening would be a difficult experience for me.

$\begin{array}{lllllll}1 & 2 & 3 & 4 & 5 & 6 & 7\end{array}$

e. Having mammography screening would reduce my chances of dying of breast cancer.

f. Having mammography screening would make me worry unnecessarily.

$\begin{array}{ccccccc}1 & 2 & 3 & 4 & 5 & 6 & 7 \\ 1 & 2 & 3 & 4 & 5 & 6 & 7 \\ 1 & 2 & 3 & 4 & 5 & 6 & 7 \\ 1 & 2 & 3 & 4 & 5 & 6 & 7 \\ 1 & 2 & 3 & 4 & 5 & 6 & 7 \\ 1 & 2 & 3 & 4 & 5 & 6 & 7\end{array}$

g. Having mammography screening would make me feel less anxious about breast cancer.

h. Having mammography screening would make me worry about the effects of radiation.

17. Please read each of the following items to indicate how much (if at all) you worry about breast cancer?

a. During the past one week including today, how often have you thought about your own chances of developing breast cancer?

Not at all Sometimes Often A lot

b. During the past one week, including this time how often have thoughts about your chances of getting breast cancer affected your mood?

Not at all Sometimes Often A lot

c. During the past one week, how often have your thoughts about your chances of getting breast cancer affected your ability to perform your daily activities?

d. During the past one week, how concerned were you about getting cancer?

Not at all Sometimes Often A lot

Not at all Sometimes Often A lot

\section{Breast Cancer Awareness}

18. Please indicate if you agree or disagree with each of the following statements:

a. The risk of breast cancer is greater in younger women than in older women.

Agree $\quad \square$ Don't Agree

Don't know

b. Women with close relatives with breast cancer have higher risk of breast cancer.

Agree

$\square$ Don't Agree

Don't know 
c. A woman currently using birth control pills has a slightly greater risk of breast cancer as compared to a woman not using them.

d. Obesity (being very heavy) is not a risk factor for breast cancer.

e. Mammography screening can detect breast lumps early.

Agree $\quad \square$ Don't Agree $\quad \square$ Don't know

Agree $\quad \square$ Don't Agree $\quad \square$ Don't know

Agree $\quad \square$ Don't Agree $\quad \square$ Don't know

f. One breast screening mammogram is enough to ensure that you will not get breast cancer.

Agree $\quad \square$ Don't Agree $\quad \square$ Don't know

\section{Preventive Care and Wellness History}

19. About how long has it been since you last visited a doctor for a routine checkup? [A routine checkup is a general physical exam, not an exam for a specific injury, illness, or condition.]

Never had one

Within past 2 years ( 1 year but less than 2 years ago)

5 or more years ago
Within past year (anytime less than 12 months ago)

Within past 5 years (2 years but less than 5 years ago)

Don't know/Not sure

20a. Are you limited in any way in any activities because of physical, mental, or emotional health problems?
$\square$ Yes
$\square$ No
Don't know/Not Sure

20b. If yes, for how long have your activities been limited because of such health problems?
Days
Weeks
Months
Years

21. Because of any health problems, do you need the help of other persons with your personal care needs, such as eating, bathing, dressing, or getting around the house?
Yes
$\square$ No
Don't know/Not Sure

22. Because of any health problems, do you need the help of other persons in handling your routine needs, such as everyday household chores, doing business, shopping, or getting around for other purposes?
$\square$ Yes
$\square$ No
Don't know/Not Sure

23. Would you say that in general your health is:
Excellent
$\square$ Very Good
$\square$ Good
Fair
Poor
Don't know/Not Sure

24. Your current height (in feet and inches):

Your current weight (in pounds):

25. Blood cholesterol is a fatty substance found in the blood. About how long has it been since you last had your blood cholesterol checked?

Never had one

Within past 2 years ( 1 year but less than 2 years ago)

5 or more years ago
Within past year (anytime less than 12 months ago)

Within past 5 years (2 years but less than 5 years ago)

Don't know/Not sure

26. About how long has it been since you last had your blood pressure checked?

Never had one

Within past year (6 to 12 months ago)

Within past 5 years (2 years but less than 5 years ago)

$\square$ Don't know/Not sure
Within past 6 months ( 1 to 6 months ago)

Within past 2 years ( 1 year but less than 2 years ago)

5 or more years ago

27. Bone mineral density (BMD) is a measurement used to determine the presence of osteoporosis (bone loss). About how long has it been since you had your last bone mineral density measured?

$\square$ Never had one

Within past year (6 to 12 months ago)

Within past 5 years (2 years but less than 5 years ago)

$\square$ Within past 6 months (1 to 6 months ago)

Don't know/Not sure

Within past 2 years (1 year but less than 2 years ago)

5 or more years ago 
28. A test for fasting blood glucose measures the level of blood sugar after you have not eaten for at least 8 hours. About how many times in the past $\mathbf{1 2}$ months has a doctor, nurse, or other health care professional checked you for fasting blood glucose?

$\square$ Number of times:

Don't know/Not sure

Never had one

29. There are many reasons why people delay getting medical care. Have you delayed getting care in the past 12 months because you didn't have transportation?
Yes
$\square$ No
Don't know/Not Sure

30. During the past 12 months, have you seen or talked to any of the following health care providers about your own health or for a health problem?

a. A general doctor who treats a variety of illnesses (for example, a doctor in general practice, family medicine, internal medicine, or nurse practitioner)? $\quad \square$ Yes $\quad \square$ No $\quad \square$ Don't know/Not Sure

b. A doctor who specializes in women's health (obstetrician/gynecologist) $\square$ Yes $\square$ No $\square$ Don't know/Not Sure

31a. Are you covered by any kind of health insurance or some other kind of health care plan?

$\square$ Yes $\square$ No $\square$ Don't know/Not Sure

31b. If yes, what kind of health insurance coverage do you have?

Private health insurance $\square$ State/local government employee insurance $\quad \square$ Medicaid $\quad \square$ Medicare
$\square$ Other insurance; please specify.
$\square$ I do not have any health insurance coverage

32. Was there a time in the past $\mathbf{1 2}$ months when you needed to see a doctor but could not because of cost?
$\square$ Yes
$\square$ No
Don't know/Not Sure

33. Was there a time in the past 12 months when you needed to see an obstetrician/gynecologist (OB/GYN) but could not because of cost?
$\square$ Yes
$\square$ No
Don't know/Not Sure

34. Was there a time in the past 12 months when you needed to get medicine but could not because of cost?
$\square$ Yes
$\square$ No
Don't know/Not Sure

35a. Has there been a time in the past 12 months when you needed a mammogram but could not get one because of some reason?
Yes
$\square$ No
Don't know/Not Sure

35b. If yes, what was the primary reason you could not get a mammogram?
$\square$ Did not have transportation
$\square$ Did not have childcare (if guardian)
Could not take time off work for appointment
$\square$ Could not afford it
Health insurance does not cover it
$\square$ Other (specify)

\section{Nutrition and Exercise History}

36. How many days per week do you eat at least five servings (one serving = one-half cup) of fruits or vegetables?
Never
One day per week
$\square$ Two days per week
Three days per week
Four or more days per week
Don't know/Not sure

37. How many days per week do you eat at least 11 servings (one serving = one slice of bread) of whole grain breads or cereal?
Never
One day per week
Two days per week
Three days per week
Four or more days per week
Don't know/Not sure

38. How many days per week do you have at least three servings (one serving = one-half to one cup) of milk, yogurt, or cheese?

$\square$ Never $\quad \square$ One day per week

$\square$ Four or more days per week

39. How many days per week do you get at least $\mathbf{3 0}$ minutes of exercise or physical activity that cause small 
increases in breathing and heart rate?

$\square$ Never $\quad \square$ One day per week $\quad \square$ Two days per week $\quad \square$ Three days per week

$\square$ Four or more days per week $\quad \square$ Don't know/Not sure

40. Do you consider yourself to be overweight, underweight, or about the right weight?

$\square$ Overweight $\quad \square$ Underweight $\quad \square$ About the right weight $\quad \square$ Don't know/Not sure

\section{Dental, Smoking, and Alcohol Consumption History}

41. How long has it been since you went to a dentist or a dental clinic for any reason? [Include visits to dental specialists, such as orthodontists.]

$\square$ Never had one

Within past 2 years ( 1 year but less than 2 years ago)

Within past 5 years ( 3 years but less than 5 years ago)

Don't know/Not sure

Within past year (anytime less than 12 months ago)

Within past 3 years (2 years but less than 3 years ago)

5 or more years ago

42. Have you smoked at least 100 cigarettes in your entire life?
Yes
No
Don't know

43. Do you now smoke cigarettes every day, some days, or not at all?
$\square$ Everyday
Some days
Not at all
Don't know

44. During the past 12 months, have you stopped smoking for one day or longer because you were trying to quit smoking?
$\square$ Yes
$\square$ No
Don't know

45. If you smoke, on average, about how many cigarettes a day do you smoke now?

46. During the past $\mathbf{3 0}$ days, have you had at least one drink of any alcoholic beverage such as beer, wine, a malt beverage, or liquor?

$\square$ Yes $\quad \square$ No $\quad \square$ Don't know

47. During the past $\mathbf{3 0}$ days, how many days per week or per month did you have at least one drink of any alcoholic beverage?
Days per week
Days per month
$\square$ No drinks in the past 30 days
Don't know/Not sure

48. One drink is equivalent to a 12-ounce beer, a 5-ounce glass of wine, or a drink with one shot of liquor. During the past $\mathbf{3 0}$ days, on the days when you drank, about how many drinks did you drink on the average?

Number of drinks $\quad \square$ Don't know/Not sure

\section{Demographic Information}

Education: $\square$ Less than HS $\quad \square$ Some HS $\quad \square$ HS Graduate $\quad \square$ GED $\quad \square$ Technical School $\square$ Some College $\square$ College Graduate $\square$ Unknown

Marital Status: $\square$ Never Married $\quad \square$ Married $\quad \square$ Divorced/Separated $\quad \square$ Partnered $\quad \square$ Widowed Family Income: What is your annual household income? (Please check only one)
a. Less than $\$ 10,000$
d. $\$ 20,001$ to $\$ 25,000$
g. Between $\$ 50,001$ and $\$ 75,000$
b. $\$ 10,001$ to $\$ 15,000$
e. $\$ 25,001$ to $\$ 35,000$
h. More than $\$ 75,000$
c. $\$ 15,001$ to $\$ 20,000$
f. $\$ 35,001$ to $\$ 50,000$

Of the persons living in your household including you, how many household members: (Please write in the blank) Are less than 14 years of age? member(s) Are between 14 and 18 years of age? member(s) 
Ethnicity: Are you Hispanic/Latina? $\quad \square$ Yes $\quad \square$ No

Race(s): Which one of these groups would you say best represents your race?

$\square$ White $\quad \square$ Black $\quad \square$ Asian $\quad \square$ Native Hawaiian or Other Pacific Islander

$\square$ American Indian or Alaska Native $\quad \square$ Other(specify)

Employment: $\square$ Employed for wages $\quad \square$ Self-employed $\quad \square$ Out of work for more than 1 year $\square$ Student $\square$ Out of work for less than 1 year $\quad \square$ Homemaker $\quad \square$ Retired $\quad \square$ Unable to work 


\section{APPENDIX B: Cover letter for the First Mailing}

Date:

Dear Madam,

Breast cancer is one of the major health problems in women in West Virginia (WV). We at the Betty Puskar Breast Care Center (BPBCC) along with West Virginia University School of Pharmacy are trying to understand the characteristics of women who utilize a stationary mammography facility such as the BPBCC and compare them with women who utilize a mobile mammography screening unit such as the Bonnie's Bus program to improve screening rates of rural women in WV. This study has been reviewed by the Institutional Review Board of West Virginia University. This study is part of a Master's thesis research project.

You are receiving this letter because your name was randomly selected from a list of women who have obtained at least one mammogram from BPBCC in the past ten years. Please find attached a survey that requests information regarding personal health history, preventive care and wellness history; cancer risk assessment, knowledge and behavior; nutrition and exercise history; dental, smoking and alcohol consumption history, and other related data. We will appreciate it very much if you will kindly take about 20 minutes to complete the enclosed survey and return it in the postage-paid business reply envelope provided. A \$5 Wal-Mart Gift Card will be mailed to you upon receipt of your completed survey as a token of our appreciation for your participation.

The information provided by you will be kept as confidential as legally possible. The survey has a unique identification number which will be only used for mailing purposes and gift card distribution.

Participation in this survey is completely voluntary. Although we hope that you answer all of the questions, you do not have to answer any question with which you are not comfortable. Refusal to participate will not affect your services at the BPBCC in any way. However, your participation is vital to make the results of this study truly meaningful.

We THANK YOU in advance for your time and participation. If you have any questions or concerns, please do not hesitate to contact Dr. Schreiman at (304) 293-3092, Ami Vyas at (304) 293-8194, or Dr. Suresh Madhavan at (304) 293-1652.

Sincerely,

Judith Schreiman, MD

Professor of Radiology, BPBCC
Ami Vyas, B.Pharm, MBA

Graduate Student
S. Suresh Madhavan, Ph.D

Professor \& Chair 


\section{APPENDIX C: Cover letter for the Second Mailing}

Date:

Dear Madam,

About two or three weeks ago, you may remember receiving a survey asking you information on knowledge and behavior about breast cancer and mammography screening, preventive care and wellness history and other related data. If you have already completed and returned the survey, please accept our sincere thanks. In case you missed that mailing or have misplaced the survey, we have enclosed another survey with this letter. We at the Betty Puskar Breast Care Center (BPBCC) along with West Virginia University School of Pharmacy are trying to understand the characteristics of women who utilize a stationary mammography facility such as the BPBCC and compare them with women who utilize a mobile mammography screening unit such as the Bonnie's Bus program to improve screening rates of rural women in WV. This study has been reviewed by the Institutional Review Board of West Virginia University. This study is part of a Master's thesis research project.

You are receiving this letter because your name was randomly selected from a list of women who have obtained at least one mammogram from BPBCC in the past ten years. Please find attached a survey that requests information regarding personal health history, preventive care and wellness history; cancer risk assessment, knowledge and behavior; nutrition and exercise history; dental, smoking and alcohol consumption history, and other related data. We will appreciate it very much if you will kindly take about 20 minutes to complete the enclosed survey and return it in the postage-paid business reply envelope provided. A \$5 Wal-Mart Gift Card will be mailed to you upon receipt of your completed survey as a token of our appreciation for your participation.

The information provided by you will be kept as confidential as legally possible. The survey has a unique identification number which will be only used for mailing purposes and gift card distribution.

Participation in this survey is completely voluntary. Although we hope that you answer all of the questions, you do not have to answer any question with which you are not comfortable. Refusal to participate will not affect your services at the BPBCC in any way. However, your participation is vital to make the results of this study truly meaningful.

We THANK YOU in advance for your time and participation. If you have any questions or concerns, please do not hesitate to contact Dr. Schreiman at (304) 293-3092, Ami Vyas at (304) 293-8194, or Dr. Suresh Madhavan at (304) 293-1652.

Sincerely,

Judith Schreiman, MD

Professor of Radiology, BPBCC
Ami Vyas, B.Pharm, MBA

Graduate Student
S. Suresh Madhavan, Ph.D

Professor \& Chair 


\section{APPENDIX D: Thank You Letter}

Date:

Dear Madam,

Thank very much for your time and participation in our 'Mammography Screening and Preventive Care Survey'. Your participation and inputs will help immensely to make the results of this study truly meaningful.

Please find attached with this letter a $\$ 5$ Walmart gift card as a token of our appreciation for your participation in the study.

If you have any questions, please do not hesitate to contact Dr. Schreiman at (304) 2933092, Ami Vyas at (304) 293-8194, or Dr. Suresh Madhavan at (304) 293-1652.

Sincerely,

Judith Schreiman, MD Medical Director, BPBCC
Ami Vyas, MBA

Graduate Student
Suresh Madhavan, Ph.D

Professor \& Chair 


\section{APPENDIX E: Cover Letter for Non-Response Bias Assessment}

Date:

Dear Madam:

In the past five weeks, we twice mailed you a survey related to a Master's thesis research project to understand characteristics of women who utilize a stationary mammography facility such as the Betty Puskar Breast Care Center (BPBCC) and compare them with women who utilize a mobile mammography screening unit, to improve screening rates of rural women in WV. Since we did not receive a completed survey from you, we are interested in getting select information about your views, attitudes toward breast cancer screening and some health related data to determine how participants and non participants of this study may be different. This study has been reviewed by the Institutional Review Board of West Virginia University.

Will you please take a few moments (2-3 minutes) to complete the enclosed BRIEF survey and return it in the postage-paid business reply envelope? We will appreciate it very much.

The information provided by you will be kept as confidential as legally possible. The survey has a unique identification number which will be only used for mailing purposes.

Participation in this survey is completely voluntary. Refusal to participate will not affect your services at the BPBCC in any way. However, your participation is vital to make the results of this study truly meaningful.

We THANK YOU in advance for your time and participation. If you have any questions, please do not hesitate to contact Dr. Schreiman at (304) 293-3092, Ami Vyas at (304) 293-8194, or Dr. Suresh Madhavan at (304) 293-1652.

Wish you a Happy Holiday season and New Year!

Sincerely,

Judith Schreiman, MD

Professor of Radiology
Ami Vyas, MBA

Graduate Student
S. Suresh Madhavan, Ph.D

Professor \& Chair 


\section{APPENDIX F: Non-Response Bias Assessment Survey}

1. You did not respond to the survey because (please mark $X$ beside the appropriate response(s)):

You did not receive it

You were on vacation

You did not have time to complete it

Misplaced the survey

Started the survey, but did not finish it
You do not respond to mail surveys in general

The survey was too long

The survey was confusing

You were not interested in the issue

You got your mammogram somewhere else

Other reasons or additional comments (Please state below)

2. A mammogram is an x-ray of each breast to look for breast cancer. How long has it been since you had your last mammogram?

Never had one

Within past year (anytime less than 12 months ago)

Within past 2 years ( 1 year but less than 2 years ago)

Within past 3 years ( 2 years but less than 3 years ago)

Within past 5 years ( 3 years but less than 5 years ago)

5 or more years ago

Don't know/Not sure

3. Having mammography screening would reassure me that everything was $\mathrm{OK}$ (Please circle a number from 1 to 7 on the following Agree-Disagree scale that best describes your level of agreement or disagreement with the statement)

$\begin{array}{ccccccc}\text { Agree } & \leftarrow- & - & & & & \text { Disagree } \\ 1 & 2 & 3 & 4 & 5 & 6 & 7\end{array}$

4. During the past one week including today, how often have you thought about your own chances of developing breast cancer? (Please indicate by marking $\mathrm{X}$ how much (if at all) you worry about breast cancer?

Not at all

Sometimes

Often

A lot

5. Mammography screening can detect breast lumps early (Please indicate by marking $X$ if you agree or disagree)

_. Agree

Don't Agree

Don't know

6. Your education level (Please mark $X$ beside the appropriate response):
Less than HS Some HS
HS Graduate
GED
Technical
School
_ College Graduate
Unknown

7. Your employment status (Please mark $\mathbf{X}$ beside the appropriate response):

Employed for wages

Self-employed

Out of work for more than 1 year

Student

Retired

\section{Unable to work}

Out of work for less than 1 year

Homemaker

8. What kind of health insurance coverage do you have?

Private health insurance

State/local government employee insurance

Medicare

Other insurance, please specify.

Medicaid

I do not have any health insurance coverage

Thank you very much 


\section{APPENDIX G: Cover Letter for Telephone Interviews}

Date:

Dear Madam:

Breast cancer is a major health problem in women in West Virginia (WV). We at the Betty Puskar Breast Care Center (BPBCC) along with West Virginia University School of Pharmacy are conducting a research study to determine ways to increase mammography screening in women built around the Bonnie's Bus mobile mammography program where you received a mammogram in the recent past. This study has been reviewed by the Institutional Review Board of West Virginia University. This study is part of a Master's thesis research project of Ami Vyas.

In this study, we are seeking women who had their first mammogram at a Bonnie's Bus mobile mammography visit in 2010 or 2011, and are willing to share their views about mammography screening and ways to improve mammography screening rates in women in WV.

You are receiving this letter because during your visit to the Bonnie's Bus mobile mammography unit for a mammogram during 2010 or 2011, you had consented to participate in future studies related to breast cancer. If you are willing to participate in this study, your involvement would mean taking part in ONE telephone interview with Ami. We will be interested in knowing your opinions about breast cancer screening, your experiences with Bonnie's Bus, and different ways of communicating with women who need to be educated/reminded about the importance of annual screening. The interview will take place at a time that is convenient to you. It will take about 45 minutes. A \$25 Wal-Mart Gift Card will be mailed to you upon completion of the telephone interview as a token of our appreciation for your participation.

Participation in this study is completely voluntary, and refusal to participate will not affect your services provided by the Bonnie's Bus program in any way. Your involvement in this study will be kept as confidential as legally possible. The telephone interviews will be audio-recorded so that the data can be transcribed; however, responses will be kept confidential and individual names will not be associated with any reported data. We will not ask any information that will reveal your identity as a participant.

If you agree to participate, please fill in the required details in the attached sheet "Telephone Interview Schedule" and mail it back to us by March 14, 2012 in the postage-paid business reply enveloped provided.

Upon receipt of completed "Telephone Interview Schedule" sheet, we will call you once in advance to confirm the date and time of the telephone interview.

We THANK YOU in advance for your time and participation. If you have any questions or concerns, please do not hesitate to contact Dr. Schreiman at (304) 293-3092, Ami Vyas at (304) 2938194, or Dr. Suresh Madhavan at (304) 293-1652.

Sincerely,

Judith Schreiman, MD

Professor of Radiology, BPBCC
Ami Vyas, MBA

Graduate Student
Suresh Madhavan, Ph.D

Professor \& Chair 


\section{APPENDIX H: TELEPHONE INTERVIEW SCHEDULE}

\section{(To be completed and returned in the postage-paid business reply envelope)}

If you are interested in participating in our study, then please mark a ' $\mathrm{X}$ ' in one of boxes below and fill out your name and telephone number:

$\square \quad$ Yes, you agree to participate

$\square$ No, you do not agree to participate

Your name:

Your telephone number:

Also, please check $(\mathrm{X})$ the boxes below for dates and times that you are available during the week of March $19^{\text {th }} 2012$ to participate in the telephone interview:

\begin{tabular}{|c|c|c|c|c|c|c|c|}
\hline & $\begin{array}{c}\text { Monday } \\
\text { (March } \\
19,2012)\end{array}$ & $\begin{array}{c}\text { Tuesday } \\
\text { (March } \\
\text { 20, 2012) }\end{array}$ & $\begin{array}{l}\text { Wednesda } \\
\text { y (March } \\
21,2012)\end{array}$ & $\begin{array}{c}\text { Thursday } \\
\text { (March } \\
\text { 22, 2012) }\end{array}$ & $\begin{array}{c}\text { Friday } \\
\text { (March } \\
23,2012)\end{array}$ & $\begin{array}{c}\text { Saturday } \\
\text { (March } \\
24,2012)\end{array}$ & $\begin{array}{c}\text { Sunday } \\
\text { (March } \\
\text { 25, 2012) }\end{array}$ \\
\hline $\begin{array}{l}\text { 10:00am- } \\
\text { 11:00am }\end{array}$ & & & & & & & \\
\hline $\begin{array}{l}11: 00 \mathrm{am}- \\
\text { 12:00noon }\end{array}$ & & & & & & & \\
\hline $\begin{array}{c}12: 00 \text { noon- } \\
1: 00 \mathrm{pm}\end{array}$ & & & & & & & \\
\hline $\begin{array}{l}1: 00 \mathrm{pm}- \\
2: 00 \mathrm{pm}\end{array}$ & & & & & & & \\
\hline $\begin{array}{l}2: 00 \mathrm{pm}- \\
3: 00 \mathrm{pm} \\
\end{array}$ & & & & & & & \\
\hline $\begin{array}{l}3: 00 \mathrm{pm}- \\
4: 00 \mathrm{pm} \\
\end{array}$ & & & & & & & \\
\hline $\begin{array}{l}: 00 \mathrm{pm}- \\
5: 00 \mathrm{pm}\end{array}$ & & & & & & & \\
\hline $\begin{array}{l}5: 00 \mathrm{pm}- \\
6: 00 \mathrm{pm}\end{array}$ & & & & & & & \\
\hline
\end{tabular}

If you have any questions or concerns, please do not hesitate to contact Dr. Schreiman at (304) 293-3092, Ami Vyas at (304) 293-8194, or Dr. Suresh Madhavan at (304) 293-1652. 


\section{APPENDIX I: Script for Telephone Interview}

[Read] Hello, my name is

Could I please speak with Ms.

?

[To be read to the participant]

Let me first confirm if I am speaking with Ms. Hello Ms. My name is and I am calling from the West Virginia

University School of Pharmacy. I am calling to ask you some questions about mammograms and breast cancer screening.

Is this STILL A GOOD TIME to complete the telephone interview?

- Yes... [Continue]

$\square$ No.... [Schedule call back time]: Date , Time $\mathrm{AM} / \mathrm{PM}$

Before we begin, I would like to thank you again for your willingness to participate. Let me briefly review this study with you:

- The purpose of this study is to identify the ways that would be effective in increasing mammography screening rates among women in WV.

- The telephone interview will take about 45 minutes and it is being recorded.

- You may refuse to answer any question or end your participation at any time.

- The information provided by you will be kept as confidential as legally possible.

Do you have any questions? [Answer questions]

1. When you think about mammography screening, what do you get in your mind? Some women have positive views about mammograms while others have negative views. What are your views?

2. Why do you think women should undergo mammography screening?

3. During the past one week, how often have you thought about your chances of developing breast cancer? Please choose one of the options:

Not at all

Sometimes

$\square$ Often

$\square$ A lot

4. What are some of the reasons you did not get a mammogram in the past? (Example, not having a baby sitter, not having health insurance, not having transportation, was not aware of its importance)

- Can you give an example?

- You stated ..... could you please explain that further? 
5. What are some of the reasons you obtained a mammogram on Bonnie's Bus? (Example, friend's recommendation, not having to take too much time off work, having a baby sitter for your baby)

- Can you give an example?

- You stated ..... could you please explain that further?

6. Who are the important people for you whose advice you seek about health? (for example, your spouse, best friend, minister, someone you know has had breast cancer, others)

7. On the scale of 1 to 5, 5 being most likely and 1 being least likely, how likely are you to seek advice for mammography screening from-------?

- Your spouse

- Your best friend

- Your children

- The Minister of the church

- Someone you know who has had breast cancer

- Your doctor

- Your obstetrician/gynecologist

- Neighbor

- Internet

- Other (Please specify)

8. Where do you normally get health information that you need (for example: mammography screening)? (example, physician, printed material, health fairs, internet, social media)

- Any other source where you have obtained this information in the past?

- Can you tell us a little bit more about the content of information?

Now let me tell you about some of the ways used to encourage women to get mammograms on a regular annual basis. I would like you to listen carefully and give me your opinion about each approach.

9. Use of 'Community Health Educators': These are regular people from a community or neighborhood who promote regular mammography screening and educate women in their community about benefits of mammography screening and healthy behaviors.

$>$ On a scale of 1 to 5, 5 being most helpful and 1 being least helpful, how likely would this approach be helpful for you?

$>$ On a scale of 1 to 5, 5 being most helpful and 1 being least helpful, how likely would this approach be helpful with the women you know in your community?

Why did you choose ___ for this approach?

$>$ If a health educator from your community educates you about benefits of mammography screening, would you get a mammogram on a regular basis?

Yes

No 
10. Developing community-based educational programs (like at public places such as church, public library, work sites): Such programs aim to improve people's health through various approaches combining education, prevention, screening, and treatment.

$>$ On a scale of 1 to 5, 5 being most helpful and 1 being least helpful, how likely would this approach be helpful for you?

$>$ On a scale of 1 to 5, 5 being most helpful and 1 being least helpful, how likely would this approach be helpful with the women you know in your community?

$>$ Why did you choose for this approach?

$>$ If health-educational programs are organized in your community that focus on the benefits of mammography screening and health, would you attend such a program? If you get some really useful information about mammography screening from such a program, would you get a mammogram on a regular basis?

Yes

No

11. Telephone counseling with printed educational material: You would receive qualified telephone counseling about mammography screening and other healthy behaviors from a health professional. After this you would receive materials in the mail showing the benefits of regular mammograms.

$>$ On a scale of 1 to 5, 5 being most helpful and 1 being least helpful, how likely would this approach be helpful for you?

$>$ On a scale of 1 to 5,5 being most helpful and 1 being least helpful, how likely would this approach be helpful with the women you know in your community?

$>$ Why did you choose for this approach?

$>$ If a health professional calls you and informs you about the benefits of mammography screening, then you receive material in mail focusing on the benefits of mammography screening, would you get a mammogram on a regular basis?

$$
\begin{aligned}
& \text { Yes } \\
& \text { No }
\end{aligned}
$$

12. Telephone counseling with a letter from your physician: You would receive telephone counseling about mammography screening and healthy behaviors from a health professional. After this you would receive a letter from your physician highlighting/reminding you about need for mammography screening and inviting you to get one.

$>$ On a scale of 1 to 5,5 being most helpful and 1 being least helpful, how likely would this approach be helpful for you?

$>$ On a scale of 1 to 5,5 being most helpful and 1 being least helpful, how likely would this approach be helpful with the women you know in your community?

$>$ Why did you choose for this approach?

$>$ If a health professional calls you and informs you about the benefits of mammography screening, then you receive a letter from your physician focusing 
on the benefits of mammography screening, would you get a mammogram on a regular basis?

$\square$ Yes

No

13. Mailed educational material: You will receive education material highlighting the benefits of mammography screening and other preventive health behaviors in mail.

$>$ On a scale of 1 to 5, 5 being most helpful and 1 being least helpful, how likely would this approach be helpful for you?

$>$ On a scale of 1 to 5, 5 being most helpful and 1 being least helpful, how likely would this approach be helpful with the women you know in your community?

$>$ Why did you choose for this approach?

$>$ If you receive some printed educational material focusing on the benefits of mammography screening, would you get a mammogram on a regular basis?

Yes

No

14. Texting on cell phone: You will receive health information related to mammograms and breast cancer screening and also reminders about your scheduled mammogram on your cell phone.

$>$ On a scale of 1 to 5,5 being most helpful and 1 being least helpful, how likely would this approach be helpful for you?

$>$ On a scale of 1 to 5,5 being most helpful and 1 being least helpful, how likely would this approach be helpful with the women you know in your community?

$>$ Why did you choose for this approach?

$>$ If you receive texts about mammography screening, would you get a mammogram on a regular basis?

\section{Yes}

No

15. Social media includes web-based and mobile technologies used to turn communication into interactive dialogue. Which of the following social media do you use often?

Facebook [Facebook is a social networking service and website where you can exchange messages, and users may join common-interest user groups, organized by workplace, school or college]

Twitter [Twitter is an online social networking service and micro blogging service that enables its users to send and read text-based posts]

Linkedin [Linkedin is a business-related social networking site, mainly used for professional networking]

Bonnie's Bus blog [Site on internet where women will share their personal experiences related to Bonnie's Bus screening experience]

E-mailed newsletters [Newsletters will be e-mailed to women, and these will have information on breast cancer screening]

16. Would you like to be friends with Bonnie's Bus on its Facebook's page? http://www.facebook.com/BonniesBus 
Yes

No

17. Would you prefer to receive health-related information (for example: breast cancer screening information) from the networking sites you use?

Yes

$\square$ No

18. Would you prefer to have health-related information (for example: breast cancer screening information) texted to you on your cell phone?

Yes

$\square$ No

19. If you do not use the Internet for health information, do you rely on someone close to you to do so? Who do you rely on?

These are all the questions that I have.

Do you have any questions or other thoughts you would like to share with us?

Thank you so much for your time and your participation in this study. The information you provided will be very helpful to our study.

You will receive a $\$ 25$ Walmart gift card in the mail within 15 days.

Thank you again! 


\section{APPENDIX J: Thank You Letter}

Date:

Dear Madam,

Thank very much for your time and participation in the telephone interview. Your participation and input will help immensely to make the results of this study truly meaningful.

Please find attached with this letter a \$25 Walmart gift card as a token of our appreciation for your participation in the study.

If you have any questions, please do not hesitate to contact Dr. Schreiman at (304) 2933092, Ami Vyas at (304) 293-8194, or Dr. Suresh Madhavan at (304) 293-1652.

Sincerely,

Judith Schreiman, MD

Ami Vyas, MBA

Medical Director, BPBCC Graduate Student
Suresh Madhavan, Ph.D

Professor \& Chair 